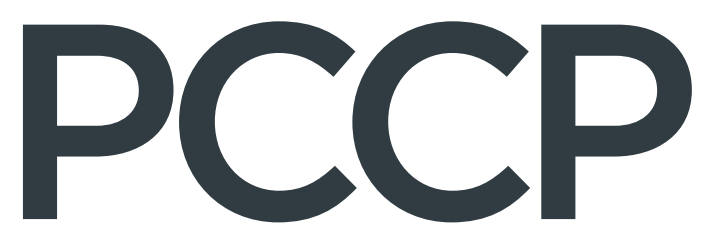

volume 23

Number 18

14 May 2021

Pages 10693-11106

Physical Chemistry Chemical Physics

rsc.li/pccp

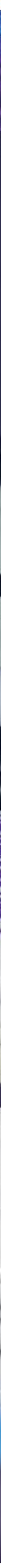

ISSN 1463-9076 
Check for updates

Cite this: Phys. Chem. Chem. Phys., 2021, 23, 10706

\title{
Ordered mesoporous metal oxides for electrochemical applications: correlation between structure, electrical properties and device performance
}

\author{
Erdogan Celik, ${ }^{a}$ Yanjiao Ma, (D) ${ }^{b}$ Torsten Brezesinski (D) *b and Matthias T. Elm (D) *acd \\ Ordered mesoporous metal oxides with a high specific surface area, tailored porosity and engineered \\ interfaces are promising materials for electrochemical applications. In particular, the method of \\ evaporation-induced self-assembly allows the formation of nanocrystalline films of controlled thickness \\ on polar substrates. In general, mesoporous materials have the advantage of benefiting from a unique \\ combination of structural, chemical and physical properties. This Perspective article addresses the \\ structural characteristics and the electrical (charge-transport) properties of mesoporous metal oxides \\ and how these affect their application in energy storage, catalysis and gas sensing.
}

Received 23rd February 2021 Accepted 30th March 2021

DOI: $10.1039 / \mathrm{d} 1 \mathrm{cp} 00834 \mathrm{j}$

rsc.li/pccp to short diffusion pathways, among others, and endows the material with mechanical flexibility. Most importantly, because of the small dimensions of the crystallites in the pore walls and the high interface density, defect chemistry and surface spacecharge effects strongly affect the device performance and provide the unique possibility of tailoring the materials properties. In this Perspective, we review and describe the interplay between structure and electrical transport properties of mesoporous metal oxides (mainly as thin films), with a particular focus on applications in electrochemical energy storage, catalysis and gas sensing. Challenges and future prospects are also discussed.

\section{Mesoporous metal oxide thin films}

\subsection{Evaporation-induced self-assembly}

The principles of self-assembly for sol-gel-derived mesoporous materials have been described in considerable detail elsewhere and will not be further discussed here. ${ }^{13-17,28-32}$ However, in the following, we briefly describe the EISA-based preparation of mesostructured thin films, which affords a high degree of control over the intrinsic (chemistry) and extrinsic (environment) processing parameters. In the past two decades, many important metal oxides, primarily with pores in the size range between 5 and $30 \mathrm{~nm}$, and with different crystalline phases have been produced by EISA and related methods. However, crystallization of the wall structure with retention of the porosity is challenging. This is due, in part, to the lack of broad availability of suitable structure-directing agents.

In general, the processing scheme shown in Fig. 1 can be described as follows: a solution containing the structure-directing 
a)

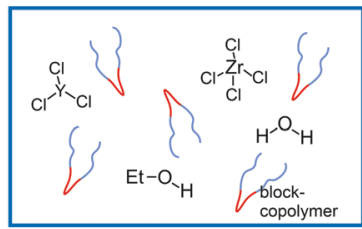

c)

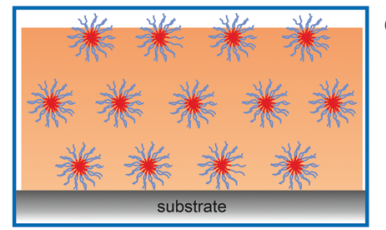

b)

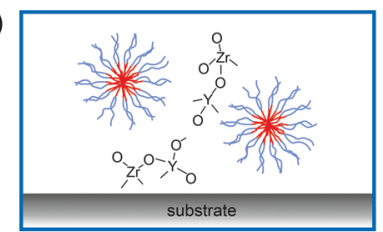

d)

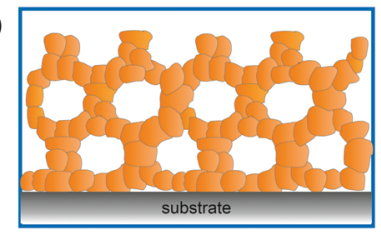

Fig. 1 Schematic illustration of the fabrication steps for ordered mesoporous thin films using an EISA process. (a) Solution consisting of structure-directing agent and inorganic precursors (shown for $\mathrm{ZrCl}_{4}$ and $\mathrm{YCl}_{3}$; chemical reactions with the solvent are omitted for clarity), (b) micelle formation, coassembly and condensation of the inorganic reagents, (c) inorganic-organic hybrid thin film formation upon solvent evaporation and (d) thermally-induced crystallization of the inorganic wall structure and combustion of the organic structure-directing agent.

agent and the precursor(s), and possibly an organic additive (e.g., swelling or stabilizing agent), is sprayed, spin- or dip-coated onto a planar substrate. Upon solvent evaporation, a mesostructured inorganic-organic hybrid thin film with short- or long-range periodicity is formed. Finally, the material is made porous by removing the structure-directing agent via extraction or combustion. Note that heating at elevated temperatures is typically used to drive condensation of the inorganic framework, crystallize the pore walls and tailor the grain size.

In general, mesoporous materials have the advantage of benefiting from a unique combination of structural, chemical and physical properties, making them interesting for a variety of applications. Especially amphiphilic polymers as structuredirecting agents have been shown well suited for the preparation of crystalline metal oxide thin films with cubic or hexagonal pore structures. In this regard, KLE diblock copolymers [KRATON LIQUID-block-poly(ethylene oxide) or poly(ethylene-co-butylene)block-poly(ethylene oxide)] seem to somewhat stand out due to their favorable templating properties. ${ }^{11,12,19,33}$ However, other di- and triblock copolymers, such as poly(ethylene oxide)-blockpoly(propylene oxide)-block-poly(ethylene oxide) (referred to as Pluronic), polyisobutylene-block-poly(ethylene oxide), poly(ethylene oxide)-block-polybutadiene-block-poly(ethylene oxide) or poly(ethylene oxide)-block-polystyrene, have also proven to be robust structure-directing agents. ${ }^{7,8,13,16,20,34-37}$

A variety of binary and multinary metal oxide thin films with cubic mesoporous morphologies have been synthesized from $\mathrm{KLE}$ and alkoxide or salt precursors, including $\mathrm{TiO}_{2}, \mathrm{Al}_{2} \mathrm{O}_{3}, \mathrm{CeO}_{2}$, $\mathrm{HfO}_{2}, \mathrm{MoO}_{3}, \mathrm{SnO}_{2}, \mathrm{SrTiO}_{3}, \mathrm{Li}_{4} \mathrm{Ti}_{5} \mathrm{O}_{12}, \mathrm{REVO}_{4}, \mathrm{BiFeO}_{3}$ and PZT, to name a few. ${ }^{11,12,19,38-49}$ In the following, we use $\mathrm{TiO}_{2}$, which is often considered as a prototype material for applications in photocatalysis, solar cells or batteries, as an example. ${ }^{50-53}$ Smarsly et al. reported on the preparation of cubic mesoporous $\mathrm{TiO}_{2}$ thin films from EtOH:THF solution containing $\mathrm{TiCl}_{4}$ and $\mathrm{KLE}$ by the dip-coating method. Crystallization into the anatase phase was

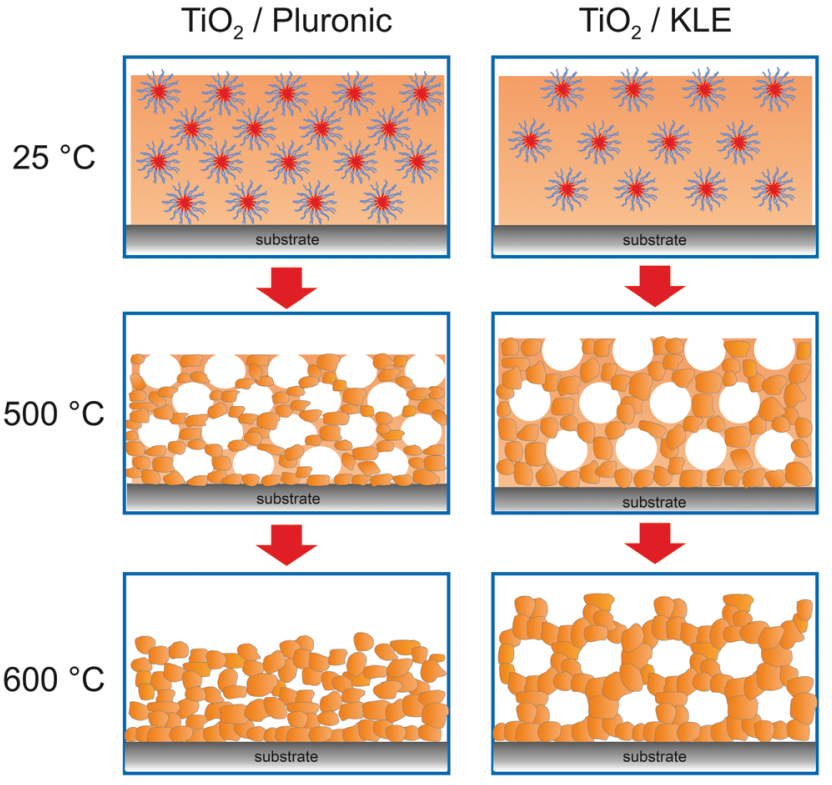

Fig. 2 The effect of annealing temperature on the pore structure of Pluronic- and KLE-templated $\mathrm{TiO}_{2}$ thin films. Adapted from ref. 54 with permission.

found to begin at $450{ }^{\circ} \mathrm{C}$ and the nanoscale porosity was retained up to about $700{ }^{\circ} \mathrm{C} .{ }^{11}$ In a related study, Fattakhova-Rohlfing et al. examined the Li-storage properties of KLE- and Pluronic P123templated mesostructured $\mathrm{TiO}_{2}$ thin films, which allowed quantifying the fraction of crystalline and amorphous phases in the samples. ${ }^{54}$ They showed that the Pluronic P123-derived films display a strong tendency for anatase formation already well below $450{ }^{\circ} \mathrm{C}$ (approx. 50\% crystallinity at $400{ }^{\circ} \mathrm{C}$ ) and that full crystallization at temperatures $\geq 600{ }^{\circ} \mathrm{C}$ is accompanied by collapse of the pore network. This behavior is in stark contrast to that of the KLE-templated material, as schematically shown in Fig. 2. Brezesinski et al. also synthesized cubic mesoporous $\mathrm{TiO}_{2}$ thin films by a conventional sol-gel route using $\mathrm{KLE}$ and $\mathrm{TiCl}_{4}$ as polymer structure-directing agent and precursor, respectively, and by a particle-based route, with anatase nanocrystals serving as preformed building blocks. ${ }^{19}$ The authors demonstrated that the nanocrystal films can withstand much higher temperatures (up to $900{ }^{\circ} \mathrm{C}$ ) before losing nanoscale order. In addition, they showed much improved Li-storage properties, especially greater power density due to high levels of pseudocapacitive charge storage.

Hartmann et al. compared the photoelectrochemical water splitting properties of cubic mesoporous $\mathrm{TiO}_{2}$ thin films produced using the same synthetic routes described by Brezesinski and coworkers. ${ }^{20}$ Both materials differed significantly in the pore walls thickness, see scanning electron microscopy (SEM) images in Fig. 3, despite using the same polymer structure-directing agent in the preparation process. Interestingly, the sol-gel material showed a significantly higher efficiency, which the authors explained by insufficient electronic connectivity of the nanocrystal films. Overall, these results indicate that not only the pore accessibility and specific surface area but also the transport properties have a profound effect on the device performance. 

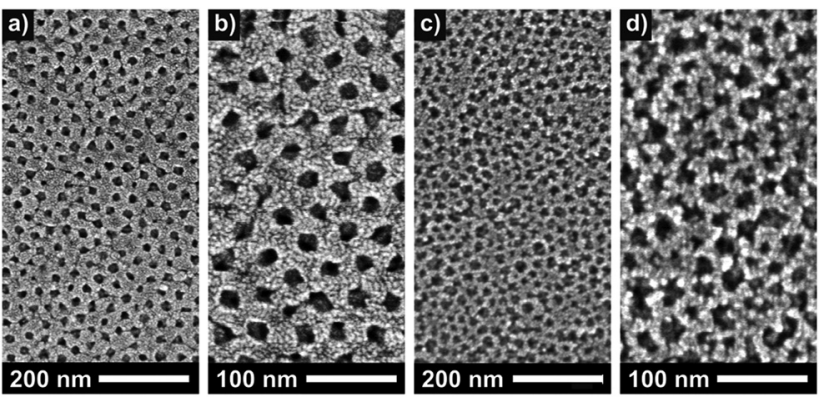

Fig. 3 Top-view SEM images of sol-gel-derived ( $a$ and $b$ ) and preformed nanoparticle-based (c and d) mesoporous $\mathrm{TiO}_{2}$ thin films. Reproduced from ref. 20 with permission.

\section{Transport properties}

As briefly discussed in the previous sections, mesoporous oxides are of interest for a broad range of electrochemical applications. For the functionality of such devices, efficient transport of electrical charge carriers (mobile defects of the ideal crystal structure) is required. As mesoporous materials are typically polycrystalline and made from individual crystallites connected in a 3-dimensional framework, as schematically shown in Fig. 4, they contain a high density of interfaces. Solid/solid (grain boundaries), solid/liquid and solid/gas interfaces may significantly alter the mobility of electronic and ionic charge carriers due to the formation of a space-charge region. In general, the electrical conductivity of a charge carrier is given by:

$$
\sigma=Z e \mu n
$$

where $Z$ is the valence, $e$ is the elementary charge, $\mu$ is the mobility and $n$ represents the charge-carrier density contributing to the transport. In the presence of an interface, both the chargecarrier density and mobility may differ from the respective bulk values, making detailed understanding of the effect of interfaces on the electrical transport properties indispensable. Apart from elemental doping, optimization of the electronic properties of mesoporous materials, and therefore of the electrochemical device performance, is feasible by tailoring the interface density, for example, by controlling the pore size, the wall thickness or the size of the crystallites (grains) in the wall structure.

In the following, we will give a short description of both the formation of a space-charge layer at interfaces and the characterization of electronic and ionic conductivity using electrochemical

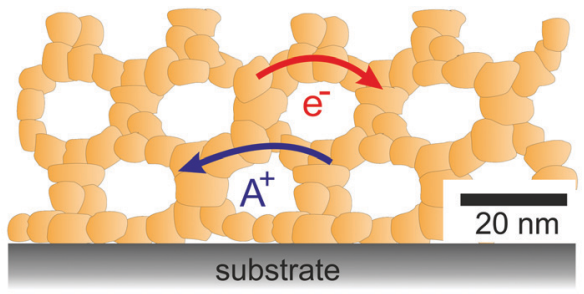

Fig. 4 Schematic illustration of the 3-dimensional architecture of mesoporous oxide thin films with efficient transport pathways for electrons and ions and a vast number of interfaces. impedance spectroscopy (EIS). The influence of a space-charge layer on the electronic and ionic transport properties has been reported in detail for $\mathrm{CeO}_{2}$ - and $\mathrm{ZrO}_{2}$-based ceramics when the crystallite size becomes comparable to its extension. The findings for these systems will be briefly summarized, followed by reports on the investigation of transport properties in mesoporous materials. Finally, we also discuss the protonic conductivity in nanoscale oxides.

\subsection{Defect chemistry at interfaces}

As indicated by eqn (1), the electrical conductivity of a material depends on the concentration and mobility of charge carriers. While the mobility is determined by the electronic and ionic structure of the crystal, the carrier concentration is related to the electrochemical potential of the corresponding defect $A$, which is given by the sum of the chemical potential and the electrical potential: ${ }^{55}$

$$
\tilde{\mu}_{\mathrm{A}}=\mu_{\mathrm{A}}^{0}+Z_{\mathrm{A}} F \phi(x) .
$$

In the absence of an electrical field, the electrochemical potential is constant throughout the bulk. However, at an interface, the local symmetry is broken. This means the chemical potential $(x=0)$ differs from that in the bulk $(x=\infty)$ :

$$
\mu_{\mathrm{A}}(x=0) \neq \mu_{\mathrm{A}}(x=\infty) .
$$

To ensure constant electrochemical potential, the mobile charge carriers redistribute, resulting in charging of the interface and local variation of the electrical potential $\phi(x)$, the so-called space-charge region, which compensates for the difference in chemical potential. The redistribution of charge carriers affects the carrier concentration at the interface, and therefore the corresponding electrical conductivity.

For an ideal interface, the change in charge-carrier concentration relative to the bulk concentration $c_{\infty}$ is given by (1-dimensional case): $:^{5-58}$

$$
\zeta(x)=\frac{c(x)}{c_{\infty}}=\exp \left(-\frac{Z e \Delta \phi(x)}{k_{\mathrm{B}} T}\right),
$$

where $\Delta \phi(x)=\phi(x)-\phi_{\infty}$ is the potential relative to the bulk potential $\phi_{\infty}$. The distribution of charge carriers can then be calculated by solving the Poisson-Boltzmann equation. ${ }^{56}$

Depending on the mobile charge carriers present in the system, different profiles of the resulting charge-carrier distribution are obtained. The two most prominent cases are Gouy-Chapman and Mott-Schottky, ${ }^{59}$ both of which are schematically shown in Fig. 5.

In the Gouy-Chapman case, two charge carriers of opposite sign are mobile and contribute to the surface charging. In the space-charge region, the carrier with the opposite sign to the surface charge accumulates at the interface, while the other is depleted. The width of the space-charge region is then given by the Debye length: ${ }^{59}$

$$
\lambda_{\mathrm{D}}=\sqrt{\frac{\varepsilon_{0} \varepsilon_{\mathrm{r}} k_{\mathrm{B}} T}{2 Z^{2} e^{2} n_{\infty}}},
$$



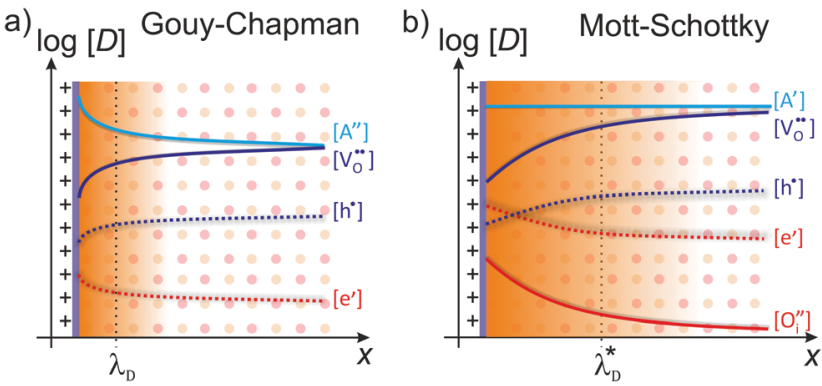

Fig. 5 Schematic illustration of the space-charge region for (a) GouyChapman and (b) Mott-Schottky case. Adapted from ref. 60 with permission.

with $\varepsilon_{0}$ and $\varepsilon_{\infty}$ being the vacuum permittivity and permittivity of the material, respectively.

If one of the charge carriers is immobile, that is, its concentration profile is independent of the distance to the boundary, redistribution of mobile charge carriers follows a Mott-Schottky profile. Compared with the Gouy-Chapman case, redistribution results in an extended space-charge region of effective width: ${ }^{59}$

$$
\lambda^{*}=\sqrt{\frac{2 \varepsilon_{0} \varepsilon_{\mathrm{r}} \Delta \phi(0)}{Z e n_{\infty}}}=\lambda_{\mathrm{D}} \sqrt{\frac{4 Z e}{\varepsilon_{0} \varepsilon_{\mathrm{r}} k_{\mathrm{B}} T} \Delta \phi(0)} .
$$

As the space-charge profile can only be calculated analytically for two charge carriers of opposite sign, for mixed cases or for low space-charge potentials, approximations are needed. Göbel et al. presented a numerical approach to calculate the concentration profile for these cases, allowing to obtain more precise analytical solutions of the Poisson-Boltzmann equation. ${ }^{61,62}$ However, determination of the space-charge profile by solving the Poisson-Boltzmann equation does not account for interactions between the charge carriers, which can become important for high defect concentrations. In 2015, Mebane and De Souza presented a generalized space-charge model (Poisson-Cahn theory) to account for defect-defect interactions at high defect concentrations. ${ }^{63,64}$ While in the dilute case, the results of the analytic model described above are well reproduced, the profile of the space charge is modified for higher defect concentration. At the positively charged interface, the oxygen-vacancy concentration increases significantly (segregation of oxygen vacancies at the interface). Interestingly, depletion of oxygen vacancies in the adjacent space-charge region is accompanied by an enrichment of carriers before the bulk value is reached.

\subsection{Electronic and ionic conductivity}

The effect of a space-charge layer on the electronic and ionic transport is reasonably well understood for polycrystalline $\mathrm{CeO}_{2}$ - and $\mathrm{ZrO}_{2}$-based ceramics. In both material systems, grain boundaries exhibit a positively charged core, resulting in depletion of oxygen vacancies in the space-charge region, and therefore in a highly resistive grain boundary. The latter hinders the transport of oxygen ions. To investigate the influence of the internal interfaces on the total resistivity, EIS is the most prominent and commonly used tool, ${ }^{65-70}$ as this method allows distinguishing to some extent between contributions of the grain and the grain boundary due to differences in the corresponding dielectric relaxation times. ${ }^{66,68,71}$

In microcrystalline oxides, the total impedance is typically described using the brick-layer model (BLM), ${ }^{71-73}$ where a transport path through the bulk, across and along the grain boundaries is considered. In oxides with highly resistive grain boundaries, such as yttria-stabilized zirconia (YSZ), the transport path parallel to the grain boundary can be neglected. ${ }^{67,74}$

The resulting impedance spectra exhibit two semicircles, as shown in Fig. 6, and can be described with an equivalent circuit consisting of two resistance-capacitance elements connected in series, representing the transport along the grain and across the grain boundary. Analysis then allows determining the grain boundary thickness $\delta_{\mathrm{gb}}{ }^{75,76}$

$$
\delta_{\mathrm{gb}}=\frac{\varepsilon_{\mathrm{gb}}}{\varepsilon_{\mathrm{bulk}}} \frac{C_{\mathrm{gb}}}{C_{\mathrm{bulk}}} \delta_{\mathrm{g}},
$$

where $\delta_{\mathrm{g}}$ denotes the grain size and $C_{\mathrm{gb}}$ and $C_{\mathrm{bulk}}$ are the capacitance values from EIS for the grain boundary and bulk, respectively. Furthermore, the space-charge potential at the interface can be calculated according to: ${ }^{74}$

$$
\rho_{\mathrm{gb}}=\rho_{\text {bulk }} \frac{\exp \left(Z e \Delta \phi(0) / k_{\mathrm{B}} T\right)}{Z e \Delta \phi(0) / k_{\mathrm{B}} T} .
$$

A detailed analysis of the impedance of microcrystalline $\mathrm{ZrO}_{2}$ (Mott-Schottky case) using the BLM confirms that the blocking behavior of grain boundaries is caused by the formation of a
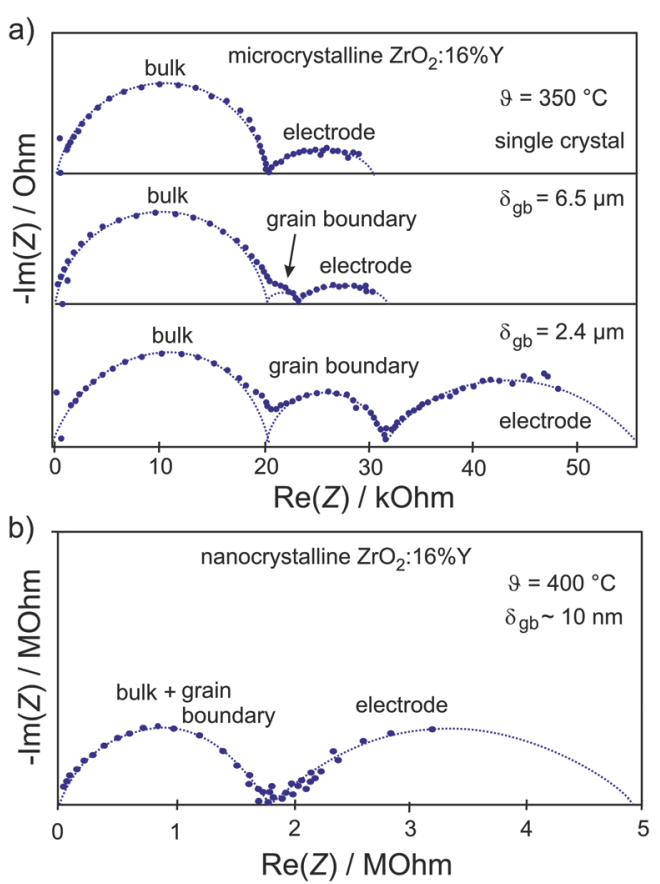

Fig. 6 (a) Impedance spectra for single-crystal and microcrystalline YSZ. The grain boundaries of the microcrystalline sample lead to the appearance of an additional semicircle. (b) Reducing the grain size to the nanometer level results in merging of semicircles representing the bulk and grain boundary transport processes. Adapted from ref. 77 with permission. 
space-charge region ${ }^{74,79,80}$ and not solely by segregation effects, as previously assumed. ${ }^{67,81,82}$ The influence of the space-charge region on the overall impedance becomes even more important when the grain size is comparable to the width of the space-charge region, ${ }^{83,84}$ which is typically a few nanometers for oxide ceramics. Then, interface effects are more pronounced and may even dominate the impedance. ${ }^{57,72}$ As shown in Fig. 6, the decrease in grain size results in merging of the semicircles representing the bulk and grain boundary transport processes, ${ }^{56,77,85}$ making their separation difficult. Furthermore, the accumulated charge carriers may also contribute to the transport through the sample. This is typically observed for the Gouy-Chapman case, ${ }^{59}$ but can also occur for the Mott-Schottky case at low doping concentration. ${ }^{86}$ For large effects, the electrons result in an additional contribution to the conductivity along the grain boundaries: ${ }^{26,59}$

$$
\sigma_{\text {eff }}^{\|}=2 \lambda_{\mathrm{D}} \sigma_{\text {bulk }} \sqrt{\frac{n_{0}}{n_{\infty}}}=2 \lambda_{\mathrm{D}} \sigma_{\text {bulk }} \exp \left(\frac{Z e \Delta \phi(0)}{k_{\mathrm{B}} T}\right),
$$

where $n_{0}$ and $n_{\infty}$ denote the electron concentration at the interface and in the bulk, respectively. An overview of the conductivity/ resistivity contributions for different space-charge situations due to accumulation/depletion of charge carriers at the interface is given in ref. 59 and 61.

A prominent example, where transport along the grain boundary becomes important, is nanostructured $\mathrm{CeO}_{2} \cdot{ }^{59,85,87}$ Here, the space-charge region results in accumulation of electrons at the grain boundary (Fig. 7). While in microcrystalline samples the transport is mainly determined by oxygen ions, nanostructured $\mathrm{CeO}_{2}$ reveals a dominant electronic conductivity. ${ }^{59}$ As shown in Fig. 8, Tschöpe et al. were capable of describing the change from ionic to electronic transport with decreasing grain size using the space-charge model. ${ }^{88,89}$ Furthermore, their numerical calculations revealed that, due to the space-charge layer and segregation effects at the interface, not only the apparent activation energy of the transport process depends on the grain size (Fig. 8) but also the characteristic exponent of the $p\left(\mathrm{O}_{2}\right)$ dependence of conductivity. ${ }^{8-90} \mathrm{~A}$ decrease of the bulk ionic conductivity with decreasing grain size is found for nanocrystalline YSZ due to depletion of oxygen vacancies in the grain, caused by the increasing impact of the space-charge layer. ${ }^{79}$

However, the analytical description of transport properties using the space-charge model is only valid as long as the grain size is four times larger than the Debye length, $\delta_{\mathrm{g}}>4 \lambda_{\mathrm{D}}{ }^{55,75,90}$
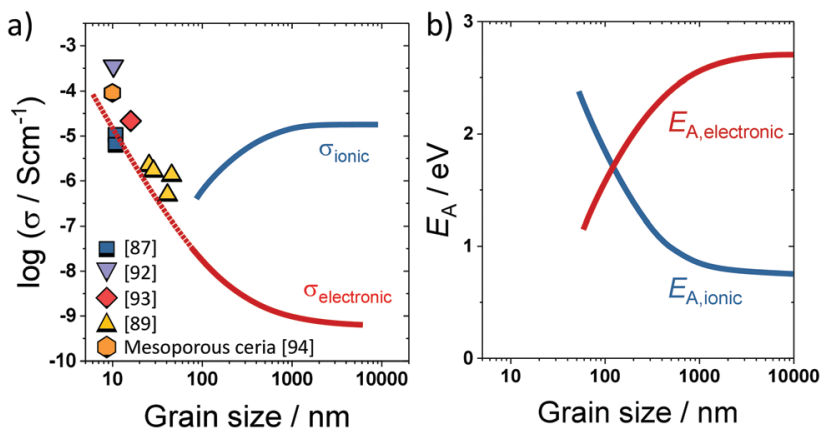

Fig. 8 (a) Change in electronic/ionic partial conductivity with the grain size; experimental data taken from ref. 87, 89 and 92-94. (b) Change in apparent activation energy of ionic/electronic transport with the grain size. Adapted from ref. 90 with permission.

If the grain size is further reduced, the space-charge regions of opposite grain boundaries start to overlap (Fig. 7) and the concentration profiles according to eqn (4) are not valid anymore. In $\mathrm{CeO}_{2}$ and $\mathrm{ZrO}_{2}$, this condition is typically fulfilled for grain sizes below approx. $20 \mathrm{~nm}$. If the grain size is further reduced to $\delta_{\mathrm{g}} \ll 4 \lambda_{\mathrm{D}}$, the space charges completely extend throughout the grain, resulting in an almost constant carrier concentration. ${ }^{91}$

For small space-charge potential, Maier derived a so-called nano-factor $g$ to describe the resulting enhancement of conductivity: ${ }^{55}$

$$
g=\frac{4 \lambda_{\mathrm{D}}}{\delta_{\mathrm{g}}} \sqrt{\frac{c_{0}-c^{*}\left(\delta_{\mathrm{g}}\right)}{c_{0}} .}
$$

Here, $c^{*}\left(\delta_{\mathrm{g}}\right)$ is the concentration of accumulated charge carriers in the center of the grain, which is given by elliptical integrals depending on the grain size $\delta_{\mathrm{g}}$, the bulk concentration $c_{\text {bulk }}$ and the concentration at the interface $c_{0}$.

The influence of the space-charge region on the electrical properties is well reported for nanocrystalline oxides with a high grain-boundary density. In case of mesoporous oxides, not only the grain boundaries act as an interface but also the free surface. Although the same description holds as for grain boundaries, ${ }^{55}$ the surface potential, and therefore the extension of the space-charge layer in the crystallites, is more sensitive to variations in the surrounding atmosphere (gas or liquid penetrating into the pores), thereby allowing to tailor the
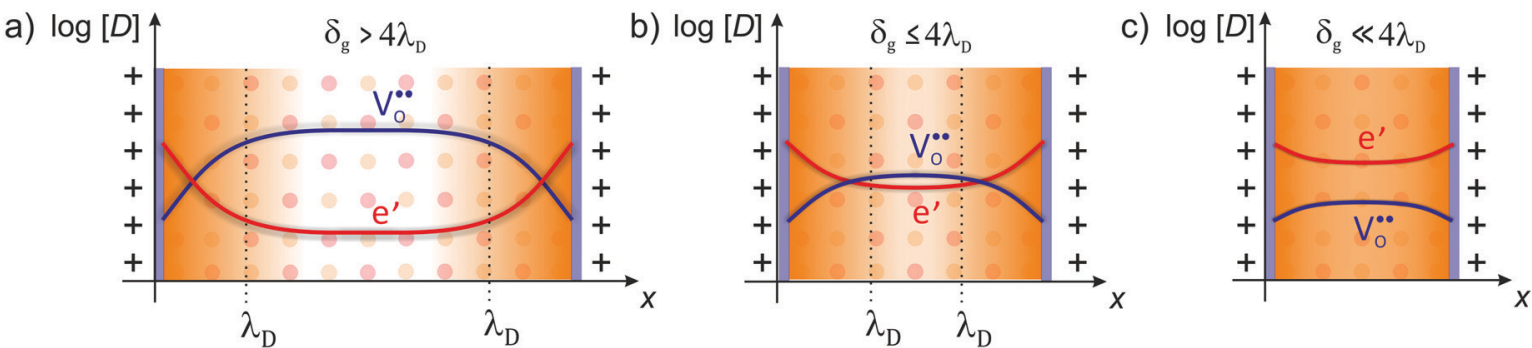

Fig. 7 Defect concentration for different grain sizes (schematically shown for $\mathrm{CeO}_{2}$ ). (a) The space-charge region affects the defect concentration near the interface in microcrystalline material. (b) For grain sizes smaller than four times the Debye length, the space-charge region starts to overlap and (c) finally completely dominates the defect concentration of the whole grain. Adapted from ref. 78 with permission. 
a)

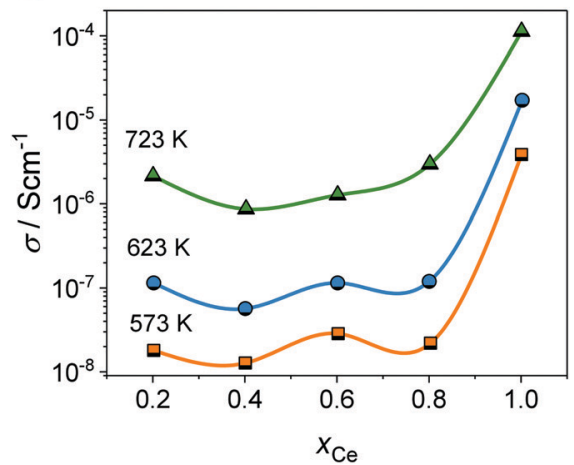

b)

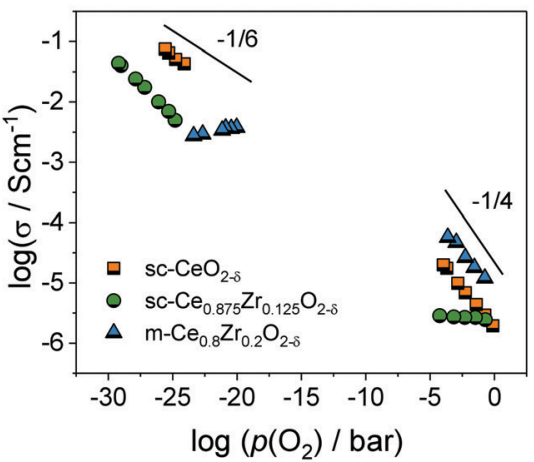

c)

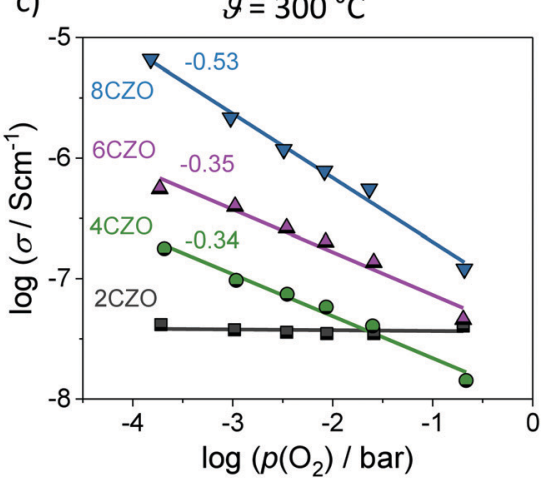

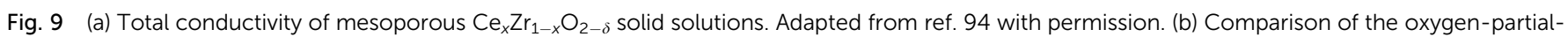

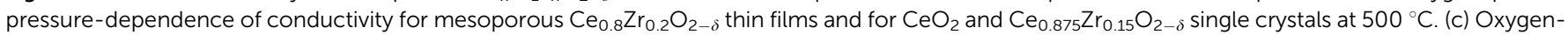

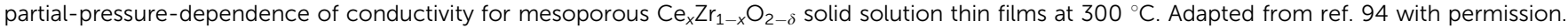

electrical properties. However, because of their unique architecture, mesoporous thin films may show significant differences compared to nanocrystalline materials.

Hartmann et al. studied the electrical conductivity of mesoporous ceria-zirconia $\left(\mathrm{Ce}_{x} \mathrm{Zr}_{1-x} \mathrm{O}_{2-\delta}\right)$ solid solutions of different composition under varying oxygen partial pressure by means of EIS. ${ }^{94}$ Because of the small crystallite size in the range between 4 and $12 \mathrm{~nm}$, only one semicircle was observed experimentally, as discussed above. Consequently, only the total impedance could be determined. Fig. 9 shows the calculated conductivity values for the different materials. Especially for the pure $\mathrm{CeO}_{2}$ sample, high conductivity was found. This result can be attributed to the electronic conductivity in the space-charge layer both at the surface and at the grain boundaries, as the obtained value is in good agreement with that expected from the model of Tschöpe et al. (Fig. 8). However, it is worth mentioning that the conductivity was calculated assuming dense films. This means the actual conductivity in the pore walls is expected to be even higher.

Fig. 9 also shows a comparison of the $p\left(\mathrm{O}_{2}\right)$-dependence of electrical conductivity at $500{ }^{\circ} \mathrm{C}$ for mesoporous $\mathrm{Ce}_{0.8} \mathrm{Zr}_{0.2} \mathrm{O}_{2}$ thin film and single crystals of comparable composition. The latter serve as a kind of reference without the influence of interfaces. Similar to the pure $\mathrm{CeO}_{2}$, mesoporous $\mathrm{Ce}_{0.8} \mathrm{Zr}_{0.2} \mathrm{O}_{2}$ showed a significant increase in total conductivity (increased electronic conductivity). The $p\left(\mathrm{O}_{2}\right)$-dependence of conductivity further supports the assumption of dominant electronic transport, as the slope of $-1 / 4$ at high oxygen partial pressure is characteristic of electronic transport according to the standard defect chemical description (if the oxygen vacancy concentration can be assumed constant [extrinsic regime]). ${ }^{85,95,96}$ For low oxygen partial pressure, standard defect chemistry predicts a -1/6dependence (intrinsic regime) when the concentration of electrons becomes comparable to the oxygen-vacancy concentration. ${ }^{85,95-97}$ The mesoporous thin film showed a maximum in conductivity and a decrease with further decreasing oxygen partial pressure, which can be attributed to a hopping maximum of the electronic transport in the $\mathrm{Ce}^{3+}$ sublattice. Because the electronic conductivity in $\mathrm{CeO}_{2}$ is determined by electron hopping from $\mathrm{Ce}^{3+}$ to $\mathrm{Ce}^{4+}$ sites, the hopping probability depends on the fraction of $\mathrm{Ce}^{3+}$ and $\mathrm{Ce}^{4+}$ ions in the lattice according to: ${ }^{98,99}$

$$
\sigma_{\mathrm{e}}=\frac{n_{\mathrm{Ce}} x_{\mathrm{Ce}^{3+}}\left(1-x_{\mathrm{Ce}^{3+}}\right) e^{2} a^{2} \nu_{0}}{k_{\mathrm{B}} T} \exp \left(-\frac{\Delta H_{\mathrm{m}}}{k_{\mathrm{B}} T}\right),
$$

with $a$ being the distance between the hopping sites, $\nu_{0}$ the attempt frequency, $n_{\mathrm{Ce}}$ the number of cerium lattice sites and $\Delta H_{\mathrm{m}}$ the migration enthalpy of the hopping process. The product $x_{\mathrm{Ce}^{3+}}\left(1-x_{\mathrm{Ce}^{3+}}\right)$ takes into account that hopping can only occur from $\mathrm{Ce}^{3+}$ to $\mathrm{Ce}^{4+}$. Hence, at high electron concentration, $x_{\mathrm{Ce}^{3+}} \gtrsim 0.5$, the hopping probability decreases again due to the reduced number of available $\mathrm{Ce}^{4+}$ species, leading to a decrease in electronic conductivity, as recently reported for Pr-doped $\mathrm{CeO}_{2}$ single crystals, where the electrons hop in the Pr-sublattice. ${ }^{99}$ The increase in electronic conductivity and the occurrence of a hopping maximum suggest high electron concentration, and therefore significantly higher reducibility of the mesoporous material compared to nanocrystalline (dense) material (due to the higher specific surface area).

However, more interesting is the $p\left(\mathrm{O}_{2}\right)$-dependence of conductivity at lower temperatures. As shown in Fig. 9, the mesoporous $\mathrm{Ce}_{0.8} \mathrm{Zr}_{0.2} \mathrm{O}_{2}$ thin film revealed a much stronger $p\left(\mathrm{O}_{2}\right)$-dependence, with a characteristic slope of $-1 / 2$ at $300{ }^{\circ} \mathrm{C}$, while for both mesoporous $\mathrm{Ce}_{0.6} \mathrm{Zr}_{0.4} \mathrm{O}_{2}$ and $\mathrm{Ce}_{0.4} \mathrm{Zr}_{0.6} \mathrm{O}_{2}$ thin films, a $p\left(\mathrm{O}_{2}\right)$ dependence with an exponent of approx. $-1 / 3$ was observed. The unusual $p\left(\mathrm{O}_{2}\right)$-dependence cannot be explained using the standard defect chemical model. Hartmann et al. proposed that oxygen vacancies with a relative charge lower than +2 are responsible for the behavior. Specifically, two scenarios have been discussed. First, formation of defect associates (due to high electron concentration) may either result in not completely ionized vacancies, $\left(\mathrm{V}_{\mathrm{O}}^{\bullet \bullet}+x e^{\prime}\right) \rightleftharpoons \mathrm{V}_{\mathrm{O}}^{(2-x) \bullet}$, or defect associates formed by vacancies and $\mathrm{Ce}^{3+}$ ions. ${ }^{101,102}$ Second, $\mathrm{O}^{-}$instead of $\mathrm{O}^{2-}$ ions were suggested to exist at the surface to compensate the $\mathrm{Ce}^{3+}$ ions. While the origin of the unusual $p\left(\mathrm{O}_{2}\right)$-dependence still remains largely unclear, the results show that the high surface area of mesoporous materials can significantly alter their electrical properties. 


\subsection{Protonic conductivity}

In recent years, especially nanostructured materials are receiving much attention, as significant protonic conductivity may be observed under wet atmospheric conditions for oxides, such as YSZ, ${ }^{103-106}$ doped $\mathrm{CeO}_{2},{ }^{107-110} \mathrm{Al}_{2} \mathrm{O}_{3},{ }^{111} \mathrm{SiO}_{2}{ }^{112}$ or $\mathrm{TiO}_{2} \cdot{ }^{113-115}$ Note that their dense counterparts show no signs of protonic conductivity. The increase in conductivity under wet atmospheric conditions is shown in Fig. 10 for various materials. In contrast to high-temperature proton conductors with a perovskite structure, ${ }^{116,117}$ like Y-doped $\mathrm{BaZrO}_{3}$, where the protons are incorporated into the bulk of the material, the protonic conductivity in nanostructured oxide ceramics at low temperatures relies on the adsorption of water molecules at the surface and grain boundaries (interfaces). Because it is directly related to the nanostructure, this offers an additional degree of freedom to tailor the protonic conductivity of mesoporous oxides, rendering them interesting as water sensors, ${ }^{118-121}$ as proton exchange membranes ${ }^{122-124}$ or for applications in energy storage and conversion. ${ }^{106,125}$

Although the high interface density is responsible for the increased protonic conductivity, at first glance, it is not obvious if the transport of protons occurs along grain boundaries or the (inner) surface. First studies on nanocrystalline YSZ revealed an increase in protonic conductivity with decreasing grain size, ${ }^{105,114}$ suggesting that the transport does occur along the grain boundaries $^{126}$ (or at least is related to the grain-boundary density). However, it is now widely accepted that the increased conductivity arises from protons moving in chemisorbed and physisorbed water layers along the pores and surface of nanostructured oxides. ${ }^{100,104,127-130}$ The strong dependence of the protonic conductivity on relative humidity and temperature is related to the structure of the adsorbed water molecules, as summarized by Stub et al. ${ }^{131}$ The structure of the water layer on $\mathrm{TiO}_{2}$ is schematically shown in Fig. 11.

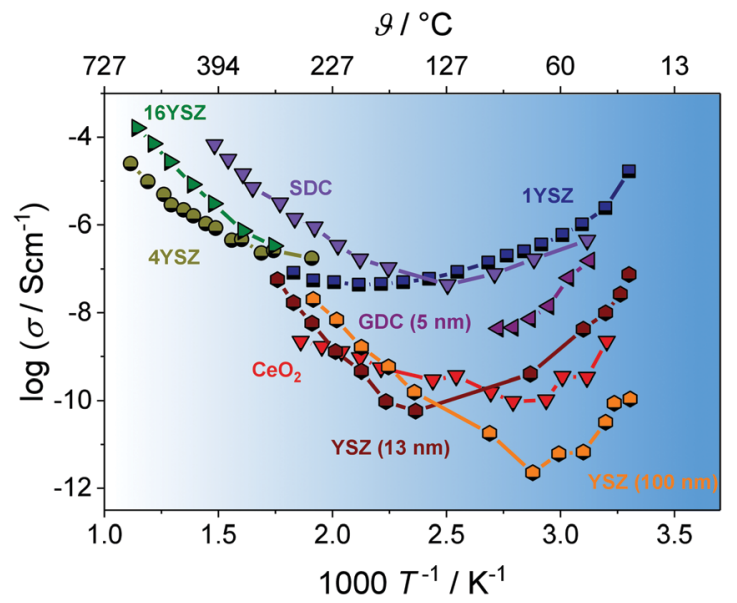

Fig. 10 Arrhenius plot of the temperature-dependent conductivity for different nanostructured oxides. Under wet atmospheric conditions, the adsorption of water molecules at the interfaces leads to significant increases due to surface protonic conductivity. Adapted from ref. 100 with permission.

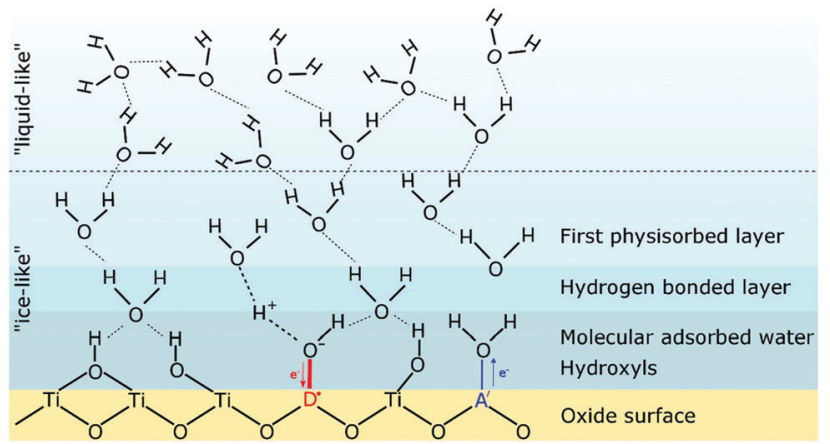

Fig. 11 Schematic illustration of the structure of adsorbed water molecules on an oxide $\left(\mathrm{TiO}_{2}\right)$ surface. The influence of an acceptor $A^{\prime}$ or a donor $D^{\bullet}$ on the water dissociation is also indicated. Reprinted from ref. 132 with permission.

At high temperature and/or low relative humidity, an "icelike" layer is formed on the surface, consisting of chemisorbed and physisorbed molecules. In the former case, the oxide surface chemistry determines the amount of adsorbed water molecules and the type of protonic charge carriers. For instance, for an ideal $\mathrm{ZrO}_{2}$ surface, hydroxyl groups are formed in the chemisorbed layer, which apparently are stable up to $600{ }^{\circ} \mathrm{C} .{ }^{100,131,133,134}$ Hydroxyl groups can also be formed due to the presence of surface defects, such as oxygen vacancies, where the water molecule fills the vacancy according to (Kröger-Vink notation): ${ }^{110,117,135}$

$$
\mathrm{H}_{2} \mathrm{O}_{(\mathrm{g})}+\mathrm{V}_{\mathrm{O}}^{\bullet \bullet}+\mathrm{O}_{\mathrm{O}}^{\times} \leftrightarrow 2(\mathrm{OH})_{\mathrm{O}}^{\bullet}
$$

At higher relative humidity, the number of physisorbed layers increases, resulting in transition from "ice-like" to "liquid-like" water layer on the surface. The increase in water layer thickness is also accompanied by a change in transport mechanism. While in the "ice-like" layer, the protonic charge carriers move via Grotthuss hopping, ${ }^{131}$ vehicle-type transport of hydronium ions is found in the physisorbed layers due to the weaker bonding between the water molecules. $^{100,131,133}$

Stub et al. probed the protonic conductivity in porous $\mathrm{TiO}_{2}$ with varying doping levels. ${ }^{132}$ High-valent dopants, which are more acidic, are likely to attract electrons, thereby increasing the dissociation of water. This in turn increases the protonic charge-carrier concentration, and consequently also their mobility. Overall, donor-dopants improve the protonic conductivity, while the opposite effect is expected for acceptor-doped oxides. Hence, higher surface acidity results in increased protonic conductivity, as also reported for Cl-doped, mesoporous $\mathrm{Al}_{2} \mathrm{O}_{3}$, for example. ${ }^{111}$ The profound effect of pore wall chemistry on the protonic conductivity has also been observed by Vichi et al., who investigated the protonic conductivity of mesoporous $\mathrm{TiO}_{2}$ pretreated in solutions of different $\mathrm{pH}$ and by modifying the surface with phosphate anions. ${ }^{137}$ Similar results have been reported by Marschall et al., who studied the influence of sulfonic acid functionalization on the protonic conductivity in mesoporous silica. ${ }^{138}$

In 2013, Gregori et al. examined the proton transport in porous $\mathrm{CeO}_{2}$. They discussed about the influence of space-charge region on the proton transport at oxide surfaces. ${ }^{107}$ Here, the 


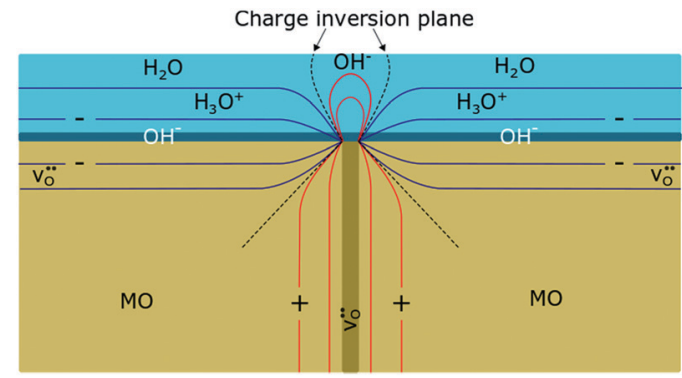

Fig. 12 Schematic illustration of the resistive behavior of a grain boundary with adsorbed water molecules on the surface of an oxide ceramic (MO). Because of the positive core, hydroxide ions accumulate at the grain boundary, impeding the transport of hydronium ions in the physisorbed water layer. Reprinted from ref. 136 with permission.

incorporation of water molecules into the space-charge region according to eqn (12) would result in an increase of hydroxide ions in the water layer at the surface, which may be responsible for the enhanced protonic conductivity at low temperature, too.

The importance of space-charge effects has also been addressed by Stub et al. in 2018. ${ }^{136}$ EIS measurements conducted on nanocrystalline YSZ revealed two transport processes, one representing the proton transport along the grains (intra-grain transport), the other was attributed to a resistive transport across the grain boundaries. The positive core of the grain boundary (space-charge region of positive electric potential) results in accumulation of hydroxide ions, as schematically shown in Fig. 12, hindering the movement of hydronium ions in the physisorbed water layer.

In porous materials, the adsorption of water not only depends on the surface chemistry but also is strongly determined by the structure. Capillary condensation into the nanoscale pores facilitates water uptake. ${ }^{107,124,127,130}$ As discussed by Vichi et al. for mesoporous $\mathrm{TiO}_{2}$, the adsorption of water at the interface occurs in two steps. ${ }^{137}$ First, water molecules are adsorbed depending on the surface chemistry of the material, while in the second step the pores are filled due to capillary condensation, independent of the surface properties. After filling of the pores with water, the protonic conductivity in mesoporous thin films can be maintained, even when changing the relative humidity. ${ }^{139}$

However, complete pore filling can also negatively affect the protonic conductivity. Vichi et al. observed an increase in activation energy of the proton transport in completely filled pores, which they attributed to bridges formed between water molecules of opposite walls. ${ }^{137}$ Comparable results were also obtained for mesoporous $\mathrm{SiO}_{2}{ }^{140-142}$ and $\mathrm{Al}_{2} \mathrm{O}_{3}{ }^{111}$ the highest protonic conductivities were achieved with 4 and $12 \mathrm{~nm}$ pores, respectively. For smaller pore size, the movement of protonic carriers is hindered by geometrical restrictions.

For cubic mesoporous YSZ thin films with a pore size of about $24 \mathrm{~nm}$, even a gradual decrease in total conductivity with increasing relative humidity was observed above $200{ }^{\circ} \mathrm{C}$, as shown in Fig. $13 .{ }^{135}$ However, porous YSZ thin films may show a significant increase in the same temperature range (Fig. 13). ${ }^{129}$

The decrease in total conductivity in case of the mesoporous films was attributed to the annihilation of oxygen vacancies at

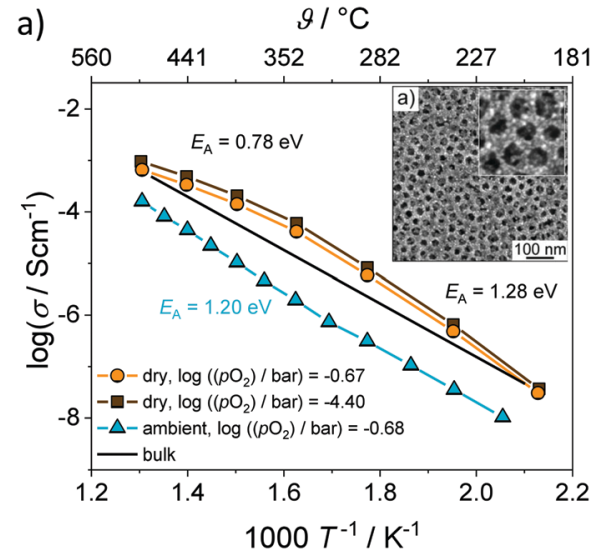

b) $\checkmark /{ }^{\circ} \mathrm{C}$

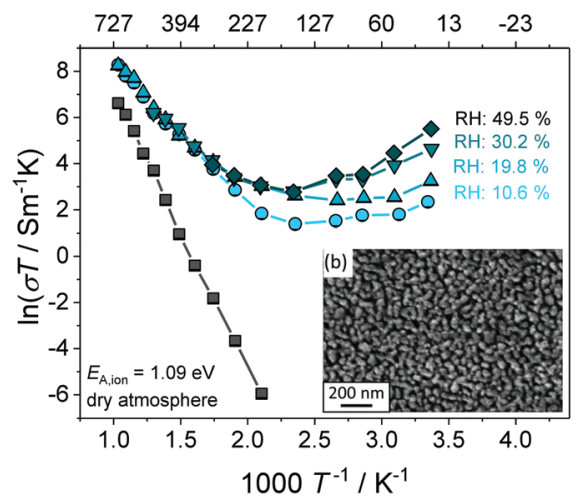

Fig. 13 Arrhenius plot of the conductivity for (a) mesoporous and (b) porous YSZ thin films under wet atmospheric conditions. Adapted from ref. 129 and 135 with permission.

the surface according to eqn (12), which are the majority charge carriers in YSZ. A decrease in total conductivity under wet atmospheric conditions has also been reported for microcrystalline $\mathrm{CeO}_{2}$ by Chueh et al. They attributed this result to changes in the space-charge potential of grain boundaries upon hydration. ${ }^{143}$ Although the influence of pore size on the protonic conductivity in oxide materials is not yet fully understood, the results clearly demonstrate the considerable effect that the pore structure has in general. In contrast to nanocrystalline oxides with an ill-defined porosity, the regular pore network of ordered mesostructured materials seems beneficial to device applications, as the pore size and structure, as well as the wall thickness, can be tailored to some degree to optimize water uptake (adsorption), and therefore the protonic conductivity.

\section{Electrochemical applications}

As discussed above, mesoporous oxides are characterized by a high specific surface area combined with a unique pore structure and nanocrystalline walls. These properties make them interesting for a broad range of electrochemical applications, ${ }^{14,144-146}$ for example, as active electrode material in batteries, for (photo-)electrocatalysis and oxygen storage or as gas sensor. It should be noted that the favorable properties are not only a result of the increased surface area. Instead, the major advantage is the 
presence of a uniform and continuous pore network, allowing effective transport of electronic and ionic charge carriers and providing good accessibility of the material and its internal structure to the surrounding medium, as gasses or liquids can readily penetrate into the porosity. In the following, we discuss in some more detail the pros and cons of mesoporous metal oxides and which properties are beneficial to the functionality and performance of electrochemical devices.

\subsection{Mesoporous metal oxides for batteries}

The working principle of an insertion- or intercalation-type material for secondary battery applications relies on both the reversible storage of ions $\left(\mathrm{Li}^{+}, \mathrm{Na}^{+}\right.$etc. $)$during electrochemical cycling and the efficient transport of charge-compensating electrons (Fig. 14). In recent years, mesoporous electrode materials have been shown to possess promising properties, allowing for superior energy storage and high power density, among others. ${ }^{147}$ The mesoporous morphology ensures equal distribution of electrolyte in the (bulk) structure, minimizing the fraction of inactive material and allowing fast ion diffusion along the pore system. ${ }^{147-149}$ Furthermore, the interconnection of nanoscale particles in the pore walls provides short diffusion lengths and efficient transport pathways for both the ions and electrons.

The positive effect of mesoporosity on the charge-storage properties has been proven for a variety of cathode and anode active materials, mainly for lithium-ion battery (LIB) applications, such as $\mathrm{LiCoO}_{2},{ }^{150} \mathrm{LiFePO}_{4}{ }^{151} \beta-\mathrm{MnO}_{2},{ }^{152} \mathrm{LiMn}_{2} \mathrm{O}_{4},{ }^{152,153}$ $\mathrm{Li}_{4} \mathrm{Ti}_{5} \mathrm{O}_{12},{ }^{38} \mathrm{TiO}_{2},{ }^{19,154-156} \alpha-\mathrm{Fe}_{2} \mathrm{O}_{3}{ }^{157}$ or NiO. ${ }^{158}$ For example, Jiao et al. compared the electrochemical performance of nanowire and mesoporous $\mathrm{LiCoO}_{2}$ to that of "normal" $\mathrm{LiCoO}_{2}$. The mesoporous material delivered the largest specific discharge capacity and showed the best capacity retention, which was attributed to the unique pore-solid architecture with good connection among adjacent crystallites. ${ }^{150}$ Brezesinski et al. came to the same conclusion from studying polymer-templated and nontemplated (nanocrystalline) $\mathrm{TiO}_{2}$ thin films. ${ }^{19}$ These results confirm the beneficial effect of nanoscale porosity on the electrochemical performance.

An important parameter when characterizing battery materials is the amount of stored charge. In general, the total amount consists of three contributions, as summarized in Fig. 15, namely, the faradaic contribution from the insertion of ions into the bulk of the material, the faradaic contribution from charge-transfer

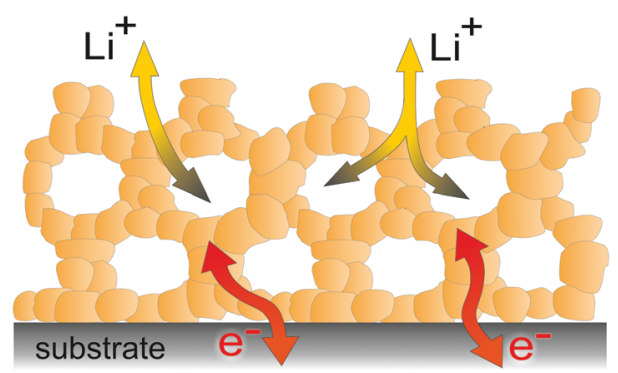

Fig. 14 Schematic illustration of the charge-transport processes accompanying lithium insertion/extraction into/from a mesoporous material, with the nanoscale porosity allowing for short diffusion path lengths.

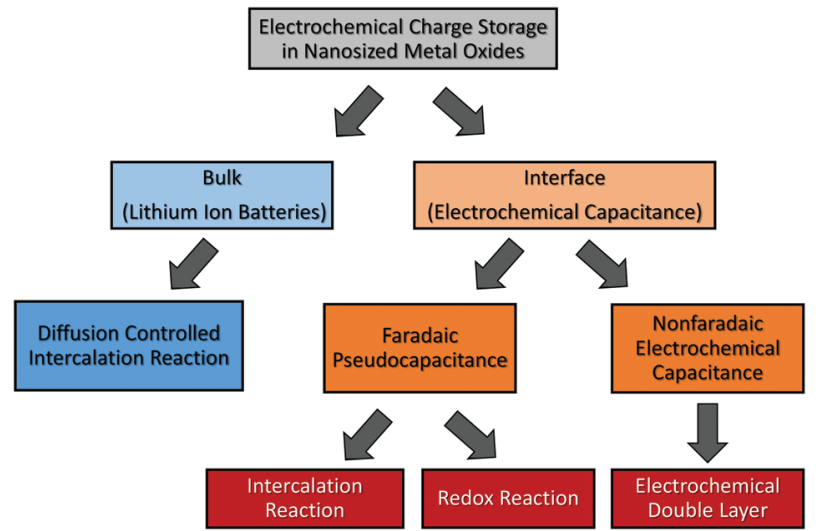

Fig. 15 Charge-storage mechanisms in nanocrystalline metal oxides. Adapted from ref. 156 with permission.

processes at the solid/liquid interface (pseudocapacitive charge storage) and the nonfaradaic contribution due to formation of a Helmholtz double layer. ${ }^{19,156,159-161}$ Analysis of cyclic voltammetry (CV) data obtained at different sweep rates $v$ allows distinguishing between diffusion- and nondiffusion-controlled charge storage. Because ion insertion into the bulk is a semi-infinite diffusion process, the current is proportional to $v^{1 / 2}$. In contrast, for capacitive processes, the current depends linearly on the sweep rate. Hence, current as a function of sweep rate is given by: ${ }^{162}$

$$
j(v)=k_{1} v+k_{2} v^{1 / 2},
$$

where $k_{1}$ depends on the surface area $A$ and the capacitance $C$ of the electrode, while $k_{2}$ is given by the Randles-Ševčík equation: ${ }^{163}$

$$
k_{2}=0.4958 n F A c\left(\frac{n F D}{R T}\right)^{1 / 2},
$$

with $F$ being the Faraday constant, $D$ the diffusion coefficient and $n$ the number of electrons transferred in the redox reaction. Rearranging eqn (13) then allows separating between both contributions:

$$
\frac{j(v)}{v^{1 / 2}}=k_{1} v^{1 / 2}+k_{2}
$$

Especially for nanocrystalline materials, capacitive charge storage becomes significant and plays an important role in the performance and for the kinetics. ${ }^{19,156,159,164-166}$ Analysis of CV data for mesoporous $\mathrm{TiO}_{2}$ thin films showed that the capacitive contribution to charge storage is virtually independent of the sweep rate, while the bulk insertion significantly decreases with increasing sweep rate. ${ }^{19}$ For mesoporous $\mathrm{MoS}_{2}$, Cook et al. found that $80 \%$ of the theoretical specific capacity is accessible within $20 \mathrm{~s}$ due to pseudocapacitive charge storage. ${ }^{167}$ These results indicate that fast kinetics in mesoporous materials also originates from nondiffusion-controlled surface charge-storage processes.

Significant pseudocapacitive charge storage has also been observed for mesoporous group $\mathrm{V}$ transition-metal oxides, including $\mathrm{Nb}_{2} \mathrm{O}_{5}$ and $\mathrm{Ta}_{2} \mathrm{O}_{5}$, and for $\mathrm{MoO}_{3} \cdot{ }^{166,168}$ Direct comparison of crystalline and amorphous thin films showed that the pseudocapacitance achieved with the crystalline samples exceeds that 
of the amorphous films by large. The increased pseudocapacitive contribution to charge storage was attributed to the lithium insertion into the interlayer gaps of the layered crystalline materials (referred to as intercalation pseudocapacitance).

An aspect that is rarely being considered is that the amount of charge stored at the interface can be much larger than that stored in the bulk due to formation of the space-charge region. ${ }^{169-172}$ This effect may even allow to store, e.g., lithium at the interface between two materials, for which such behavior is not possible in the individual phases. ${ }^{173}$ For example, Yue et al. investigated the pseudocapacitive charge storage in mesoporous Nb-doped $\mathrm{TiO}_{2}$. ${ }^{156}$ Because $\mathrm{TiO}_{2}$ has a low electronic conductivity, doping with $\mathrm{Nb}$, acting as a donor, can significantly improve the conductivity of the material. ${ }^{174,175}$ Apart from the increase in electronic conductivity, the authors found that the pseudocapacitance is also increased up to doping levels of about 5 at\%. Higher concentrations led to a decrease in pseudocapacitive charge storage. This behavior was explained by changes in the space-charge layer at the interface, as shown in Fig. 16. For $\mathrm{TiO}_{2}$ in contact with a $\mathrm{Li}^{+}$-containing electrolyte, the space-charge region results in depletion of electrons at the interface and accumulation of lithium ions due to differences in electrical potential between the surface (interface) and the bulk. ${ }^{170}$ For low doping concentration, the space-charge region of opposite sites overlaps, resulting in negligible potential differences, ${ }^{176,177}$ and therefore in low surface charge storage. With increasing doping level, the space-charge region decreases. Hence, the potential differences increase and more ions can be stored at the interface, leading to increased pseudocapacitance. However, the width of the space-charge region continues to decrease with
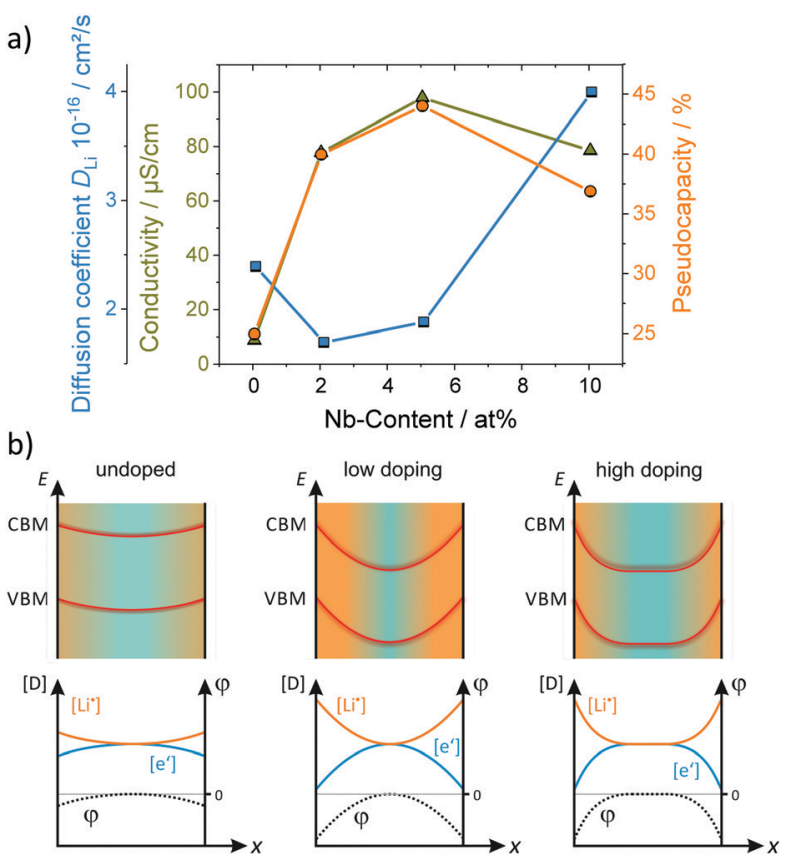

Fig. 16 (a) Electrical conductivity and pseudocapacitive charge storage of mesoporous $\mathrm{TiO}_{2}$ versus the $\mathrm{Nb}$ doping level. (b) Schematic illustration of the surface band bending and the corresponding defect concentration for different doping situations. Adapted from ref. 156 with permission. further increasing doping concentration. For that reason, the pseudocapacitive contribution to charge storage starts to decrease again at some point.

Although the extension of the space-charge region in oxides is typically less than a few nanometers, this example shows that, in mesoporous materials with crystallites of similar dimensions, the charge storage in the space-charge region can become significant and even dominate the overall behavior.

Another major advantage of mesoporous materials is their mechanical flexibility. The insertion/extraction of ions into/ from the electrode during electrochemical cycling is usually accompanied by volume changes, ${ }^{178-181}$ often resulting in mechanical degradation (fracturing or even pulverization of the active material). ${ }^{182-188}$ In mesoporous materials, such adverse effects can be mitigated, as mechanical strain is accommodated to some degree by pore flexing. ${ }^{144,189,190}$ Liu et al. investigated the electrochemical properties and cycling stability of ordered mesoporous $\mathrm{NiO}$ produced by hard templating. ${ }^{158}$ While NiO as anode in LIBs typically suffers from pulverization and accelerated capacity fading due to volume changes during the conversion reaction, among others, ${ }^{191,192}$ the mesoporous material maintained a specific capacity of $680 \mathrm{~mA} \mathrm{~h} \mathrm{~g} \mathrm{~g}^{-1}$ at $0.1 \mathrm{C}$ rate after 50 cycles. Lee et al. studied ordered mesoporous niobium nitride/N-doped carbon composite as an advanced anode material for application in K-ion batteries. ${ }^{193}$ Structural characterization using in situ X-ray diffraction (XRD) showed that the high cycling stability (stable performance for $>2000$ cycles) is due, in part, to the negligible mechanical strain that the material experiences during cycling.

The mechanical flexibility also improved the lithium storage in mesoporous $\mathrm{CeO}_{2}$. Specifically, Brezesinski et al. probed the charge-storage behavior of polymer-templated and nontemplated thin films (Fig. 17). As expected, the authors observed a significant increase in pseudocapacitive charge storage in the
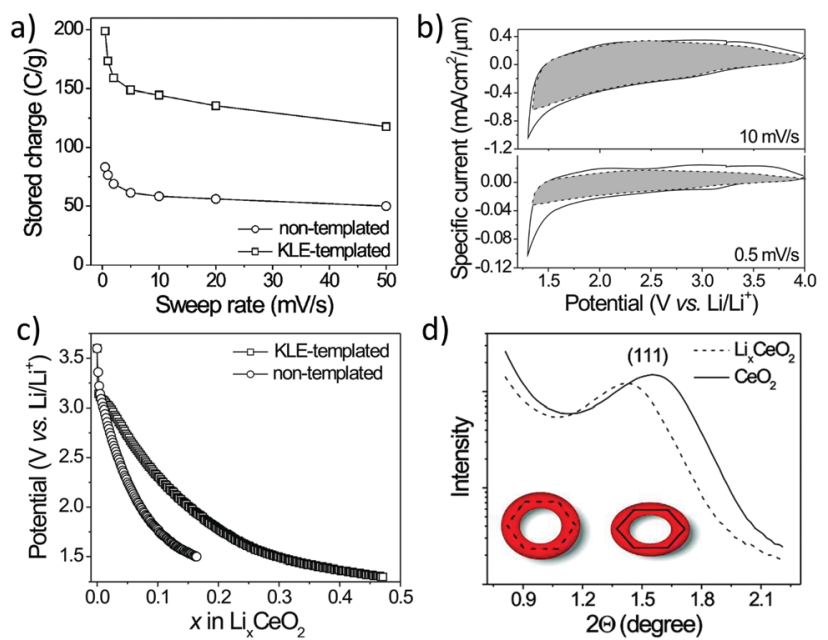

Fig. 17 (a) Charge-storage dependence on sweep rate for nanocrystalline (nontemplated) and mesoporous (KLE-templated) $\mathrm{CeO}_{2}$ thin films. (b) $\mathrm{CV}$ curves for mesoporous $\mathrm{CeO}_{2}$. The capacitive current is highlighted in gray. (c) Galvanostatic discharge curves at $\mathrm{C} / 2$ rate. (d) SAXS patterns for mesoporous $\mathrm{CeO}_{2}$ and $\mathrm{Li}_{x} \mathrm{CeO}_{2}$. Adapted from ref. 165 with permission. 
mesoporous $\mathrm{CeO}_{2} \cdot{ }^{165}$ However, for slow sweep rates or long charging times, that is, if the lithium ions have enough time to diffuse into the lattice, the total amount of stored charge was also increased by a factor of about two compared to the nontemplated material. Using small-angle X-ray scattering (SAXS), they were able to show that the mesoporous $\mathrm{CeO}_{2}$ thin films have tensile stress imposed by the substrate (note that templated sol-gel films usually undergo unidirectional volume contraction during heating). Upon ion insertion into the lattice, the porous structure expands normal to the substrate, relieving in-plane stress, which in turn facilitates charge storage.

The structural stability of ordered mesoporous $\mathrm{NiCo}_{2} \mathrm{O}_{4}$ during electrochemical cycling has been examined by Bhaway et al. ${ }^{194}$ Using grazing-incidence SAXS (GISAXS) and XRD (GIXD), they were able to correlate structural changes of the anode material with the electrochemical performance. Electrodes with approx. $9 \mathrm{~nm}$ pores showed severe capacity fading caused by collapse of the nanostructure during the initial cycles. In contrast, for electrodes with larger pores, the nanostructure was retained, which agrees well with the improved cyclability.

Increased structural stability has also been observed by Krins et al. for mesoporous amorphous $\mathrm{NbVO}_{5}$ thin films with a wormlike pore structure. ${ }^{195}$ The authors found that their ability to accommodate the strain from lithium insertion increases with decreasing pore size from 100 to $15 \mathrm{~nm}$, suggesting that the optimal size is closer to $10 \mathrm{~nm}$.

Mesoporous nanocrystalline architectures offer an additional advantage in terms of ion uptake, as the particle size may have a strong impact on the thermodynamics. ${ }^{196}$ For example, lithium insertion into bulk $\mathrm{TiO}_{2}$ is accompanied by a phase transition from anatase $\mathrm{TiO}_{2}$ to $\mathrm{Li}_{0.55} \mathrm{TiO}_{2} \cdot{ }^{197-200}$ With further insertion of lithium, a second phase transition occurs, resulting in the formation of a blocking $\mathrm{LiTiO}_{2}$ layer at the particle surface. $\mathrm{LiTiO}_{2}$ exhibits a low lithium-diffusion coefficient, and therefore prevents complete phase transformation (kinetic limitation). ${ }^{198}$ However, as discussed by Wagemaker et al., increasing contribution of surface free energy to the total free enthalpy of the system alters the solubility limit of lithium in $\mathrm{TiO}_{2}$ and can even suppress phase separation. ${ }^{198,199}$ For particles $\leq 7 \mathrm{~nm}$ in diameter, both phase transitions are suppressed, allowing full lithiation to form $\mathrm{LiTiO}_{2}{ }^{198}$ which also helps explain the larger specific capacity of nanostructured $\mathrm{TiO}_{2}$ compared with bulk material. $^{200-202}$

Similar behavior has been observed for $\alpha-\mathrm{Fe}_{2} \mathrm{O}_{3}$ (hematite). While larger particles undergo a phase transition from trigonal $\alpha-\mathrm{Fe}_{2} \mathrm{O}_{3}$ to cubic $\mathrm{Li}_{x} \mathrm{Fe}_{2} \mathrm{O}_{3}$ at $x \approx 0.05$, in nanoparticles, this transition is suppressed and lithium can be inserted into the lattice up to $x \approx 1$. As the lithium uptake is reversible for $\alpha-\mathrm{Li}_{x} \mathrm{Fe}_{2} \mathrm{O}_{3}$, nanoparticles exhibit much improved cyclability. ${ }^{203,204}$ Note that increased lithium storage and good cycling stability have also been found for mesoporous hematite and other Fe-based oxide thin films. ${ }^{205,206}$

\subsection{Mesoporous metal oxides in catalysis}

Because of their unique structural properties, mesoporous oxides represent a promising class of materials for a variety of catalytic applications, for example, as catalyst or support for $\mathrm{CO}$ and NO conversion reactions or for (photo-)catalytic hydrogen production and water splitting. While their high surface area provides a large number of catalytically active sites, the 3-dimensional pore structure ensures good accessibility of the bulk and enables efficient transport of reaction species to/from the material. However, the catalytic properties not only depend on the specific surface area but also the wall structure (grain size, crystallinity etc.).

Ceria-zirconia solid solutions are among the most prominent catalytic materials for $\mathrm{CO}$ and NO conversion due to the high redox activity of the $\mathrm{Ce}^{3+} / \mathrm{Ce}^{4+}$ couple. ${ }^{207}$ Furthermore, because of its smaller ionic radius, the incorporation of $\mathrm{Zr}^{4+}$ ions into the lattice distorts the cubic fluorite structure, resulting in the formation of defects and higher reducibility. ${ }^{97,208}$ Overall, ceria-zirconia solid solutions exhibit favorable catalytic properties as a result of their unique oxygen-storage capacity, despite the fact that $\mathrm{Zr}^{4+}$ is redox inactive. ${ }^{207,209}$

There are several reports on the investigation into catalytic properties of mesoporous $\mathrm{Ce}_{x} \mathrm{Zr}_{1-x} \mathrm{O}_{2-\delta} \cdot{ }^{210-214}$ For example, Petkovich et al. probed the catalytic activity of ordered macroporous versions of such materials, prepared using two different synthetic routes, for $\mathrm{H}_{2} \mathrm{O}$ splitting and $\mathrm{H}_{2}$ production. ${ }^{215}$ They found increased $\mathrm{H}_{2}$ production rates compared to commercial $\mathrm{CeO}_{2}$ powder, which was attributed to the increased specific surface area. However, the reaction rate was not directly related to the surface area, but instead to the composition and homogeneity of the crystallites. The highest rate was observed for materials with a $\mathrm{Zr}$ content between 10 and 20\%. Furthermore, samples with compositional heterogeneity, that is, the presence of Ce- and Zr-rich phases, offered better performance than the respective homogeneous (single-phase) materials. Mamontov et al. also observed a correlation between heterogeneity and oxygenstorage capacity in nanocrystalline ceria-zirconia powders. ${ }^{216}$

Ho et al. reported on mesoporous $\mathrm{Pd} /$ ceria-zirconia solid solutions with macrochannels, ${ }^{217}$ showing superior activity for CO oxidation over reference samples without macrochannels. The improvement in performance was attributed to two main factors: first, alignment of macrochannels, enabling effective mass transport through the pore system, and second, increased $\mathrm{Ce}^{3+}$ and oxygen-vacancy concentrations at the surface (preferred reaction sites). ${ }^{218}$ In contrast to the report by Petkovich et al., crystal structure homogeneity was found to be advantageous, in agreement with other reports, ${ }^{209,219}$ as oxygen vacancies are more readily formed in the cubic phase than in mixed-phase structures. $^{220}$ Cui et al. examined the influence of La and Pr doping on the catalytic properties of ceria-zirconia solid solutions. They came to the same conclusion that larger pores allow for more effective gas diffusion. They also observed that an increased fraction of $\mathrm{Ce}^{3+}$ ions due to doping is beneficial to the catalytic activity and the oxygen-storage capacity. ${ }^{221}$ Similar results were obtained for mesoporous $\mathrm{CeO}_{2}$-based catalysts used in methanol decomposition. ${ }^{210,222}$

The strong correlation between oxygen-storage capacity and catalytic activity has been theoretically studied by Sayle et al. for nanoscale $\mathrm{CeO}_{2}{ }^{223}$ Molecular dynamics (MD) simulations 
confirmed that the catalytic activity is strongly affected by its oxygen content, and therefore directly related to the oxygenstorage capacity. Furthermore, they found that the catalytic activity depends on the morphology of the material, such as wall diameter and particle size. In general, oxygen extraction from nanoparticles is more facile. This is in agreement with density-functional theory (DFT) calculations by Migani $e t$ al., predicting the least oxygen-vacancy formation energy for nanoscale $\mathrm{CeO}_{2} \cdot{ }^{224,225}$

In 2018, Hao et al. confirmed the considerable effect that the particle size has on the oxygen-storage capacity of $\mathrm{CeO}_{2} \cdot{ }^{226}$ The oxygen-storage capacity of $5 \mathrm{~nm}$ particles (approx. $260 \mu \mathrm{mol} \mathrm{g}^{-1}$ at $250{ }^{\circ} \mathrm{C}$ ) was shown to be two times larger than that of $12 \mathrm{~nm}$ particles (Fig. 18). Using scanning tunneling microscopy (STEM) combined with electron energy loss spectroscopy (EELS), they observed an increase in $\mathrm{Ce}^{3+}$ concentration at the surface of the nanoparticles or, in other words, the presence of a space-charge layer. The space-charge layer extends over the whole nanoparticles when their size is below $6 \mathrm{~nm}$, resulting in a total $\mathrm{Ce}^{3+}$ content of more than $50 \%$. The increase of $\mathrm{Ce}^{3+}$ at the surface is accompanied by an increase of the lattice parameter, leading to a lower formation energy for oxygen vacancies. This helps explain the increase in oxygen-storage capacity with decreasing particle size.

Apart from ceria-zirconia solid solutions, other oxides have also been considered for catalytic applications. Ren et al. studied the $\mathrm{CO}$ conversion on ordered mesoporous metal oxides, such as $\mathrm{Co}_{3} \mathrm{O}_{4}, \mathrm{Cr}_{2} \mathrm{O}_{3}$ and $\mathrm{Fe}_{2} \mathrm{O}_{3}$, to name a few. ${ }^{227}$ These materials
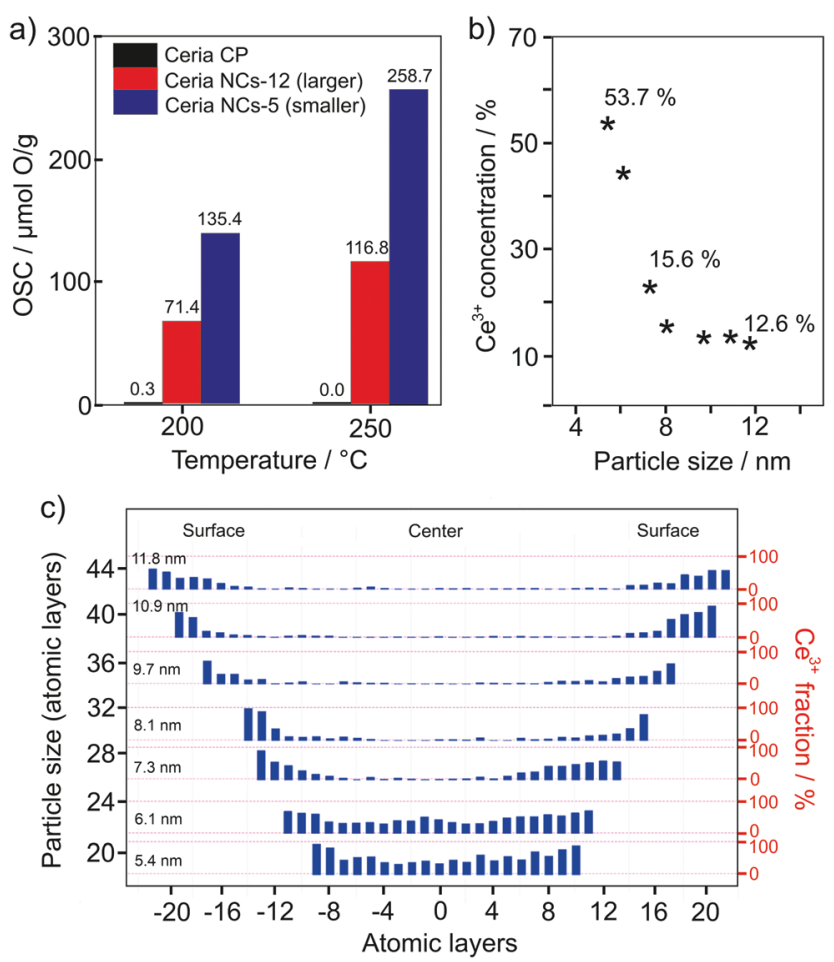

Fig. 18 (a) Comparison of the oxygen-storage capacity of $\mathrm{CeO}_{2}$ nanoparticles of different size and commercially available nanopowder. (b) $\mathrm{Ce}^{3+}$ content as function of the particle size and (c) valence-state distribution. Adapted from ref. 226 with permission.
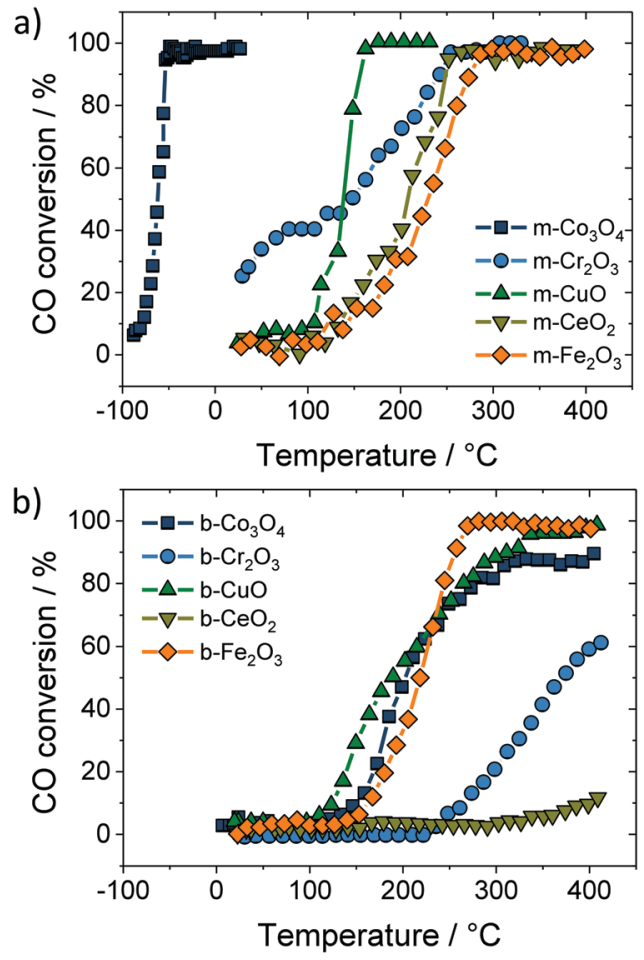

Fig. 19 CO conversion on (a) mesoporous and (b) bulk oxide catalysts. Adapted from ref. 227 with permission.

exhibited increased $\mathrm{CO}$ conversion rates compared to their bulk counterparts, as shown in Fig. 19. The improvements were attributed not only to the increased specific surface area but also to the presence of a regular 3-dimensional pore structure, providing well-defined pathways for gas transport and equally accessible internal surfaces. Similar results were obtained by both Sun $e t$ al. and Tüysüz et al. for CO oxidation over ordered mesoporous $\mathrm{Co}_{3} \mathrm{O}_{4} \cdot{ }^{228,229}$

Furthermore, noble-metal nanoparticles as co-catalysts have been shown capable of strongly affecting the activity of oxides by facilitating the conversion reaction (for oxide-supported transition-metal catalysts). The reason is that metallic nanoclusters on the surface increase the oxygen-vacancy concentration and improve the charge transfer. ${ }^{232,233}$ Both results in an enhancement of catalytic activity at the metal/oxide interface. ${ }^{234,235}$ The beneficial effect of using metallic nanoclusters has been shown for a variety of mesoporous oxides. ${ }^{210,217,236}$ However, the reaction rate also depends on the size (smaller particles are usually more active), shape and distribution of nanoparticles inside the mesoporous framework, as demonstrated, for example, by Kapoor et al. ${ }^{210}$ Because the mesoporous support can be post-loaded, ${ }^{236}$ this allows for presynthesis of tailored nanoparticles. Furthermore, the interaction with the oxide surface prevents the agglomeration of particles.

In addition to their application in conversion reactions, mesoporous metal oxides also gained great interest in the field of photo(electro-)catalysis for water splitting (hydrogen/oxygen production) or carbon dioxide reduction. The basic principle is based on the generation of an electron-hole pair in a semiconducting material under light irradiation, as shown in Fig. 20 
a)
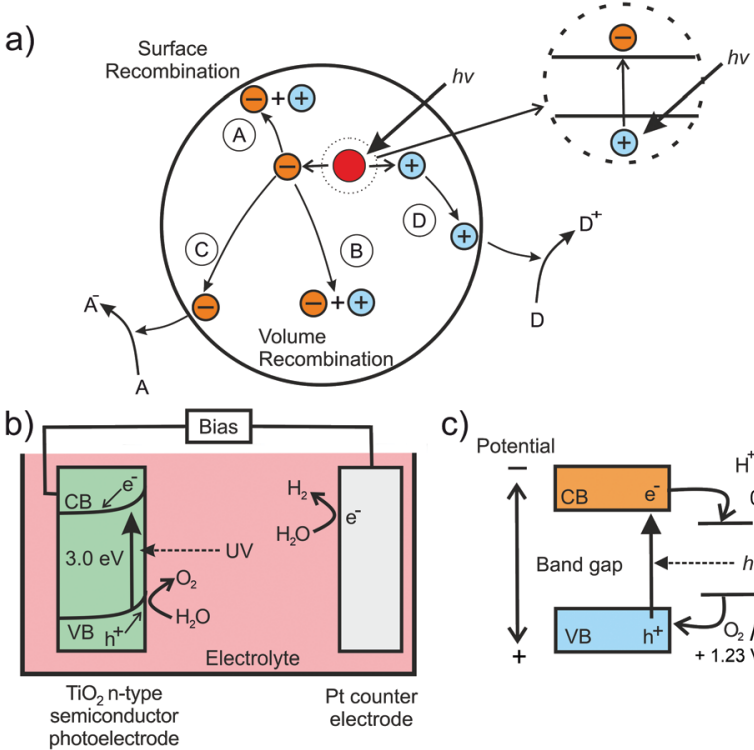

c)

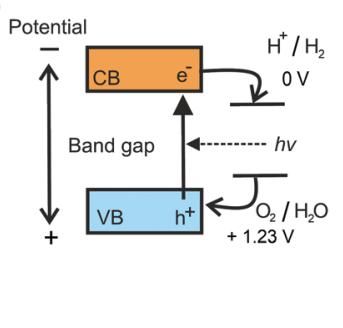

Fig. 20 (a) Schematic of the electron-hole pair generation in semiconducting nanoparticles and possible recombination mechanisms: (A) surface and (B) volume recombination and (C) reduction and (D) oxidation reactions. Adapted from ref. 230 with permission. (b) Schematic illustration of the setup for photoelectrocatalytic water splitting using $\mathrm{TiO}_{2}$ as photoanode. (c) Energetic position of redox states relative to the bands of the semiconductor. Adapted from ref. 231 with permission.

for the water-splitting reaction using a particulate photocatalyst. $^{230,231,237}$ Both the electron and electron hole then undergo secondary reactions at the surface, which may also be supported by a metal co-catalyst. At the surface of the catalyst, electrons reduce $\mathrm{H}_{2} \mathrm{O}$ molecules to form $\mathrm{H}_{2}$, while $\mathrm{H}_{2} \mathrm{O}$ molecules are oxidized by holes to produce $\mathrm{O}_{2}$. Hence, for photocatalysis, semiconductors with a sufficiently large band gap are needed. Specifically, the valence band should be more positive than the potential for the $\mathrm{O}_{2} / \mathrm{H}_{2} \mathrm{O}$ redox reaction, while the conduction band has to be more negative than the potential of $\mathrm{H}^{+} / \mathrm{H}_{2}$.

In photoelectrocatalysis, both reactions are separated by applying an electrical bias (Fig. 20). The catalyst is used as photoelectrode, where only one of the redox reactions occurs. An important aspect for efficient photo(electro-)catalysis is the separation of electron and hole to ensure that both carriers can diffuse to the active surface sites for the redox reactions to occur. High (crystal) quality of the absorber material is advantageous, as defects act as carrier traps, increasing the probability of recombination. Overall, there are many reports on mesoporous semiconducting oxides for photocatalytic applications, including $\mathrm{TiO}_{2},{ }^{20,238-240} \mathrm{Ta}_{2} \mathrm{O}_{5},{ }^{241} \mathrm{LiFe}_{5} \mathrm{O}_{8},{ }^{242} \mathrm{ZnFe}_{2} \mathrm{O}_{4},{ }^{243-245}$ and $\mathrm{Rh}_{2} \mathrm{O}_{3} \cdot{ }^{246}$

Given that the water-splitting reaction takes place at the surface of the photocatalytic material, it is reasonable to assume that a high specific surface area leads to superior activity. Cherevan et al. analyzed around 200 publications regarding the photocatalytic activity of mesoporous semiconductors, aiming at correlating improved performance with surface area. ${ }^{247}$ They found that increased specific surface area is not the only reason and may even impede any performance improvements, as a high surface area may also increase the probability of carrier recombination. For example, for $\mathrm{Ta}_{2} \mathrm{O}_{5}$, an increase of the specific surface area by a factor of approx. 100 (mesoporous $v s$. nonporous material) only resulted in a relatively small activity rise by a factor of 1.5. ${ }^{248}$ Instead, the crystallinity, the pore size, the pore connectivity and the wall thickness can significantly affect the performance of the material.

Kirchberg et al. compared the photocurrent density of mesoporous $\mathrm{ZnFe}_{2} \mathrm{O}_{4}$ photoanodes prepared using two different polymer templates and calcined at various temperatures. In fact, they observed that differences in pore morphology only have a minor influence on the photocurrent. Samples of high crystallinity showed better performance due to the relatively lower concentration of defects acting as recombination centers for the electron-hole pairs. ${ }^{243}$ Increased photocatalytic activity because of improved crystallinity has also been reported for mesoporous $\mathrm{Nb}_{2} \mathrm{O}_{5}, \mathrm{Mn}_{2} \mathrm{O}_{3}$ and $\mathrm{NaTaO}_{3} .{ }^{249-251}$

Tüysüz et al. compared mesoporous nanocrystalline $\mathrm{NaTaO}_{3}$ and amorphous $\mathrm{NaTaO}_{x}$ photoanodes and observed a decrease in photocatalytic activity for the crystalline material. ${ }^{252}$ Although the crystallinity should reduce the probability of carrier recombination, crystallization of the amorphous matrix resulted in an increase in particle size and a decrease in specific surface area. As discussed by the authors, smaller particles are considered beneficial to the photocatalytic activity. The reason is that the space-charge regions of opposite surfaces overlap, resulting in complete depletion of the particle and negligible band bending at the surface (flat-band condition), ${ }^{176,177}$ as mentioned previously. Both photogenerated charge carriers can then easily diffuse to the active surface sites, leading to improved photocatalytic activity, as schematically shown in Fig. 21. For larger particles/crystallites, increasing

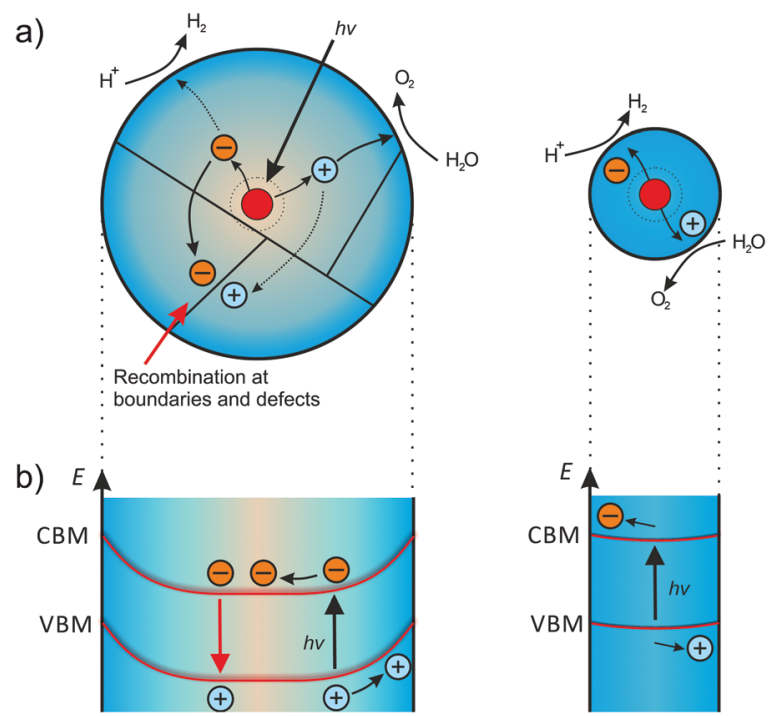

Fig. 21 Effect of particle size on the band bending and photocatalytic activity. (a) Generated carriers show high probability to recombine at boundaries or defects in larger particles. In smaller particles, the carriers can readily diffuse to the catalytically active surface sites. Adapted from ref. 231 with permission. (b) The corresponding band structure. In larger particles, the space-charge region separates the generated carriers, while smaller particles exhibit negligible band bending. Adapted from ref. 176 with permission. 
band bending impedes the diffusion of one kind of charge carrier to the surface, resulting in higher recombination rates in the bulk, and therefore in lower efficiency.

The opposite holds true when the mesoporous material is used for photoelectrocatalytic applications, where the two redox reactions occur at different electrodes. In this case, the band bending in larger crystallites promotes charge separation, thus preventing undesirable recombination. For example, Hartmann et al. investigated the photoelectrocatalytic activity of mesoporous $\mathrm{TiO}_{2}$ prepared from preformed nanoparticles and a classical sol-gel route. ${ }^{20}$ They observed higher photocurrents and improved quantum efficiency for the sol-gel-derived thin films with thicker pore walls and larger crystallites. The results were explained, in part, by a reduced probability of electrons to react at the surface (Fig. 22). This can be directly related to the existing band bending, preventing the diffusion of electrons to the surface. Furthermore, the thicker wall structure gave rise to better connectivity between individual crystallites, allowing for more efficient transport of electrons in the pore-solid architecture and contributing to the higher efficiency. The positive effect that a 3-dimensional pore structure has on the photocatalytic performance (due to improved transport of electronic charge carriers) has also been discussed by Hossain et al. ${ }^{253}$ and Zhou et al..$^{254}$

As in case of battery applications, the pore connectivity and pore size are critical parameters affecting the photocatalytic activity, as they determine the transport of reactants and products. For example, Weller et al. investigated the influence of pore size of mesoporous $\mathrm{CsTaWO}_{6}$ (with Rh as co-catalyst) on
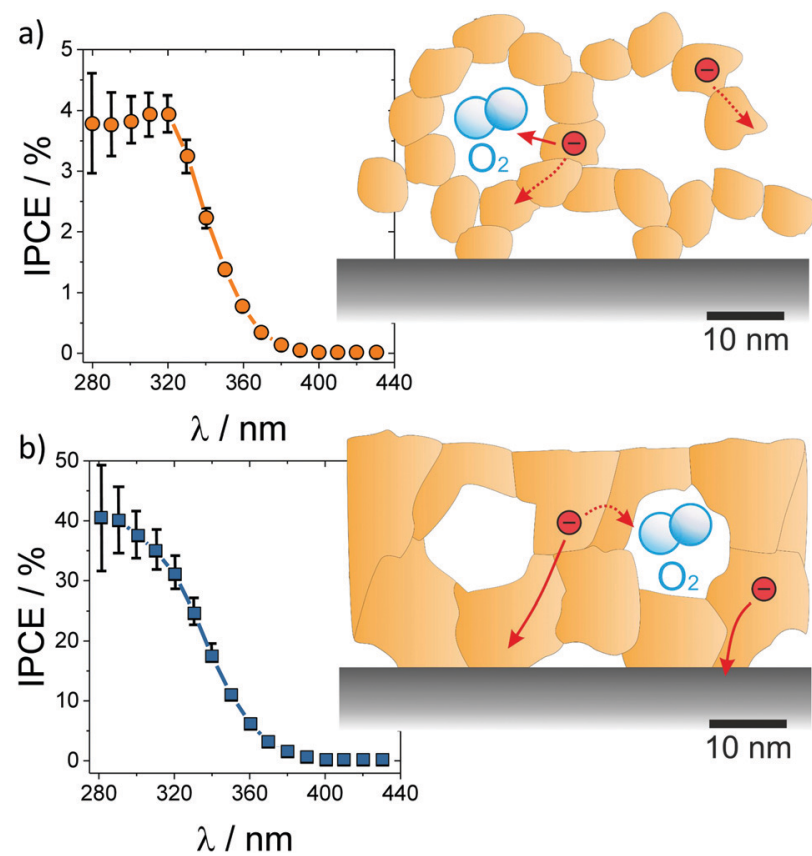

Fig. 22 Incident photon-to-current efficiency for water photoelectrocatalysis over (a) nanoparticle-derived and (b) sol-gel mesoporous $\mathrm{TiO}_{2}$ thin films. The nanoparticles in the wall structure result in low electronic conductivity and high recombination rate, while the sol-gel films with thicker and continuous pore walls reveal high photocurrents with a relatively lower recombination rate. Adapted from ref. 20 with permission.

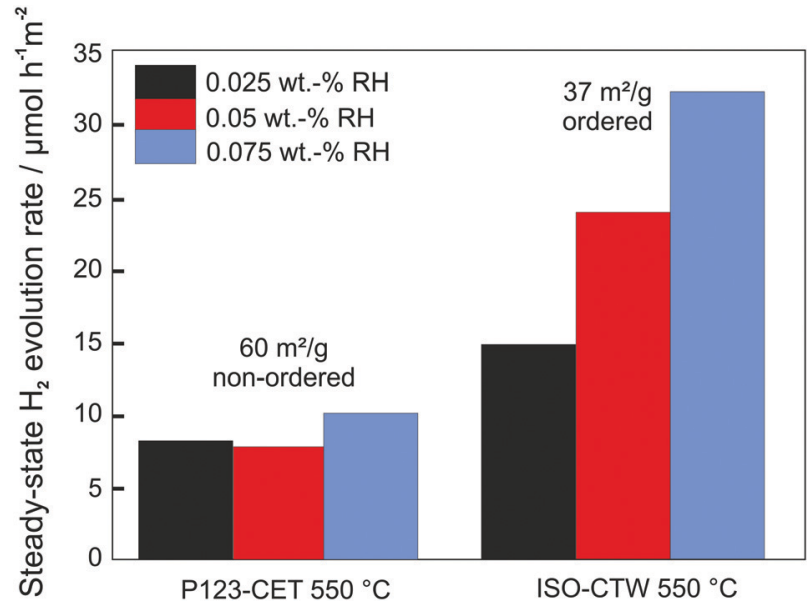

Fig. 23 Comparison of steady-state $\mathrm{H}_{2}$ evolution rates for disordered and ordered mesoporous $\mathrm{CsTaWO}_{6}$ with different amounts of Rh co-catalyst. Adapted from ref. 256 with permission.

the photocatalytic performance for $\mathrm{H}_{2}$ evolution. ${ }^{255}$ An optimized synthesis route allowed varying the pore size and mesoporous morphology without affecting the crystallinity of the material. Analysis of the photocatalytic activity revealed that the $\mathrm{H}_{2}$ evolution rate strongly depends on the pore size and the pore size distribution. This result was explained by transport limitations, as the water/methanol mixture used as electrolyte was partly confined in the small pores due to capillary forces, blocking the release of gas bubbles. ${ }^{256}$ Furthermore, comparison between samples with (large-pore) ordered and disordered mesoporous structures revealed higher $\mathrm{H}_{2}$ evolution rates for the former material, despite having a lower specific surface area (Fig. 23). The increase in activity was rationalized by better accessibility of the bulk material and improved transport pathways in case of the regular pore structure. Similar results have been reported by Fang et al., for example, who were capable of achieving efficient mass transport by introducing additional macropores. ${ }^{240}$

Another interesting aspect is that the regular arrangement of crystallites apparently affects the optical properties. For example, Hossain et al. ${ }^{253}$ found that ordered mesoporous anatase $\mathrm{TiO}_{2}$ with $5 \mathrm{~nm}$ thick walls exhibits a smaller band gap than individual $25 \mathrm{~nm}$ particles. The decrease in band-gap energy by about $0.2 \mathrm{eV}$ was ascribed to the interconnectivity of nanoparticles, increasing their effective size. ${ }^{253}$ Hufnagel et al. also observed a significant improvement in light-absorption properties (light-harvesting efficiency) for nanoscale $\mathrm{ZnFe}_{2} \mathrm{O}_{4}$ grown on macroporous antimony-doped tin oxide films compared to nonstructured thin films. ${ }^{244}$ This result was attributed to the presence of extended light paths caused by multiple light reflection and scattering in the porous electrode, as also reported by Fang et al. for hierarchically structured $\mathrm{TiO}_{2}$ microspheres. ${ }^{240}$

Taken together, the results indicate that a favorable structure for catalytic applications depends on the interplay between surface area, crystallinity, particle size (often determined by the wall thickness), pore size and pore size distribution. However, the individual parameters can significantly differ among different materials, making it necessary to vary them independently. 
For mesoporous oxides, unfortunately, this is only feasible to some degree, as e.g., high crystallinity usually requires high-temperature treatment, which in turn results in grain growth and coarsening, and therefore in lowering of the active surface area.

\subsection{Mesoporous metal oxides for gas sensors}

Most gas sensors rely on the interaction of a specific gas with the surface of the sensing material. There are different kinds of sensing principles, all of which take advantage of changes in the materials properties under varying atmosphere. In capacitive gas sensors, the change of permittivity is measured, while optical gas sensors usually detect changes in photoluminescence, reflection or optical absorption. ${ }^{119}$

Because oxides are often used as resistive sensors, we only focus on this type in the following. The basic working principle of most resistive gas sensors is schematically shown in Fig. 24 . Gas/oxide interactions induce changes of the surface potential, e.g., due to chemisorption of gas molecules (receptor function). The change of the electronic surface structure then results in changes in conductivity, which are detected as the sensing signal (transducer function). In case of an n-type semiconductor, a)
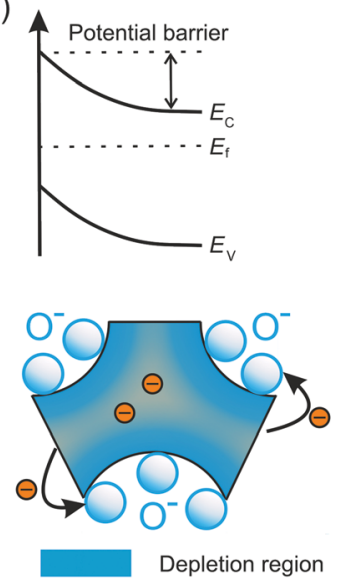

Conduction channel

c)

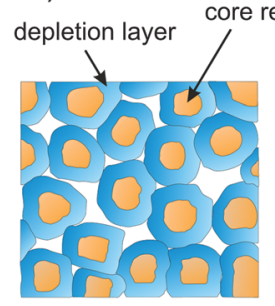

partially depleted particles unaffected

core region

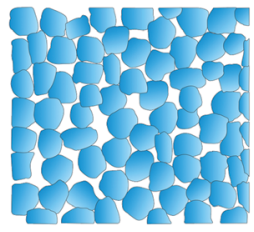

fully depleted particles
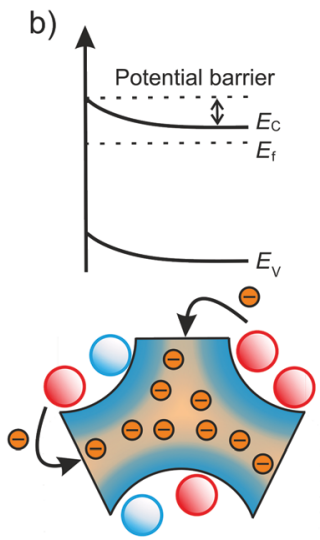

Adsorbed oxygen species Reducing gas
Fig. 24 Schematic illustration of the sensing mechanism in n-type semiconducting metal oxides. (a) The oxide is completely depleted under air exposure due to extension of the space-charge layer. (b) Upon adsorption of reducing gas molecules, the extension of the space-charge layer is reduced, thereby opening conductive channels in the sensor material. Adapted from ref. 257 with permission. (c) Electron-depletion layer in resistive sensors. Granular material with grain size larger than about twice the depletion layer (left), fully depleted granular material (middle) and fully depleted mesoporous material (right). Adapted from ref. 119 with permission. for example, the adsorption of oxygen species $\left(\mathrm{O}^{-}\right)$typically gives rise to formation of an electron-depleted space-charge layer. In the presence of a gas, such as $\mathrm{H}_{2}, \mathrm{O}^{-}$species are consumed, resulting in a decrease of the space-charge width, and therefore in a decrease of resistance. ${ }^{258-260}$ Hence, the working principle of a resistive gas sensor is directly related to the space-charge region at the interfaces (grain boundary or surface) of the oxide material. The largest sensitivity is achieved when the conductivity of the grains is completely determined by the space-charge region, that is, when the grain size is smaller than approx. twice the depletion layer. ${ }^{261-263}$

The large influence of grain size on the resistance and sensitivity of granular $\mathrm{SnO}_{2}$ sensors is depicted in Fig. 25. Both the sensitivity and response time depend strongly on the morphology and microstructure of the sensing material. To achieve high sensitivity, high surface area is desirable, while efficient and fast diffusion of gas molecules enables good response characteristics of the sensor to changes in the surrounding atmosphere. Consequently, mesoporous materials with tailorable pore and crystallite sizes are of great interest for sensor applications. ${ }^{119}$

Similar to granular materials, the crystallite size strongly affects the sensitivity of mesoporous materials. For example, Aqeel et al. probed the $\mathrm{NO}_{2}$ detection capabilities of mesoporous $\mathrm{SnO}_{2}$ calcined at 400 and $500{ }^{\circ} \mathrm{C}^{264}$ They found that the material heated at $400{ }^{\circ} \mathrm{C}$ shows significantly better sensing properties, as the crystallite size $(4-5 \mathrm{~nm})$ was smaller than twice the depletion layer. The material heated at $500{ }^{\circ} \mathrm{C}$ had larger crystallites of approx. $8 \mathrm{~nm}$ in diameter, and therefore showed worse sensing performance. Conductivity measurements confirmed the complete depletion of electrons in the smaller crystallites, which exhibited a much larger resistance. In addition, the selectivity for $\mathrm{NO}_{2}$ was much improved in case of the smaller crystallites. $\mathrm{Xu}$ et al. obtained similar findings for $\mathrm{SnO}_{2} \cdot{ }^{262,263}$ They noticed an increase in sensitivity and resistance with decreasing grain size (Fig. 25).

Waitz et al. examined the methane sensing properties of mesoporous $\operatorname{In}_{2} \mathrm{O}_{3}$ as function of the pore size and wall thickness. ${ }^{265}$ The sensitivity scaled linearly with the specific surface area. The authors also found that especially the wall a)

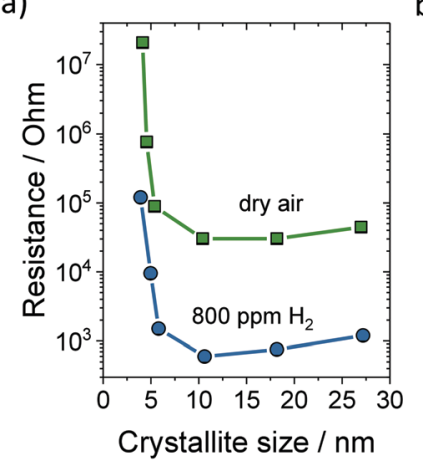

b)

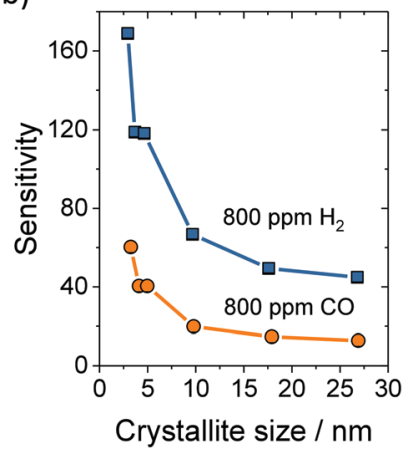

Fig. 25 (a) Electrical resistance at $300{ }^{\circ} \mathrm{C}$ in dry air or $800 \mathrm{ppm} \mathrm{H}_{2}$ versus the crystallite size of $\mathrm{SnO}_{2}$. (b) Sensitivity to $800 \mathrm{ppm} \mathrm{H}$ or $\mathrm{CO}$ versus the crystallite size of $\mathrm{SnO}_{2}$. Adapted from ref. 263 with permission. 
thickness has a strong effect on sensitivity, confirming that a fully depleted pore wall gives rise to superior performance. However, they pointed out that the structural parameters are coupled to one another, and thus cannot be varied independently, making it difficult to distinguish between the impact of each parameter on sensitivity.

Ghom et al. tested mesoporous ceria-zirconia solid solutions as oxygen sensors at $600{ }^{\circ} \mathrm{C}^{266}$ In $\mathrm{Ce}_{x} \mathrm{Zr}_{1-x} \mathrm{O}_{2-\delta}$, the change in resistance is not caused by changes of the surface space-charge layer due to adsorbed oxygen species, but instead by the significant increase in conductivity because of the release of oxygen under reducing conditions, as described above. As discussed by the authors, the fast response time of such mesoporous sensors is directly related to the oxygen-storage capacity of the material. ${ }^{209,219}$ Both the regular arrangement of pores and the pore size not only affect the sensitivity but are also responsible for fast diffusion of gas through the bulk of the material, the latter of which determines the sensor response time. ${ }^{267}$

$\mathrm{Li}$ et al. investigated ordered mesoporous $\mathrm{WO}_{3}$ for $\mathrm{H}_{2} \mathrm{~S}$ sensing and observed a fast response of $2 \mathrm{~s}$, with a recovery time of approx. $38 \mathrm{~s}$, which they attributed to the unique (continuous) pore-solid architecture and the resulting fast gas diffusion. ${ }^{269}$ The similar response time (1-3 s) of mesoporous $\alpha-\mathrm{Fe}_{2} \mathrm{O}_{3}$ for ethanol sensing was also ascribed to the high diffusivity through the pore network. ${ }^{157}$ Li et al. synthesized mesoporous-macroporous $\mathrm{SnO}_{2}{ }^{268}$ Compared with conventional granular $\mathrm{SnO}_{2}$ sensors, the hierarchical pore structure led to significant improvements in response and recovery times, as shown in Fig. 26, which was attributed to facilitated gas diffusion in the macropores. ${ }^{268}$

While the sensitivity and response times are determined by structural properties, the selectivity of a sensor depends strongly on the material type and its surface properties. To control or even tailor the selectivity for various gases, the sensing material can be loaded with catalytically active noble-metal nanoparticles, such as Au, Pd or Pt. ${ }^{260,270,271}$ As shown in Fig. 27, electrons move from the active oxide to the metal nanoparticles due to different work functions, leading to the formation of a Schottky barrier at the interface, and therefore to an increased

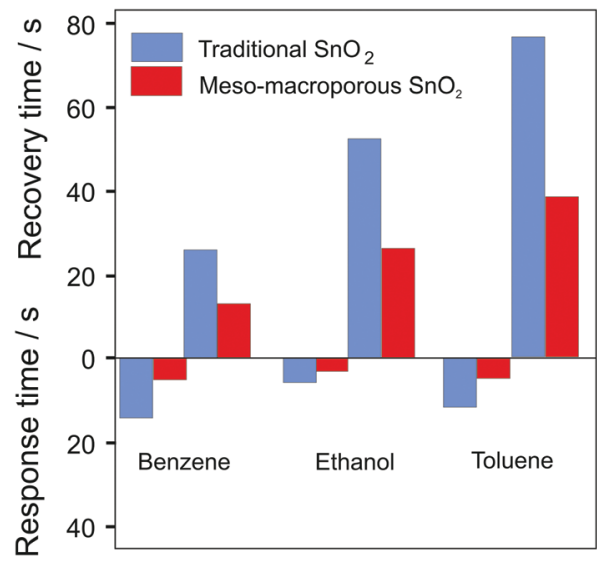

Fig. 26 Comparison of recovery and response times to $100 \mathrm{ppm}$ benzene, ethanol or toluene for "traditional" $\mathrm{SnO}_{2}$ and mesoporous-macroporous $\mathrm{SnO}_{2}$. Adapted from ref. 268 with permission. a) Electronic sensitization

b) Chemical sensitization
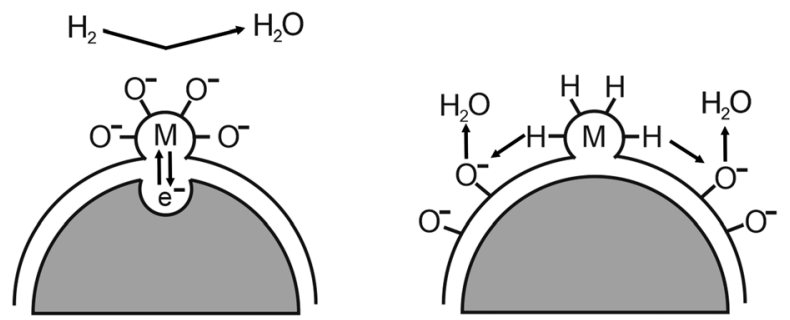

Fig. 27 Schematic illustration of (a) electronic and (b) chemical sensitization by metal or metal-oxide nanoparticles. Adapted from ref. 259 with permission.

electron depletion (electronic sensitization). However, the metal nanoparticles on the surface not only affect the adsorption and dissociation reactions by activating the gas molecules (chemical sensitization) $)^{257,259}$ but also facilitate oxygen-vacancy formation. $^{232,233}$

Shimizu et al. studied the gas sensing properties of porous thick films of $\mathrm{SnO}_{2}$ loaded with $1 \mathrm{wt} \%$ Pt or Pd. ${ }^{260,270}$ While the sensitivity to $\mathrm{H}_{2}$ and $\mathrm{CH}_{4}$ at the surface was improved in the presence of noble metals, it deteriorated in the interior. This result was explained by reduced permeation into the bulk due to increased surface reactivity, emphasizing the necessity of optimizing the gas diffusion pathways.

Ma et al. reported on a positive effect of partially oxidized Pt nanoparticles on the sensitivity and selectivity of mesoporous $\mathrm{WO}_{3}$ for CO sensing. ${ }^{272}$ The improvements were attributed to the sensitizing effect of nanoparticles on the $\mathrm{WO}_{3}$ framework. Using X-ray photoelectron spectroscopy (XPS), they found $\mathrm{W}^{5+}$ states because of the formation of oxygen vacancies (note that they increase the adsorption of oxygen species at the surface). Furthermore, the good sensitivity was justified by changes in the depletion region at the $\mathrm{Pt} / \mathrm{WO}_{3}$ interface with varying atmosphere. After exposure to air, PtO nanoparticles were detected, leading to the formation of a depletion layer at the interface due to their p-type character. The PtO nanoparticles were reduced back to $\mathrm{Pt}(0)$ upon $\mathrm{CO}$ exposure, resulting in a vanishing depletion layer and pronounced changes in resistance with varying atmosphere. A positive impact of oxygen vacancies on the $\mathrm{NO}_{2}$ sensing properties has also been reported for mesoporous $\mathrm{WO}_{3}$ nanofibers ${ }^{273}$ and $\mathrm{CeO}_{2}$ /graphene heterostructures. ${ }^{274}$

\section{Surface modification}

Although porous architectures are, without doubt, beneficial to various applications, there are certain constraints in using mesostructured powder and thin film materials. First, they tend to suffer from thermal stability issues. Especially for catalytic applications, elevated temperatures (or high relative humidity) are often required. However, such experimental conditions may result in changes of the pore structure due to phase transitions and/or growth of crystallites (sintering effects) or even complete collapse of the pore network. Second, while some variation in pore size (and wall thickness, pore symmetry etc.) can be achieved, 
it is mainly determined by the template used. Nevertheless, small changes in pore size can significantly affect the performance of mesoporous materials, as discussed above. Hence, tailoring of structural features on the nanometer level and precise interfacial engineering are desirable.

It has been shown that the properties of mesoporous materials can be altered by coating the surface using atomic layer deposition (ALD). ALD is a variant of the chemical vapor deposition (CVD) technique and is receiving increasing attention in recent years. $^{275-278}$ The reason is that ALD is the only method that is suited to produce uniform and conformal coatings on complex surfaces. This is achieved by sequential pulsing of gaseous reactants with intermediate purging steps. The pulses represent self-limiting gas-solid surface reactions, leading to controlled film growth [2-dimensional layer-by-layer (Frank-van der Merwe) growth] and excellent step coverage, unlike other deposition techniques.

The deposition of thin coatings using ALD finds lots of applications, among others, in protection and functionalization of surfaces or stabilization of porous materials. ${ }^{279}$ For instance, in the battery field, ALD is typically used to modify electrode surfaces. ${ }^{280-284}$ The coating acts as an artificial interphase between the electrode and the electrolyte to suppress adverse side reactions, which may result in gas evolution and/or formation of an ion-transport-blocking layer (anode/cathode solid-electrolyte interface). However, ALD also lends itself to the preparation of active electrode materials. ${ }^{285,286}$

Apart from electrochemical energy-storage applications, ALD is actively used to improve the catalytic performance of materials by either depositing metal nanoparticles onto their top surface 287,288 or (partial) overcoating them with an oxide layer. $^{278,289-293}$ The growth of single nanoparticles on carbon or oxide surfaces is usually achieved at comparably high deposition temperatures, where the precursor tends to agglomerate depending on the presence of surface defects and the atmospheric conditions instead of forming a conformal coating during the initial ALD cycles. ${ }^{294-296}$ In case of partial overcoating, one takes advantage of differences in surface chemistry of the solid (area-selective deposition, also referred to as AS-ALD). ${ }^{292,297-300}$

In the following, we focus on some selected examples, where ALD has been used to produce a uniform oxide coating in order to modify the structural and/or electrical properties of mesoporous oxides.

Mesoporous oxides are metastable, that is, accelerated grain growth occurs at elevated temperatures, leading to collapse of the pore structure. The deposition of a thin coating using ALD may help to enhance the thermal stability of mesoporous materials. For example, Kraffert et al. synthesized mesoporous ferrihydrite, ${ }^{301}$ showing a phase transition to hematite at $400{ }^{\circ} \mathrm{C}$. By depositing silica onto the pore walls of the mesostructured thin films using a single ALD cycle, the stability of the ferrihydrite phase could be increased to $600{ }^{\circ} \mathrm{C}$. Similar results were achieved for alumina-coated samples. In addition, the onset temperature for sintering, and therefore the thermal stability of the mesoporous thin films, was found to be significantly increased by ALD coating (up to $800{ }^{\circ} \mathrm{C}$ for silica). Differences in the stabilizing effect were attributed to different interaction strengths of the coating materials with the mesoporous substrate. Significant improvement in thermal stability of mesoporous $\mathrm{Rh}_{2} \mathrm{O}_{3}$ thin films by ALD coating (by $>300{ }^{\circ} \mathrm{C}$ compared to uncoated material) has also been observed by Dubraja et al. ${ }^{246}$ Pagán-Torres et al. reversed the strategy to stabilize mesoporous materials for applications under harsh conditions. They deposited catalytically active niobia onto the pore walls of mesoporous silica. ${ }^{302}$ The hybrid material revealed improved hydrothermal stability, with catalytic activity superior to that of commercial niobia. ${ }^{303}$

Optimizing the pore size to achieve a high active surface area while providing efficient mass transport through the material and/or efficient charge-transport pathways in the walls is crucial for many applications. Unfortunately, arbitrary variation of pore size on the nanometer level is experimentally not possible. However, ALD can be used to reduce the pore size of pre-synthesized materials in a systematic fashion. ${ }^{304}$

Dendooven et al. investigated the decrease in pore size in mesoporous $\mathrm{TiO}_{2}$ thin films with ink-bottle shaped pores upon deposition of $\mathrm{HfO}_{2}$ using ALD. Achieving a conformal coating in such films is challenging, as there are only small channels within the walls that connect the mesopores and may lead to pore clogging during deposition. Using X-ray fluorescence (XRF) measurements, the authors confirmed that the inner surfaces are uniformly coated until the pore necks are closed, preventing further diffusion of molecular precursor into the architecture, as schematically shown in Fig. 28. Additional ALD cycles then only result in growth of a top (sealing) layer. ${ }^{304,305}$ Comparable results were obtained by Cop et al., who investigated $\mathrm{TiO}_{2}$ ALD coating of mesoporous $\mathrm{Ce}_{x} \mathrm{Zr}_{1-x} \mathrm{O}_{2-\delta}$ thin films. ${ }^{306}$

a)

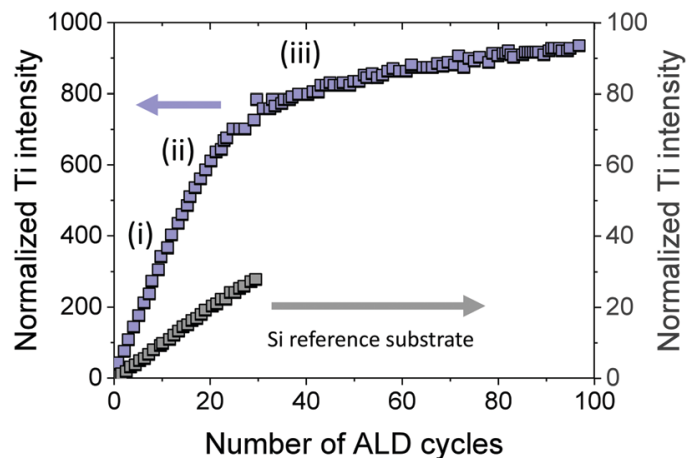

b) (i)

(ii)

(iii)

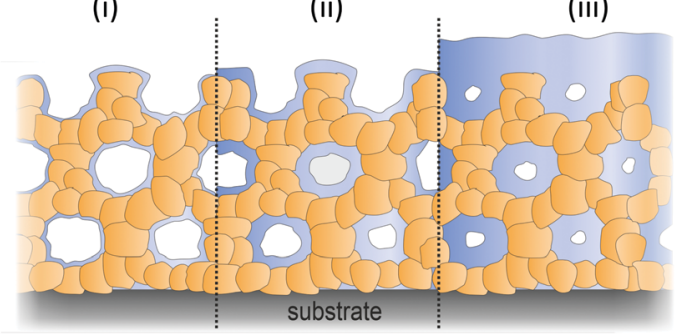

Fig. 28 (a) In situ XRF monitoring of filling of mesoporous thin films with an initial pore size of $4 \mathrm{~nm}$ during $\mathrm{ALD}$ of $\mathrm{TiO}_{2}$. After pore filling, the growth rate decreases and $\mathrm{TiO}_{2}$ only grows as a top layer on the films. (b) Schematic illustration of the pore filling process. Adapted from ref. 304 with permission. 
Dendooven et al. also reported on the implementation of ellipsometric porosimetry onto an ALD reactor, allowing to determine the pore size, the film thickness and the mechanical properties in situ during ALD. ${ }^{307}$ In another work, the authors monitored the pore shrinkage by means of in situ GISAXS, also confirming uniform and conformal coating of the inner surfaces. ${ }^{308}$ Note that for sub-nm control of the coating thickness, the process parameters must be tailored. ${ }^{309}$ Too long exposure and/or insufficient purging result in precursor condensation (at the bottom of the pores) and pore plugging, whereas insufficient doses prevent full coverage of the inner surfaces. Especially for materials with a complex porosity, precursor diffusion limitations can lead to anisotropic ALD profiles, as reported for example by Pulinthanathu Sree et al. ${ }^{310}$

Spatial control of deposition has been achieved using plasma-assisted ALD. Here, ALD precursors are employed that need to be activated through plasma irradiation. As shown by Jiang et al., this method allows sealing the pores of mesoporous materials at the immediate surface, as the plasma cannot penetrate into the inner structure. ${ }^{311}$

These and other examples demonstrate that conformal surface coating of mesoporous materials can be achieved using ALD. ${ }^{313-316}$ However, in order to tailor the surface properties to a certain application, it is necessary to control the crystallinity of the deposited material (note that the lattice structure determines the electrical or catalytic properties, among others). Mitchell et al. characterized ALD-derived $\mathrm{TiO}_{2}$ thin films on silicon substrates. ${ }^{317}$ They found that native-oxide-free silicon promotes the growth of crystalline $\mathrm{TiO}_{2}$ islands. In contrast, an initially amorphous $\mathrm{TiO}_{2}$ film is formed on silicon with an amorphous interfacial $\mathrm{SiO}_{x}$ layer. Nevertheless, after exceeding a critical thickness, the amorphous $\mathrm{TiO}_{2}$ crystallizes. Zscherp et al. also examined the nanostructure of an ALD oxide coating, namely, 9-20 $\mathrm{nm}$ ceria deposited onto porous YSZ thin films. ${ }^{312}$ TEM investigations revealed epitaxial growth of ceria with a columnar structure and excellent conformality (Fig. 29). An amorphous-to-crystalline phase transition with increasing layer thickness has also been reported by Celik et al. ${ }^{129}$ They coated porous YSZ thin films by ALD of $\mathrm{TiO}_{2}$. While the deposition of $6 \mathrm{~nm} \mathrm{TiO}_{2}$ resulted in the formation of amorphous material, a crystalline coating (anatase $\mathrm{TiO}_{2}$ ) was found for a thickness of

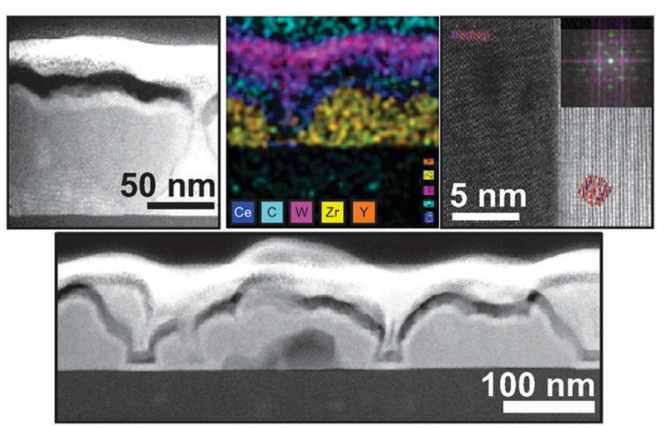

Fig. 29 TEM images and mapping results showing the epitaxial growth of ALD-derived ceria on porous YSZ thin films. Reprinted from ref. 312 with permission.
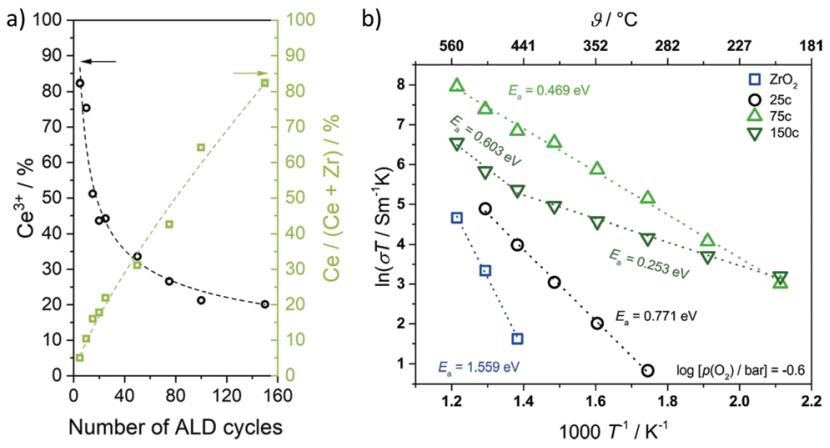

Fig. 30 (a) $\mathrm{Ce}^{3+}$ content of ceria deposited onto mesoporous $\mathrm{ZrO}_{2}$ thin films as function of the ALD cycle number. The $\mathrm{Ce}^{3+}$ content decreases with increasing coating thickness. (b) Temperature-dependence of total conductivity for mesoporous $\mathrm{ZrO}_{2}$ and $\mathrm{CeO}_{2}-\mathrm{ZrO}_{2}$ composite thin films (25, 75 and 150 ALD cycles). Adapted from ref. 318 with permission.

approx. $18 \mathrm{~nm}$ using the same deposition conditions $\left(150{ }^{\circ} \mathrm{C}\right.$ substrate temperature). Furthermore, the authors studied the influence of crystallinity on the surface protonic conductivity. The amorphous $\mathrm{TiO}_{2}$ coating led to a lower protonic conductivity compared with bare YSZ thin films. However, it increased again for the sample with the crystalline surface shell (accompanied by a decrease in proton mobility at high relative humidity, as the reduced pore size resulted in complete filling with water).

Cop et al. further probed the electrical properties of mesoporous $\mathrm{ZrO}_{2}$ thin films coated with ceria using different numbers of ALD cycles. ${ }^{318}$ Characterization via ellipsometry confirmed the homogeneity of coating in the pores up to 100 ALD cycles, after which pore plugging occurred. XPS measurements revealed a large $\mathrm{Ce}^{3+}$ fraction in the coating because of the space-charge layer at the surface, which decreased with increasing thickness, as shown in Fig. 30. In addition, the total conductivity of the composite thin films was found to be strongly affected by the coating and its thickness due to the non-stoichiometry of the ceria layer. High $\mathrm{Ce}^{3+}$ concentration resulted in dominant electronic conductivity because of small polaron hopping of electrons between the $\mathrm{Ce}^{3+}$ and $\mathrm{Ce}^{4+}$ ions.

Collectively, these studies demonstrate the profound effect that the coating thickness has on the structural and electrical properties. Because the thickness can be controlled precisely, post ALD treatment allows for rational materials design.

\section{Conclusions}

Herein, developments in the field of ordered mesoporous metal oxides for electrochemical applications are reviewed. Advantages and disadvantages arising from the unique architecture, consisting of open $\leq 50 \mathrm{~nm}$ pores surrounded by interconnected crystallites, are discussed. In the last decades, much research has been carried out into assessing the potential of mesoporous metal oxides for energy applications, ranging from batteries and catalysis to sensors. The presence of an ordered 3-dimensional pore network is advantageous, as it offers a large number of active surface sites and facilitates the accessibility of the material and its internal structure to the surrounding medium. For instance, high-surface-area metal 
oxide electrodes may increase the charge-storage capacity of batteries due to pseudocapacitive redox reactions, while the porosity is capable of somewhat mediating the transport of reaction species in catalysis. It also endows the materials with a certain degree of mechanical flexibility, which helps accommodate volume changes during electrochemical cycling, among others. However, the favorable properties cannot only be attributed to the increased surface area and uniform pore size distribution, but also to the interconnectivity of crystallites in the wall structure, giving rise to short diffusion pathways for electron and ion transport.

An important aspect affecting the properties of mesoporous metal oxides is the existence of a space-charge region at the surface, which has been shown to exert a profound effect on the charge transport. Resistive oxide sensors are based on this working principle. Considering the surface space-charge region is also critical when evaluating the performance of mesoporous battery electrodes, as it directly affects the interfacial charge storage. In case of catalytic applications, the space-charge potential facilitates the separation of photogenerated charge carriers. This is beneficial for photoelectrocatalytic devices, but counterproductive in photocatalysis, where both redox reactions occur at the surface of the catalyst. However, the structural features of mesoporous metal oxides come at a price. For instance, the high surface area may lead to severe corrosion and adverse side reactions with liquid electrolytes or reactive gases. Furthermore, the nanoscale porosity negatively affects the thermal stability of the material, which in turn limits the temperature range for operation, especially in catalysis. In general, there is a complex interplay between the structural parameters, which makes it difficult to vary them independently (note that this is one of the major drawbacks of mesoporous materials).

Finally, this review article also summarizes recent work on post-surface modification of mesoporous metal oxides using atomic layer deposition (ALD). Because ALD allows conformal coating of complex substrates, it represents a promising technique to tackle the above-mentioned problems. Recent results confirm that surface coating helps to improve the thermal and structural stability. The thickness of the deposited material can also be controlled on the atomic level, since the ALD process relies on self-limiting surface reactions. Hence, the pore size can be adjusted without altering other structural parameters. In addition, the surface potential/chemistry can be manipulated via interfacial engineering, thus directly affecting the space-charge region and offering the possibility to tailor the electrical and electrochemical properties of mesoporous metal oxides for future device applications.

\section{Conflicts of interest}

There are no conflicts to declare.

\section{Acknowledgements}

Financial support by the German Research Foundation (to T. B., grant no. BR 3499/5-1 and to M. T. E., grant no. EL 863/3-1) is gratefully acknowledged. M. T. E. is grateful to the German Federal Ministry of Education and Research (BMBF) for funding the NanoMatFutur project NiKo (03XP0093).

\section{References}

1 T. Yanagisawa, T. Shimizu, K. Kuroda and C. Kato, The preparation of alkyltriinethylaininonium-kaneinite complexes and their conversion to microporous materials, Bull. Chem. Soc. Jpn., 1990, 63, 988-992.

2 C. T. Kresge, M. E. Leonowicz, W. J. Roth, J. C. Vartuli and J. S. Beck, Ordered mesoporous molecular sieves synthesized by a liquid-crystal template mechanism, Nature, 1992, 359, 710-712.

3 J. S. Beck, J. C. Vartuli, W. J. Roth, M. E. Leonowicz, C. T. Kresge, K. D. Schmitt, C. T. W. Chu, D. H. Olson, E. W. Sheppard, S. B. McCullen, J. B. Higgins and J. L. Schlenker, A new family of mesoporous molecular sieves prepared with liquid crystal templates, J. Am. Chem. Soc., 1992, 114, 10834-10843.

4 M. Ogawa, Formation of novel oriented transparent films of layered silica-surfactant nanocomposites, J. Am. Chem. Soc., 1994, 116, 7941-7942.

5 C. J. Brinker, Y. Lu, A. Sellinger and H. Fan, Evaporationinduced self-assembly: Nanostructures made easy, $A d v$. Mater., 1999, 11, 579-585.

6 Y. Lu, R. Ganguli, C. A. Drewien, M. T. Anderson, C. J. Brinker, W. Gong, Y. Guo, H. Soyez, B. Dunn, M. H. Huang and J. I. Zink, Continuous formation of supported cubic and hexagonal mesoporous films by sol-gel dip-coating, Nature, 1997, 389, 364-368.

7 P. Yang, D. Zhao, D. I. Margolese, B. F. Chmelka and G. D. Stucky, Block copolymer templating syntheses of mesoporous metal oxides with large ordering lengths and semicrystalline framework, Chem. Mater., 1999, 11, 2813-2826.

8 P. Yang, D. Zhao, D. I. Margolese, B. F. Chmelka and G. D. Stucky, Generalized syntheses of large-pore mesoporous metal oxides with semicrystalline frameworks, Nature, 1998, 396, 152-155.

9 D. Li, H. Zhou and I. Honma, Design and synthesis of selfordered mesoporous nanocomposite through controlled in-situ crystallization, Nat. Mater., 2004, 3, 65-72.

10 S. Y. Choi, M. Mamak, N. Coombs, N. Chopra and G. A. Ozin, Thermally stable two-dimensional hexagonal mesoporous nanocrystalline anatase, meso-nc-TiO ${ }_{2}$ : Bulk and crack-free thin film morphologies, Adv. Funct. Mater., 2004, 14, 335-344.

11 B. Smarsly, D. Grosso, T. Brezesinski, N. Pinna, C. Boissière, M. Antonietti and C. Sanchez, Highly crystalline cubic mesoporous $\mathrm{TiO}_{2}$ with 10-nm pore diameter made with a new block copolymer template, Chem. Mater., 2004, 16, 2948-2952.

12 D. Grosso, C. Boissiere, B. Smarsly, T. Brezesinski, N. Pinna, P. A. Albouy, H. Amenitsch, M. Antonietti and C. Sanchez, Periodically ordered nanoscale islands and mesoporous films composed of nanocrystalline multimetallic oxides, Nat. Mater., 2004, 3, 787-792. 
13 C. Sanchez, C. Boissière, D. Grosso, C. Laberty and L. Nicole, Design, synthesis, and properties of inorganic and hybrid thin films having periodically organized nanoporosity, Chem. Mater., 2008, 20, 682-737.

14 Y. Ren, Z. Ma and P. G. Bruce, Ordered mesoporous metal oxides: Synthesis and applications, Chem. Soc. Rev., 2012, 41, 4909-4927.

15 P. Innocenzi and L. Malfatti, Mesoporous thin films: Properties and applications, Chem. Soc. Rev., 2013, 42, 4198-4216.

16 Y. Deng, J. Wei, Z. Sun and D. Zhao, Large-pore ordered mesoporous materials templated from non-Pluronic amphiphilic block copolymers, Chem. Soc. Rev., 2013, 42, 4054-4070.

17 D. Gu and F. Schüth, Synthesis of non-siliceous mesoporous oxides, Chem. Soc. Rev., 2014, 43, 313-344.

18 J. Ba, J. Polleux, M. Antonietti and M. Niederberger, Nonaqueous synthesis of tin oxide nanocrystals and their assembly into ordered porous mesostructures, Adv. Mater., 2005, 17, 2509-2512.

19 T. Brezesinski, J. Wang, J. Polleux, B. Dunn and S. H. Tolbert, Templated nanocrystal-based porous $\mathrm{TiO}_{2}$ films for next-generation electrochemical capacitors, J. Am. Chem. Soc., 2009, 131, 1802-1809.

20 P. Hartmann, D.-K. Lee, B. M. Smarsly and J. Janek, Mesoporous $\mathrm{TiO}_{2}$ : Comparison of classical sol-gel and nanoparticle based photoelectrodes for the water splitting reaction, ACS Nano, 2010, 4, 3147-3154.

21 I. E. Rauda, R. Buonsanti, L. C. Saldarriaga-Lopez, K. Benjauthrit, L. T. Schelhas, M. Stefik, V. Augustyn, J. Ko, B. Dunn, U. Wiesner, D. J. Milliron and S. H. Tolbert, General method for the synthesis of hierarchical nanocrystal-based mesoporous materials, ACS Nano, 2012, 6, 6386-6399.

22 D. J. Milliron, R. Buonsanti, A. Llordes and B. A. Helms, Constructing functional mesostructured materials from colloidal nanocrystal building blocks, Acc. Chem. Res., 2014, 47, 236-246.

23 A. M. Seayad and D. M. Antonelli, Recent advances in hydrogen storage in metal-containing inorganic nanostructures and related materials, Adv. Mater., 2004, 16, 765-777.

24 D. R. Rolison, Catalytic nanoarchitectures - the importance of nothing and the unimportance of periodicity, Science, 2003, 299, 1698-1701.

25 M. Tiemann, Porous metal oxides as gas sensors, Chem. Eur. J., 2007, 13, 8376-8388.

26 M. Grätzel, Mesoscopic solar cells for electricity and hydrogen production from sunlight, Chem. Lett., 2005, 34, 8-13.

27 J. W. Long, B. Dunn, D. R. Rolison and H. S. White, Threedimensional battery architectures, Chem. Rev., 2004, 104, 4463-4492.

28 B. Smarsly and M. Antonietti, Block copolymer assemblies as templates for the generation of mesoporous inorganic materials and crystalline films, Eur. J. Inorg. Chem., 2006, 1111-1119.

29 S. Fujita and S. Inagaki, Self-organization of organosilica solids with molecular-scale and mesoscale periodicities, Chem. Mater., 2008, 20, 891-908.
30 S. Mann, Self-assembly and transformation of hybrid nano-objects and nanostructures under equilibrium and non-equilibrium conditions, Nat. Mater., 2009, 8, 781-792.

31 M. Rawolle, M. A. Niedermeier, G. Kaune, J. Perlich, P. Lellig, M. Memesa, Y.-J. Cheng, J. S. Gutmann and P. Müller-Buschbaum, Fabrication and characterization of nanostructured titania films with integrated function from inorganic-organic hybrid materials, Chem. Soc. Rev., 2012, 41, 5131-5142.

32 N. D. Petkovich and A. Stein, Controlling macro- and mesostructures with hierarchical porosity through combined hard and soft templating, Chem. Soc. Rev., 2013, 42, 3721-3739.

33 A. Thomas, H. Schlaad, B. Smarsly and M. Antonietti, Replication of lyotropic block copolymer mesophases into porous silica by nanocasting: Learning about finer details of polymer self-assembly, Langmuir, 2003, 19, 4455-4459.

34 M. Groenewolt, T. Brezesinski, H. Schlaad, M. Antonietti, P. W. Groh and B. Iván, Polyisobutylene-block-poly(ethylene oxide) for robust templating of highly ordered mesoporous materials, Adv. Mater., 2005, 17, 1158-1162.

35 E. Ortel, A. Fischer, L. Chuenchom, J. Polte, F. Emmerling, B. Smarsly and R. Kraehnert, New triblock copolymer templates, PEO-PB-PEO, for the synthesis of titania films with controlled mesopore size, wall thickness, and bimodal porosity, Small, 2012, 8, 298-309.

36 J. Wei, Z. Sun, W. Luo, Y. Li, A. A. Elzatahry, A. M. Al-Enizi, Y. Deng and D. Zhao, New insight into the synthesis of large-pore ordered mesoporous materials, J. Am. Chem. Soc., 2017, 139, 1706-1713.

37 C. Reitz, J. Haetge, C. Suchomski and T. Brezesinski, Facile and general synthesis of thermally stable ordered mesoporous rare-earth oxide ceramic thin films with uniform mid-size to large-size pores and strong crystalline texture, Chem. Mater., 2013, 25, 4633-4642.

38 J. Haetge, P. Hartmann, K. Brezesinski, J. Janek and T. Brezesinski, Ordered large-pore mesoporous $\mathrm{Li}_{4} \mathrm{Ti}_{5} \mathrm{O}_{12}$ spinel thin film electrodes with nanocrystalline framework for high rate rechargeable lithium batteries: Relationships among charge storage, electrical conductivity, and nanoscale structure, Chem. Mater., 2011, 23, 4384-4393.

39 C. Reitz, C. Suchomski, C. Weidmann and T. Brezesinski, Block copolymer-templated $\mathrm{BiFeO}_{3}$ nanoarchitectures composed of phase-pure crystallites intermingled with a continuous mesoporosity: Effective visible-light photocatalysts?, Nano Res., 2011, 4, 414-424.

40 C. Weidmann, K. Brezesinski, C. Suchomski, K. Tropp, N. Grosser, J. Haetge, B. M. Smarsly and T. Brezesinski, Morphology-controlled synthesis of nanocrystalline $\eta-\mathrm{Al}_{2} \mathrm{O}_{3}$ thin films, powders, microbeads, and nanofibers with tunable pore sizes from preformed oligomeric oxo-hydroxo building blocks, Chem. Mater., 2012, 24, 486-494.

41 C. Reitz, P. M. Leufke, H. Hahn and T. Brezesinski, Ordered mesoporous thin film ferroelectrics of biaxially textured lead zirconate titanate (PZT) by chemical solution deposition, Chem. Mater., 2014, 26, 2195-2202. 
42 C. Reitz, B. Smarsly and T. Brezesinski, General synthesis of ordered mesoporous rare-earth orthovanadate thin films and their use as photocatalysts and phosphors for lighting applications, ACS Appl. Nano Mater., 2019, 2, 1063-1071.

43 M. Kuemmel, D. Grosso, C. Boissière, B. Smarsly, T. Brezesinski, P. A. Albouy, H. Amenitsch and C. Sanchez, Thermally stable nanocrystalline $\gamma$-alumina layers with highly ordered 3D mesoporosity, Angew. Chem., Int. Ed., 2005, 44, 4589-4592.

44 T. Brezesinski, B. Smarsly, K.-i. Iimura, D. Grosso, C. Boissière, H. Amenitsch, M. Antonietti and C. Sanchez, Self-assembly and crystallization behavior of mesoporous, crystalline $\mathrm{HfO}_{2}$ thin films: A model system for the generation of mesostructured transition-metal oxides, Small, 2005, 1, 889-898.

45 T. Brezesinski, M. Antonietti, M. Groenewolt, N. Pinna and B. Smarsly, The generation of mesostructured crystalline $\mathrm{CeO}_{2}, \mathrm{ZrO}_{2}$ and $\mathrm{CeO}_{2}-\mathrm{ZrO}_{2}$ films using evaporation-induced self-assembly, New J. Chem., 2005, 29, 237-242.

46 T. Brezesinski, M. Groenewolt, N. Pinna, H. Amenitsch, M. Antonietti and B. Smarsly, Surfactant-mediated generation of iso-oriented dense and mesoporous crystalline metal-oxide layers, Adv. Mater., 2006, 18, 1827-1831.

47 T. Brezesinski, A. Fischer, K.-i. Iimura, C. Sanchez, D. Grosso, M. Antonietti and B. M. Smarsly, Generation of self-assembled 3D mesostructured $\mathrm{SnO}_{2}$ thin films with highly crystalline frameworks, Adv. Funct. Mater., 2006, 16, 1433-1440.

48 T. Brezesinski, M. Antonietti and B. M. Smarsly, Selfassembled metal oxide bilayer films with "single-crystalline" overlayer mesopore structure, Adv. Mater., 2007, 19, 1074-1078.

49 T. Coquil, C. Reitz, T. Brezesinski, E. J. Nemanick, S. H. Tolbert and L. Pilon, Thermal conductivity of ordered mesoporous titania films made from nanocrystalline building blocks and sol-gel reagents, J. Phys. Chem. C, 2010, 114, 12451-12458.

50 B. Niu, X. Wang, K. Wu, X. He and R. Zhang, Mesoporous titanium dioxide: Synthesis and applications in photocatalysis, energy and biology, Materials, 2018, 11, 1910.

51 W. Zhang, Y. Tian, H. He, L. Xu, W. Li and D. Zhao, Recent advances in the synthesis of hierarchically mesoporous $\mathrm{TiO}_{2}$ materials for energy and environmental applications, Natl. Sci. Rev., 2020, 7, 1702-1725.

52 A. E. H. Machado, K. A. Borges, T. A. Silva, L. M. Santos, M. F. Borges, W. A. Machado, B. P. Caixeta, S. M. Oliveira, A. G. Trovó and A. O. T. Patrocínio, in Solar Radiation Applications, 2015.

53 W. Li, Z. Wu, J. Wang, A. A. Elzatahry and D. Zhao, A perspective on mesoporous $\mathrm{TiO}_{2}$ materials, Chem. Mater., 2014, 26, 287-298.

54 D. Fattakhova-Rohlfing, M. Wark, T. Brezesinski, B. M. Smarsly and J. Rathouský, Highly organized mesoporous $\mathrm{TiO}_{2}$ films with controlled crystallinity: A Li-insertion study, Adv. Funct. Mater., 2007, 17, 123-132.

55 J. Maier, Ionic conduction in space charge regions, Prog. Solid State Chem., 1995, 23, 171-263.

56 K. L. Kliewer and J. S. Koehler, Space charge in ionic crystals. I. General approach with application to $\mathrm{NaCl}$, Phys. Rev., 1965, 140, 897-902.
57 J. Maier, Defect chemistry and conductivity effects in heterogeneous solid electrolytes, J. Electrochem. Soc., 1987, 134, 1524-1535.

$58 \mathrm{~J}$. Maier, Space charge regions in solid two-phase systems and their conduction contribution-I. Conductance enhancement in the system ionic conductor-'inert' phase and application on $\mathrm{AgC1}: \mathrm{Al}_{2} \mathrm{O}_{3}$ and $\mathrm{AgC1}: \mathrm{SiO}_{2}$, J. Phys. Chem. Solids, 1985, 46, 309-320.

59 S. Kim, J. Fleig and J. Maier, Space charge conduction: Simple analytical solutions for ionic and mixed conductors and application to nanocrystalline ceria, Phys. Chem. Chem. Phys., 2003, 5, 2268-2273.

60 G. Gregori, R. Merkle and J. Maier, Ion conduction and redistribution at grain boundaries in oxide systems, Prog. Mater. Sci., 2017, 89, 252-305.

61 M. C. Göbel, G. Gregori and J. Maier, Numerical calculations of space charge layer effects in nanocrystalline ceria. Part I: Comparison with the analytical models and derivation of improved analytical solutions, Phys. Chem. Chem. Phys., 2014, 16, 10214-10231.

62 M. C. Göbel, G. Gregori and J. Maier, Numerical calculations of space charge layer effects in nanocrystalline ceria. Part II: Detailed analysis of the space charge layer properties, Phys. Chem. Chem. Phys., 2014, 16, 10175-10186.

63 D. S. Mebane and R. A. De Souza, A generalised spacecharge theory for extended defects in oxygen-ion conducting electrolytes: From dilute to concentrated solid solutions, Energy Environ. Sci., 2015, 8, 2935-2940.

64 A. F. Zurhelle, X. Tong, A. Klein, D. S. Mebane and R. A. De Souza, A space-charge treatment of the increased concentration of reactive species at the surface of a ceria solid solution, Angew. Chem., Int. Ed., 2017, 56, 14516-14520.

65 A. R. C. Bredar, A. L. Chown, A. R. Burton and B. H. Farnum, Electrochemical impedance spectroscopy of metal oxide electrodes for energy applications, ACS Appl. Energy Mater., 2020, 3, 66-98.

66 J. T. S. Irvine, D. C. Sinclair and A. R. West, Electroceramics: Characterization by impedance spectroscopy, $A d v$. Mater., 1990, 2, 132-138.

67 J. E. Bauerle, Study of solid electrolyte polarization by a complex admittance method, J. Phys. Chem. Solids, 1969, 30, 2657-2670.

68 I. M. Hodge, M. D. Ingram and A. R. West, Impedance and modulus spectroscopy of polycrystalline solid electrolytes, J. Electroanal. Chem. Interfacial Electrochem., 1976, 74, 125-143.

69 D. D. Macdonald, Reflections on the history of electrochemical impedance spectroscopy, Electrochim. Acta, 2006, 51, 1376-1388.

70 J. R. Macdonald and W. B. Johnson, in Impedance Spectroscopy, John Wiley \& Sons, Inc., Hoboken, NJ, USA, 2018, pp. 1-20.

71 J. Fleig and J. Maier, A finite element study on the grain boundary impedance of different microstructures, J. Electrochem. Soc., 1998, 145, 2081-2089.

$72 \mathrm{H}$. L. Tuller, Ionic conduction in nanocrystalline materials, Solid State Ionics, 2000, 131, 143-157. 
$73 \mathrm{~J}$. Maier, On the conductivity of polycrystalline materials, Ber. Bunseng. Phys. Chem., 1986, 90, 26-33.

$74 \mathrm{X}$. Guo, W. Sigle and J. Maier, Blocking grain boundaries in yttria-doped and undoped ceria ceramics of high purity, J. Am. Ceram. Soc., 2003, 86, 77-87.

$75 \mathrm{X}$. Guo and R. Waser, Space charge concept for acceptordoped zirconia and ceria and experimental evidences, Solid State Ionics, 2004, 173, 63-67.

76 X. Guo and J. Maier, Grain boundary blocking effect in zirconia: A Schottky barrier analysis, J. Electrochem. Soc., 2001, 148, E121-E126.

77 I. Kosacki and H. U. Anderson, Microstructure-property relationships in nanocrystalline oxide thin films, Ionics, 2000, 6, 294-311.

78 J. Maier, Defect chemistry and ionic conductivity in thin films, Solid State Ionics, 1987, 23, 59-67.

79 O. J. Durá, M. A. López De La Torre, L. Vázquez, J. Chaboy, R. Boada, A. Rivera-Calzada, J. Santamaria and C. Leon, Ionic conductivity of nanocrystalline yttria-stabilized zirconia: Grain boundary and size effects, Phys. Rev. B: Condens. Matter Mater. Phys., 2010, 81, 7126-7133.

80 J.-S. Lee and D.-Y. Kim, Space-charge concepts on grain boundary impedance of a high-purity yttria-stabilized tetragonal zirconia polycrystal, J. Mater. Res., 2001, 16, 2739-2751.

81 M. Gödickemeier, B. Michel, A. Orliukas, P. Bohac, K. Sasaki, L. Gauckler, H. Heinrich, P. Schwander, G. Kostorz, H. Hofmann and O. Frei, Effect of intergranular glass films on the electrical conductivity of 3Y-TZP, J. Mater. Res., 1994, 9, 1228-1240.

82 S. P. S. Badwal and J. Drennan, Evaluation of conducting properties of yttria-zirconia wafers, Solid State Ionics, 1990, 40-41, 869-873.

83 J. Maier, Nanoionics: Ion transport and electrochemical storage in confined systems, Nat. Mater., 2005, 4, 805-815.

84 J. Maier, Nanoionics: Ionic charge carriers in small systems, Phys. Chem. Chem. Phys., 2009, 11, 3011-3022.

85 Y. M. Chiang, E. B. Lavik, I. Kosacki, H. L. Tuller and J. Y. Ying, Defect and transport properties of nanocrystalline $\mathrm{CeO}_{2-x}$, Appl. Phys. Lett., 1996, 69, 185-187.

86 X. Guo, I. Matei, J. Jamnik, J.-S. Lee and J. Maier, Defect chemical modeling of mesoscopic ion conduction in nanosized $\mathrm{CaF}_{2} / \mathrm{BaF}_{2}$ multilayer heterostructures, Phys. Rev. B: Condens. Matter Mater. Phys., 2007, 76, 125429.

87 Y. M. Chiang, E. B. Lavik, I. Kosacki, H. L. Tuller and J. Y. Ying, Nonstoichiometry and electrical conductivity of nanocrystalline $\mathrm{CeO}_{2-x}$, J. Electroceram., 1997, 1, 7-14.

88 A. Tschöpe, Grain size-dependent electrical conductivity of polycrystalline cerium oxide. II: Space charge model, Solid State Ionics, 2001, 139, 267-280.

89 A. Tschöpe, E. Sommer and R. Birringer, Grain sizedependent electrical conductivity of polycrystalline cerium oxide: I. Experiments, Solid State Ionics, 2001, 139, 255-265.

90 A. Tschöpe and R. Birringer, Grain size dependence of electrical conductivity in polycrystalline cerium oxide, J. Electroceram., 2001, 7, 169-177.
91 A. Tschöpe, Interface defect chemistry and effective conductivity in polycrystalline cerium oxide, J. Electroceram., 2005, 14, 5-23.

92 A. Tschöpe, J. Y. Ying and H. L. Tuller, Catalytic redox activity and electrical conductivity of nanocrystalline nonstoichiometric cerium oxide, Sens. Actuators, B, 1996, 31, 111-114.

93 J.-H. Hwang and T. O. Mason, Defect chemistry and transport properties of nanocrystalline cerium oxide, Z. Phys. Chem., 1998, 207, 21-38.

94 P. Hartmann, T. Brezesinski, J. Sann, A. Lotnyk, J.-P. Eufinger, L. Kienle and J. Janek, Defect chemistry of oxide nanomaterials with high surface area: Ordered mesoporous thin films of the oxygen storage catalyst $\mathrm{CeO}_{2}-$ $\mathrm{ZrO}_{2}$, ACS Nano, 2013, 7, 2999-3013.

95 M. Boaro, A. Trovarelli, J. H. Hwang and T. O. Mason, Electrical and oxygen storage/release properties of nanocrystalline ceria-zirconia solid solutions, Solid State Ionics, 2002, 147, 85-95.

96 J. H. Lee, S. M. Yoon, B. K. Kim, H. W. Lee and H. S. Song, Electrical conductivity and defect structure of $\mathrm{CeO}_{2}-\mathrm{ZrO}_{2}$ mixed oxide, J. Mater. Sci., 2002, 37, 1165-1171.

97 J.-P. Eufinger, M. Daniels, K. Schmale, S. Berendts, G. Ulbrich, M. Lerch, H.-D. Wiemhöfer and J. Janek, The model case of an oxygen storage catalyst - non-stoichiometry, point defects and electrical conductivity of single crystalline $\mathrm{CeO}_{2}-\mathrm{ZrO}_{2}-$ $\mathrm{Y}_{2} \mathrm{O}_{3}$ solid solutions, Phys. Chem. Chem. Phys., 2014, 16, 25583-25600.

98 H. L. Tuller and A. S. Nowick, Small polaron electron transport in reduced $\mathrm{CeO}_{2}$ single crystals, J. Phys. Chem. Solids, 1977, 38, 859-867.

99 K. Michel, J.-P. Eufinger, G. Ulbrich, M. Lerch, J. Janek and M. T. Elm, Combining two redox active rare earth elements for oxygen storage - electrical properties and defect chemistry of ceria-praseodymia single crystals, Phys. Chem. Chem. Phys., 2017, 19, 17661-17669.

100 S. Miyoshi, Y. Akao, N. Kuwata, J. Kawamura, Y. Oyama, T. Yagi and S. Yamaguchi, Low-temperature protonic conduction based on surface protonics: An example of nanostructured yttria-doped zirconia, Chem. Mater., 2014, 26, 5194-5200.

101 K. L. Duncan, Y. Wang, S. R. Bishop, F. Ebrahimi and E. D. Wachsman, The role of point defects in the physical properties of nonstoichiometric ceria, J. Appl. Phys., 2007, 101, 44906.

102 L. J. Gauckler, M. Gödickemeier and D. Schneider, Nonstoichiometry and defect chemistry of ceria solid solutions, J. Electroceram., 1997, 1, 165-172.

103 C. Tandé, D. Pérez-Coll and G. C. Mather, Surface proton conductivity of dense nanocrystalline YSZ, J. Mater. Chem., 2012, 22, 11208-11213.

104 B. Scherrer, M. V. F. Schlupp, D. Stender, J. Martynczuk, J. G. Grolig, H. Ma, P. Kocher, T. Lippert, M. Prestat and L. J. Gauckler, On proton conductivity in porous and dense yttria stabilized zirconia at low temperature, Adv. Funct. Mater., 2013, 23, 1957-1964. 
105 H. J. Avila-Paredes, J. Zhao, S. Wang, M. Pietrowski, R. A. De Souza, A. Reinholdt, Z. A. Munir, M. Martin and S. Kim, Protonic conductivity of nano-structured yttria-stabilized zirconia: Dependence on grain size, J. Mater. Chem., 2010, 20, 990-994.

106 S. Kim, U. Anselmi-Tamburini, H. J. Park, M. Martin and Z. A. Munir, Unprecedented room-temperature electrical power generation using nanoscale fluorite-structured oxide electrolytes, Adv. Mater., 2008, 20, 556-559.

107 G. Gregori, M. Shirpour and J. Maier, Proton conduction in dense and porous nanocrystalline ceria thin films, $A d v$. Funct. Mater., 2013, 23, 5861-5867.

108 M. Shirpour, G. Gregori, R. Merkle and J. Maier, On the proton conductivity in pure and gadolinium doped nanocrystalline cerium oxide, Phys. Chem. Chem. Phys., 2011, 13, 937-940.

109 E. Ruiz-Trejo and J. A. Kilner, Possible proton conduction in $\mathrm{Ce}_{0.9} \mathrm{Gd}_{0.1} \mathrm{O}_{2-\delta}$ nanoceramics, J. Appl. Electrochem., 2009, 39, 523-528.

110 H. J. Avila-Paredes, C.-T. Chen, S. Wang, R. A. De Souza, M. Martin, Z. Munir and S. Kim, Grain boundaries in dense nanocrystalline ceria ceramics: Exclusive pathways for proton conduction at room temperature, J. Mater. Chem., 2010, 20, 10110-10112.

111 H. Shen, H. Maekawa, J. Kawamura, Y. Matsumoto, T. Yamamura, Y. Kawakita, K. Shibata and M. Kawai, Effect of pore size and salt doping on the protonic conductivity of mesoporous alumina, Solid State Ionics, 2008, 179, 1133-1137.

112 R. Fan, S. Huh, R. Yan, J. Arnold and P. Yang, Gated proton transport in aligned mesoporous silica films, Nat. Mater., 2008, 7, 303-307.

113 F. Maglia, I. G. Tredici, G. Spinolo and U. AnselmiTamburini, Low temperature proton conduction in bulk nanometric $\mathrm{TiO}_{2}$ prepared by high-pressure field assisted sintering, J. Mater. Res., 2012, 27, 1975-1981.

114 G. Chiodelli, F. Maglia, U. Anselmi-Tamburini and Z. A. Munir, Characterization of low temperature protonic conductivity in bulk nanocrystalline fully stabilized zirconia, Solid State Ionics, 2009, 180, 297-301.

115 M. T. Colomer, Nanoporous anatase thin films as fast proton-conducting materials, Adv. Mater., 2006, 18, 371-374.

116 K. D. Kreuer, Proton-conducting oxides, Annu. Rev. Mater. Res., 2003, 33, 333-359.

117 K.-D. Kreuer, Proton conductivity: Materials and applications, Chem. Mater., 1996, 8, 610-641.

118 L. Almar, A. Tarancón, T. Andreu, M. Torrell, Y. Hu, G. Dezanneau and A. Morata, Mesoporous ceramic oxides as humidity sensors: A case study for gadolinium-doped ceria, Sens. Actuators, B, 2015, 216, 41-48.

119 T. Wagner, S. Haffer, C. Weinberger, D. Klaus and M. Tiemann, Mesoporous materials as gas sensors, Chem. Soc. Rev., 2013, 42, 4036-4053.

120 J. Zhao, Y. Liu, X. Li, G. Lu, L. You, X. Liang, F. Liu, T. Zhang and Y. Du, Highly sensitive humidity sensor based on high surface area mesoporous $\mathrm{LaFeO}_{3}$ prepared by a nanocasting route, Sens. Actuators, B, 2013, 181, 802-809.
121 P. M. Faia, C. S. Furtado and A. J. Ferreira, Humidity sensing properties of a thick-film titania prepared by a slow spinning process, Sens. Actuators, B, 2004, 101, 183-190.

122 P. Zhang, S.-Y. Huang and B. N. Popov, Mesoporous tin oxide as an oxidation-resistant catalyst support for proton exchange membrane fuel cells, J. Electrochem. Soc., 2010, 157, B1163.

123 J. D. Halla, M. Mamak, D. E. Williams and G. A. Ozin,

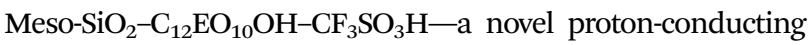
solid electrolyte, Adv. Funct. Mater., 2003, 13, 133-138.

124 F. M. Vichi, M. T. Colomer and M. A. Anderson, Nanopore ceramic membranes as novel electrolytes for proton exchange membranes, Electrochem. Solid-State Lett., 1999, 2, 313-316.

125 W. H. J. Hogarth, J. C. Diniz da Costa, J. Drennan and G. Q. (Max) Lu, Proton conductivity of mesoporous sol-gel zirconium phosphates for fuel cell applications, J. Mater. Chem., 2005, 15, 754-758.

126 S. Kim, H. J. Avila-Paredes, S. Wang, C.-T. Chen, R. A. De Souza, M. Martin and Z. A. Munir, On the conduction pathway for protons in nanocrystalline yttria-stabilized zirconia, Phys. Chem. Chem. Phys., 2009, 11, 3035-3038.

127 S. Miyoshi, Y. Akao, N. Kuwata, J. Kawamura, Y. Oyama, T. Yagi and S. Yamaguchi, Water uptake and conduction property of nano-grained yttria-doped zirconia fabricated by ultra-high pressure compaction at room temperature, Solid State Ionics, 2012, 207, 21-28.

128 I. G. Tredici, F. Maglia, C. Ferrara, P. Mustarelli and U. Anselmi-Tamburini, Mechanism of low-temperature protonic conductivity in bulk, high-density, nanometric titanium oxide, Adv. Funct. Mater., 2014, 24, 5137-5146.

129 E. Celik, R. S. Negi, M. Bastianello, D. Boll, A. Mazilkin, T. Brezesinski and M. T. Elm, Tailoring the protonic conductivity of porous yttria-stabilized zirconia thin films by surface modification, Phys. Chem. Chem. Phys., 2020, 22, 11519-11528.

130 M. J. Pietrowski, R. A. De Souza, S. Kim, Z. A. Munir and M. Martin, Dehydration kinetics of nano-YSZ ceramics monitored by in situ infrared spectroscopy, Solid State Ionics, 2012, 225, 241-244.

131 S. Ø. Stub, E. Vøllestad and T. Norby, Mechanisms of protonic surface transport in porous oxides: Example of YSZ, J. Phys. Chem. C, 2017, 121, 12817-12825.

132 S. Ø. Stub, K. Thorshaug, P. M. Rørvik, T. Norby and E. Vøllestad, The influence of acceptor and donor doping on the protonic surface conduction of $\mathrm{TiO}_{2}$, Phys. Chem. Chem. Phys., 2018, 20, 15653-15660.

133 S. Raz, K. Sasaki, J. Maier and I. Riess, Characterization of adsorbed water layers on $\mathrm{Y}_{2} \mathrm{O}_{3}$-doped $\mathrm{ZrO}_{2}$, Solid State Ionics, 2001, 143, 181-204.

134 E.-M. Köck, M. Kogler, B. Klötzer, M. F. Noisternig and S. Penner, Structural and electrochemical properties of physisorbed and chemisorbed water layers on the ceramic oxides $\mathrm{Y}_{2} \mathrm{O}_{3}$, YSZ, and $\mathrm{ZrO}_{2}$, ACS Appl. Mater. Interfaces, 2016, 8, 16428-16443.

135 M. T. Elm, J. D. Hofmann, C. Suchomski, J. Janek and T. Brezesinski, Ionic conductivity of mesostructured yttriastabilized zirconia thin films with cubic pore symmetry-on 
the influence of water on the surface oxygen ion transport, ACS Appl. Mater. Interfaces, 2015, 7, 11792-11801.

136 S. Ø. Stub, E. Vøllestad and T. Norby, Protonic surface conduction controlled by space charge of intersecting grain boundaries in porous ceramics, J. Mater. Chem. A, 2018, 6, 8265-8270.

137 F. M. Vichi, M. I. Tejedor-Tejedor and M. A. Anderson, Effect of pore-wall chemistry on proton conductivity in mesoporous titanium dioxide, Chem. Mater., 2000, 12, 1762-1770.

138 R. Marschall, I. Bannat, J. Caro and M. Wark, Proton conductivity of sulfonic acid functionalised mesoporous materials, Microporous Mesoporous Mater., 2007, 99, 190-196.

$139 \mathrm{H}$. Li and M. Nogami, Pore-controlled proton conducting silica films, Adv. Mater., 2002, 14, 912-914.

140 M. T. Colomer and M. A. Anderson, High porosity silica xerogels prepared by a particulate sol-gel route: Pore structure and proton conductivity, J. Non-Cryst. Solids, 2001, 290, 93-104.

141 Y. Daiko, T. Kasuga and M. Nogami, Pore size effect on proton transfer in sol-gel porous silica glasses, Microporous Mesoporous Mater., 2004, 69, 149-155.

142 N. Koone, Y. Shao and T. W. Zerda, Diffusion of simple liquids in porous sol-gel glass, J. Phys. Chem., 1995, 99, 16976-16981.

143 W. C. Chueh, C.-K. Yang, C. M. Garland, W. Lai and S. M. Haile, Unusual decrease in conductivity upon hydration in acceptor doped, microcrystalline ceria, Phys. Chem. Chem. Phys., 2011, 13, 6442-6451.

144 Y. Yan, G. Chen, P. She, G. Zhong, W. Yan, B. Y. Guan and Y. Yamauchi, Mesoporous nanoarchitectures for electrochemical energy conversion and storage, Adv. Mater., 2020, 32, 2004654.

145 A. Vu, Y. Qian and A. Stein, Porous electrode materials for lithium-ion batteries - how to prepare them and what makes them special, Adv. Energy Mater., 2012, 2, 1056-1085.

146 A. Walcarius, Mesoporous materials and electrochemistry, Chem. Soc. Rev., 2013, 42, 4098-4140.

147 P. G. Bruce, B. Scrosati and J.-M. Tarascon, Nanomaterials for rechargeable lithium batteries, Angew. Chem., Int. Ed., 2008, 47, 2930-2946.

148 W. Li, J. Liu and D. Zhao, Mesoporous materials for energy conversion and storage devices, Nat. Rev. Mater., 2016, 1, 16023.

149 L. Zu, W. Zhang, L. Qu, L. Liu, W. Li, A. Yu and D. Zhao, Mesoporous materials for electrochemical energy storage and conversion, Adv. Energy Mater., 2020, 10, 2002152.

150 F. Jiao, K. M. Shaju and P. G. Bruce, Synthesis of nanowire and mesoporous low-temperature $\mathrm{LiCoO}_{2}$ by a post-templating reaction, Angew. Chem., Int. Ed., 2005, 44, 6550-6553.

151 G. Wang, H. Liu, J. Liu, S. Qiao, G. M. Lu, P. Munroe and H. Ahn, Mesoporous $\mathrm{LiFePO}_{4} / \mathrm{C}$ nanocomposite cathode materials for high power lithium ion batteries with superior performance, Adv. Mater., 2010, 22, 4944-4948.

152 Y. Ren, A. R. Armstrong, F. Jiao and P. G. Bruce, Influence of size on the rate of mesoporous electrodes for lithium batteries, J. Am. Chem. Soc., 2010, 132, 996-1004.

153 J. Luo, Y. Wang, H. Xiong and Y. Xia, Ordered mesoporous spinel $\mathrm{LiMn}_{2} \mathrm{O}_{4}$ by a soft-chemical process as a cathode material for lithium-ion batteries, Chem. Mater., 2007, 19, 4791-4795.

154 M. G. Fischer, X. Hua, B. D. Wilts, I. Gunkel, T. M. Bennett and U. Steiner, Mesoporous titania microspheres with highly tunable pores as an anode material for lithium ion batteries, ACS Appl. Mater. Interfaces, 2017, 9, 22388-22397.

155 H. Liu, W. Li, D. Shen, D. Zhao and G. Wang, Graphitic carbon conformal coating of mesoporous $\mathrm{TiO}_{2}$ hollow spheres for high-performance lithium ion battery anodes, J. Am. Chem. Soc., 2015, 137, 13161-13166.

156 J. Yue, C. Suchomski, P. Voepel, R. Ellinghaus, M. Rohnke, T. Leichtweiss, M. T. Elm and B. M. Smarsly, Mesoporous niobium-doped titanium dioxide films from the assembly of crystalline nanoparticles: Study on the relationship between the band structure, conductivity and charge storage mechanism, J. Mater. Chem. A, 2017, 5, 1978-1988.

157 B. Sun, J. Horvat, H. S. Kim, W.-S. Kim, J. Ahn and G. Wang, Synthesis of mesoporous $\alpha-\mathrm{Fe}_{2} \mathrm{O}_{3}$ nanostructures for highly sensitive gas sensors and high capacity anode materials in lithium ion batteries, J. Phys. Chem. C, 2010, 114, 18753-18761.

158 H. Liu, G. Wang, J. Liu, S. Qiao and H. Ahn, Highly ordered mesoporous $\mathrm{NiO}$ anode material for lithium ion batteries with an excellent electrochemical performance, J. Mater. Chem., 2011, 21, 3046-3052.

159 I. E. Rauda, V. Augustyn, B. Dunn and S. H. Tolbert, Enhancing pseudocapacitive charge storage in polymer templated mesoporous materials, Acc. Chem. Res., 2013, 46, 1113-1124.

160 S. Fleischmann, J. B. Mitchell, R. Wang, C. Zhan, D. Jiang, V. Presser and V. Augustyn, Pseudocapacitance: From fundamental understanding to high power energy storage materials, Chem. Rev., 2020, 120, 6738-6782.

161 T. Brezesinski, J. Wang, S. H. Tolbert and B. Dunn, Next generation pseudocapacitor materials from sol-gel derived transition metal oxides, J. Sol-Gel Sci. Technol., 2011, 57, 330-335.

162 H. Lindström, S. Södergren, A. Solbrand, H. Rensmo, J. Hjelm, A. Hagfeldt and S.-E. Lindquist, $\mathrm{Li}^{+}$ion insertion in $\mathrm{TiO}_{2}$ (anatase). 2. Voltammetry on nanoporous films, J. Phys. Chem. B, 1997, 101, 7717-7722.

163 A. J. Bard and L. R. Faulkner, Electrochemical Methods: Fundamentals and Applications, 2nd edn, John Wiley \& Sons, Inc., 2000.

164 Y. Ma, Y. Ma, G. Giuli, H. Euchner, A. Groß, G. O. Lepore, F. D’Acapito, D. Geiger, J. Biskupek, U. Kaiser, H. M. Schütz, A. Carlsson, T. Diemant, R. J. Behm, M. Kuenzel, S. Passerini and D. Bresser, Introducing highly redox-active atomic centers into insertion-type electrodes for lithium-ion batteries, $A d v$. Energy Mater., 2020, 10, 2000783.

165 T. Brezesinski, J. Wang, R. Senter, K. Brezesinski, B. Dunn and S. H. Tolbert, On the correlation between mechanical flexibility, nanoscale structure, and charge storage in periodic mesoporous $\mathrm{CeO}_{2}$ thin films, ACS Nano, 2010, 4, 967-977.

166 K. Brezesinski, J. Wang, J. Haetge, C. Reitz, S. O. Steinmueller, S. H. Tolbert, B. M. Smarsly, B. Dunn and T. Brezesinski, 
Pseudocapacitive contributions to charge storage in highly ordered mesoporous group $\mathrm{v}$ transition metal oxides with iso-oriented layered nanocrystalline domains, J. Am. Chem. Soc., 2010, 132, 6982-6990.

167 J. B. Cook, H. S. Kim, Y. Yan, J. S. Ko, S. Robbennolt, B. Dunn and S. H. Tolbert, Mesoporous $\mathrm{MoS}_{2}$ as a transition metal dichalcogenide exhibiting pseudocapacitive Li and Na-ion charge storage, Adv. Energy Mater., 2016, 6, 1501937.

168 T. Brezesinski, J. Wang, S. H. Tolbert and B. Dunn, Ordered mesoporous $\alpha-\mathrm{MoO}_{3}$ with iso-oriented nanocrystalline walls for thin-film pseudocapacitors, Nat. Mater., 2010, 9, 146-151.

169 J. Maier, Thermodynamics of electrochemical lithium storage, Angew. Chem., Int. Ed., 2013, 52, 4998-5026.

170 C. Li, L. Gu, X. Guo, D. Samuelis, K. Tang and J. Maier, Charge carrier accumulation in lithium fluoride thin films due to Li-ion absorption by titania(100) subsurface, Nano Lett., 2012, 12, 1241-1246.

171 J. Maier, Pushing nanoionics to the limits: Charge carrier chemistry in extremely small systems, Chem. Mater., 2014, 26, 348-360.

172 C.-C. Chen and J. Maier, Space charge storage in composites: Thermodynamics, Phys. Chem. Chem. Phys., 2017, 19, 6379-6396.

173 C.-C. Chen, L. Fu and J. Maier, Synergistic, ultrafast mass storage and removal in artificial mixed conductors, Nature, 2016, 536, 159-164.

174 Y. Wang, B. M. Smarsly and I. Djerdj, Niobium doped $\mathrm{TiO}_{2}$ with mesoporosity and its application for lithium insertion, Chem. Mater., 2010, 22, 6624-6631.

175 Y. Liu, J. M. Szeifert, J. M. Feckl, B. Mandlmeier, J. Rathousky, O. Hayden, D. Fattakhova-Rohlfing and T. Bein, Niobiumdoped titania nanoparticles: Synthesis and assembly into mesoporous films and electrical conductivity, ACS Nano, 2010, 4, 5373-5381.

176 Z. Zhang and J. T. Yates, Band bending in semiconductors: Chemical and physical consequences at surfaces and interfaces, Chem. Rev., 2012, 112, 5520-5551.

177 K. Ozawa, M. Emori, S. Yamamoto, R. Yukawa, S. Yamamoto, R. Hobara, K. Fujikawa, H. Sakama and I. Matsuda, Electronhole recombination time at $\mathrm{TiO}_{2}$ single-crystal surfaces: Influence of surface band bending, J. Phys. Chem. Lett., 2014, 5, 1953-1957.

178 M. N. Obrovac and V. L. Chevrier, Alloy negative electrodes for Li-ion batteries, Chem. Rev., 2014, 114, 11444-11502.

179 K. Ishidzu, Y. Oka and T. Nakamura, Lattice volume change during charge/discharge reaction and cycle performance of $\mathrm{Li}\left[\mathrm{Ni}_{x} \mathrm{Co}_{y} \mathrm{Mn}_{z}\right] \mathrm{O}_{2}$, Solid State Ionics, 2016, 288, 176-179.

180 P. Li, Y. Zhao, Y. Shen and S.-H. Bo, Fracture behavior in battery materials, J. Phys. Energy, 2020, 2, 022002.

181 F. Strauss, L. de Biasi, A.-Y. Kim, J. Hertle, S. Schweidler, J. Janek, P. Hartmann and T. Brezesinski, Rational design of quasi-zero-strain NCM cathode materials for minimizing volume change effects in all-solid-state batteries, ACS Mater. Lett., 2020, 2, 84-88.

182 R. Ruess, S. Schweidler, H. Hemmelmann, G. Conforto, A. Bielefeld, D. A. Weber, J. Sann, M. T. Elm and J. Janek,
Influence of NCM particle cracking on kinetics of lithiumion batteries with liquid or solid electrolyte, J. Electrochem. Soc., 2020, 167, 100532.

183 J. Gonzalez, K. Sun, M. Huang, J. Lambros, S. Dillon and I. Chasiotis, Three dimensional studies of particle failure in silicon based composite electrodes for lithium ion batteries, J. Power Sources, 2014, 269, 334-343.

184 R. S. Negi, S. P. Culver, A. Mazilkin, T. Brezesinski and M. T. Elm, Enhancing the electrochemical performance of $\mathrm{LiNi}_{0.70} \mathrm{Co}_{0.15} \mathrm{Mn}_{0.15} \mathrm{O}_{2}$ cathodes using a practical solutionbased $\mathrm{Al}_{2} \mathrm{O}_{3}$ coating, ACS Appl. Mater. Interfaces, 2020, 12, 31392-31400.

185 A. Mukhopadhyay and B. W. Sheldon, Deformation and stress in electrode materials for Li-ion batteries, Prog. Mater. Sci., 2014, 63, 58-116.

186 H. Wang, Y. Jang, B. Huang, D. R. Sadoway and Y. Chiang, TEM study of electrochemical cycling-induced damage and disorder in $\mathrm{LiCoO}_{2}$ cathodes for rechargeable lithium batteries, J. Electrochem. Soc., 1999, 146, 473-480.

187 X. H. Liu, L. Zhong, S. Huang, S. X. Mao, T. Zhu and J. Y. Huang, Size-dependent fracture of silicon nanoparticles during lithiation, ACS Nano, 2012, 6, 1522-1531.

188 S. Schweidler, L. de Biasi, G. Garcia, A. Mazilkin, P. Hartmann, T. Brezesinski and J. Janek, Investigation into mechanical degradation and fatigue of high-Ni NCM cathode material: A long-term cycling study of full cells, ACS Appl. Energy Mater., 2019, 2, 7375-7384.

189 F. Jiao, J. Bao, A. H. Hill and P. G. Bruce, Synthesis of ordered mesoporous $\mathrm{Li}-\mathrm{Mn}-\mathrm{O}$ spinel as a positive electrode for rechargeable lithium batteries, Angew. Chem., Int. Ed., 2008, 47, 9711-9716.

190 Y. Ma, Y. Ma, G. Kim, T. Diemant, R. J. Behm, D. Geiger, U. Kaiser, A. Varzi and S. Passerini, Superior lithium storage capacity of $\alpha$-MnS nanoparticles embedded in S-doped carbonaceous mesoporous frameworks, Adv. Energy Mater., 2019, 9, 1902077.

191 W. Wen, J. M. Wu and M. H. Cao, NiO/Ni powders with effective architectures as anode materials in Li-ion batteries, J. Mater. Chem. A, 2013, 1, 3881-3885.

192 G. Li, Y. Li, J. Chen, P. Zhao, D. Li, Y. Dong and L. Zhang, Synthesis and research of egg shell-yolk $\mathrm{NiO} / \mathrm{C}$ porous composites as lithium-ion battery anode material, Electrochim. Acta, 2017, 245, 941-948.

193 J. Lee, S. Kim, J.-H. Park, C. Jo, J. Chun, Y.-E. Sung, E. Lim and J. Lee, A small-strain niobium nitride anode with ordered mesopores for ultra-stable potassium-ion batteries, J. Mater. Chem. A, 2020, 8, 3119-3127.

194 S. M. Bhaway, Z. Qiang, Y. Xia, X. Xia, B. Lee, K. G. Yager, L. Zhang, K. Kisslinger, Y.-M. Chen, K. Liu, Y. Zhu and B. D. Vogt, Operando grazing incidence small-angle X-ray scattering/X-ray diffraction of model ordered mesoporous lithium-ion battery anodes, ACS Nano, 2017, 11, 1443-1454.

195 N. Krins, J. D. Bass, D. Grosso, C. Henrist, R. Delaigle, E. M. Gaigneaux, R. Cloots, B. Vertruyen and C. Sanchez, $\mathrm{NbVO}_{5}$ mesoporous thin films by evaporation induced micelles packing: Pore size dependence of the mechanical 
stability upon thermal treatment and Li insertion/extraction, Chem. Mater., 2011, 23, 4124-4131.

196 S.-K. Jung, I. Hwang, D. Chang, K.-Y. Park, S. J. Kim, W. M. Seong, D. Eum, J. Park, B. Kim, J. Kim, J. H. Heo and K. Kang, Nanoscale phenomena in lithium-ion batteries, Chem. Rev., 2020, 120, 6684-6737.

197 D.-H. Lee, B.-H. Lee, A. K. Sinha, J.-H. Park, M.-S. Kim, J. Park, H. Shin, K.-S. Lee, Y.-E. Sung and T. Hyeon, Engineering titanium dioxide nanostructures for enhanced lithium-ion storage, J. Am. Chem. Soc., 2018, 140, 16676-16684.

198 N. J. J. de Klerk, A. Vasileiadis, R. B. Smith, M. Z. Bazant and $\mathrm{M}$. Wagemaker, Explaining key properties of lithiation in $\mathrm{TiO}_{2}$-anatase Li-ion battery electrodes using phase-field modelling, Phys. Rev. Mater., 2017, 1, 025404.

199 M. Wagemaker, W. J. H. Borghols and F. M. Mulder, Large impact of particle size on insertion reactions. A case for anatase $\mathrm{Li}_{x} \mathrm{TiO}_{2}$, J. Am. Chem. Soc., 2007, 129, 4323-4327.

200 T. Fröschl, U. Hörmann, P. Kubiak, G. Kučerová, M. Pfanzelt, C. K. Weiss, R. J. Behm, N. Hüsing, U. Kaiser, K. Landfester and M. Wohlfahrt-Mehrens, High surface area crystalline titanium dioxide: Potential and limits in electrochemical energy storage and catalysis, Chem. Soc. Rev., 2012, 41, 5313-5360.

201 V. Gentili, S. Brutti, L. J. Hardwick, A. R. Armstrong, S. Panero and P. G. Bruce, Lithium insertion into anatase nanotubes, Chem. Mater., 2012, 24, 4468-4476.

202 U. Lafont, D. Carta, G. Mountjoy, A. V. Chadwick and E. M. Kelder, In situ structural changes upon electrochemical lithium insertion in nanosized anatase $\mathrm{TiO}_{2}$, J. Phys. Chem. C, 2010, 114, 1372-1378.

203 D. Larcher, C. Masquelier, D. Bonnin, Y. Chabre, V. Masson, J.-B. Leriche and J.-M. Tarascon, Effect of particle size on lithium intercalation into $\alpha-\mathrm{Fe}_{2} \mathrm{O}_{3}$, J. Electrochem. Soc., 2003, 150, A133-A139.

204 X. L. Wu, Y. G. Guo, L. J. Wan and C. W. Hu, $\alpha-\mathrm{Fe}_{2} \mathrm{O}_{3}$ nanostructures: Inorganic salt-controlled synthesis and their electrochemical performance toward lithium storage, J. Phys. Chem. C, 2008, 112, 16824-16829.

205 K. Brezesinski, J. Haetge, J. Wang, S. Mascotto, C. Reitz, A. Rein, S. H. Tolbert, J. Perlich, B. Dunn and T. Brezesinski, Ordered mesoporous $\alpha-\mathrm{Fe}_{2} \mathrm{O}_{3}$ (Hematite) thin-film electrodes for application in high rate rechargeable lithium batteries, Small, 2011, 7, 407-414.

206 L. A. Dubraja, C. Reitz, L. Velasco, R. Witte, R. Kruk, H. Hahn and T. Brezesinski, Electrochemical tuning of magnetism in ordered mesoporous transition-metal ferrite films for micromagnetic actuation, ACS Appl. Nano Mater., 2018, 1, 65-72.

207 P. Li, X. Chen, Y. Li and J. W. Schwank, A review on oxygen storage capacity of $\mathrm{CeO}_{2}$-based materials: Influence factors, measurement techniques, and applications in reactions related to catalytic automotive emissions control, Catal. Today, 2019, 327, 90-115.

208 R. Si, Y.-W. Zhang, S.-J. Li, B.-X. Lin and C.-H. Yan, Ureabased hydrothermally derived homogeneous nanostructured $\mathrm{Ce}_{1-x} \mathrm{Zr}_{x} \mathrm{O}_{2}(x=0-0.8)$ solid solutions: A strong correlation between oxygen storage capacity and lattice strain, J. Phys. Chem. B, 2004, 108, 12481-12488.
209 S. Abdollahzadeh-Ghom, C. Zamani, T. Andreu, M. Epifani and J. R. Morante, Improvement of oxygen storage capacity using mesoporous ceria-zirconia solid solutions, Appl. Catal., B, 2011, 108-109, 32-38.

210 M. P. Kapoor, A. Raj and Y. Matsumura, Methanol decomposition over palladium supported mesoporous $\mathrm{CeO}_{2}-$ $\mathrm{ZrO}_{2}$ mixed oxides, Microporous Mesoporous Mater., 2001, 44-45, 565-572.

211 Q. Yuan, Q. Liu, W.-G. Song, W. Feng, W.-L. Pu, L.-D. Sun, Y.-W. Zhang and C.-H. Yan, Ordered mesoporous $\mathrm{Ce}_{1-x} \mathrm{Zr}_{x} \mathrm{O}_{2}$ solid solutions with crystalline walls, J. Am. Chem. Soc., 2007, 129, 6698-6699.

212 Q. Yuan, L.-L. Li, S.-L. Lu, H.-H. Duan, Z.-X. Li, Y.-X. Zhu and C.-H. Yan, Facile synthesis of Zr-based functional materials with highly ordered mesoporous structures, J. Phys. Chem. C, 2009, 113, 4117-4124.

213 J. Xiong, Y. Wei, Y. Zhang, X. Mei, Q. Wu, Z. Zhao, J. Liu, D. Wu and J. Li, Facile synthesis of 3D ordered macromesoporous $\mathrm{Ce}_{1-x} \mathrm{Zr}_{x} \mathrm{O}_{2}$ catalysts with enhanced catalytic activity for soot oxidation, Catal. Today, 2020, 355, 587-595.

$214 \mathrm{~J}$. Ouyang and H. Yang, Enhanced reduction properties of mesostructured $\mathrm{Ce}_{0.5} \mathrm{Zr}_{0.5} \mathrm{O}_{2}$ solid solutions, Mater. Chem. Phys., 2013, 140, 294-299.

215 N. D. Petkovich, S. G. Rudisill, L. J. Venstrom, D. B. Boman, J. H. Davidson and A. Stein, Control of heterogeneity in nanostructured $\mathrm{Ce}_{1-x} \mathrm{Zr}_{x} \mathrm{O}_{2}$ binary oxides for enhanced thermal stability and water splitting activity, J. Phys. Chem. C, 2011, 115, 21022-21033.

216 E. Mamontov, R. Brezny, M. Koranne and T. Egami, Nanoscale heterogeneities and oxygen storage capacity of $\mathrm{Ce}_{0.5} \mathrm{Zr}_{0.5} \mathrm{O}_{2}$, J. Phys. Chem. B, 2003, 107, 13007-13014.

217 C. Ho, J. C. Yu, X. Wang, S. Lai and Y. Qiu, Meso- and macro-porous $\mathrm{Pd} / \mathrm{Ce}_{x} \mathrm{Zr}_{1-x} \mathrm{O}_{2}$ as novel oxidation catalysts, J. Mater. Chem., 2005, 15, 2193-2201.

218 J. G. Nunan, H. J. Robota, M. J. Cohn and S. A. Bradley, Physicochemical properties of Ce-containing three-way catalysts and the effect of Ce on catalyst activity, J. Catal., 1992, 133, 309-324.

219 M. Epifani, T. Andreu, S. Abdollahzadeh-Ghom, J. Arbiol and J. R. Morante, Synthesis of ceria-zirconia nanocrystals with improved microstructural homogeneity and oxygen storage capacity by hydrolytic sol-gel process in coordinating environment, Adv. Funct. Mater., 2012, 22, 2867-2875.

220 P. Fornasiero, R. Dimonte, G. R. Rao, J. Kaspar, S. Meriani, A. Trovarelli and M. Graziani, Rh-Loaded $\mathrm{CeO}_{2}-\mathrm{ZrO}_{2}$ solidsolutions as highly efficient oxygen exchangers: Dependence of the reduction behavior and the oxygen storage capacity on the structural-properties, J. Catal., 1995, 151, 168-177.

221 Y. Cui, L. Lan, Z. Shi, S. Yuan, M. Gong, Y. Chen and Y. Dan, Effect of surface tension on the properties of a doped $\mathrm{CeO}_{2}-\mathrm{ZrO}_{2}$ composite and its application in a Pd-only three-way catalyst, RSC Adv., 2016, 6, 66524-66536.

222 J. Roggenbuck, H. Schäfer, T. Tsoncheva, C. Minchev, J. Hanss and M. Tiemann, Mesoporous $\mathrm{CeO}_{2}$ : Synthesis by nanocasting, characterisation and catalytic properties, Microporous Mesoporous Mater., 2007, 101, 335-341. 
223 T. X. T. Sayle, F. Caddeo, X. Zhang, T. Sakthivel, S. Das, S. Seal, S. Ptasinska and D. C. Sayle, Structure-activity map of ceria nanoparticles, nanocubes, and mesoporous architectures, Chem. Mater., 2016, 28, 7287-7295.

224 A. Migani, G. N. Vayssilov, S. T. Bromley, F. Illas and K. M. Neyman, Dramatic reduction of the oxygen vacancy formation energy in ceria particles: A possible key to their remarkable reactivity at the nanoscale, J. Mater. Chem., 2010, 20, 10535-10546.

225 A. Migani, G. N. Vayssilov, S. T. Bromley, F. Illas and K. M. Neyman, Greatly facilitated oxygen vacancy formation in ceria nanocrystallites, Chem. Commun., 2010, 46, 5936-5938.

226 X. Hao, A. Yoko, C. Chen, K. Inoue, M. Saito, G. Seong, S. Takami, T. Adschiri and Y. Ikuhara, Atomic-scale valence state distribution inside ultrafine $\mathrm{CeO}_{2}$ nanocubes and its size dependence, Small, 2018, 14, 1802915.

227 Y. Ren, Z. Ma, L. Qian, S. Dai, H. He and P. G. Bruce, Ordered crystalline mesoporous oxides as catalysts for CO oxidation, Catal. Lett., 2009, 131, 146-154.

228 S. Sun, Q. Gao, H. Wang, J. Zhu and H. Guo, Influence of textural parameters on the catalytic behavior for $\mathrm{CO}$ oxidation over ordered mesoporous $\mathrm{Co}_{3} \mathrm{O}_{4}$, Appl. Catal., B, 2010, 97, 284-291.

229 H. Tüysüz, M. Comotti and F. Schüth, Ordered mesoporous $\mathrm{Co}_{3} \mathrm{O}_{4}$ as highly active catalyst for low temperature CO-oxidation, Chem. Commun., 2008, 4022-4024.

230 A. L. Linsebigler, G. Lu and J. T. Yates, Photocatalysis on $\mathrm{TiO}_{2}$ surfaces: Principles, mechanisms, and selected results, Chem. Rev., 1995, 95, 735-758.

231 A. Kudo and Y. Miseki, Heterogeneous photocatalyst materials for water splitting, Chem. Soc. Rev., 2009, 38, 253-278.

232 M. V. Grabchenko, G. V. Mamontov, V. I. Zaikovskii, V. La Parola, L. F. Liotta and O. V. Vodyankina, The role of metal-support interaction in $\mathrm{Ag} / \mathrm{CeO}_{2}$ catalysts for $\mathrm{CO}$ and soot oxidation, Appl. Catal., B, 2020, 260, 118148.

233 B. P. Bastakoti, D. Kuila, C. Salomon, M. Konarova, M. Eguchi, J. Na and Y. Yamauchi, Metal-incorporated mesoporous oxides: Synthesis and applications, J. Hazard. Mater., 2021, 401, 123348.

234 J. A. Rodriguez, J. Graciani, J. Evans, J. B. Park, F. Yang, D. Stacchiola, S. D. Senanayake, S. Ma, M. Pérez, P. Liu, J. F. Sanz and J. Hrbek, Water-gas shift reaction on a highly active inverse $\mathrm{CeO}_{x} / \mathrm{Cu}(111)$ catalyst: Unique role of ceria nanoparticles, Angew. Chem., Int. Ed., 2009, 48, 8047-8050.

235 G. N. Vayssilov, Y. Lykhach, A. Migani, T. Staudt, G. P. Petrova, N. Tsud, T. Skála, A. Bruix, F. Illas, K. C. Prince, V. Matolín, K. M. Neyman and J. Libuda, Support nanostructure boosts oxygen transfer to catalytically active platinum nanoparticles, Nat. Mater., 2011, 10, 310-315.

236 K. An, S. Alayoglu, N. Musselwhite, S. Plamthottam, G. Melaet, A. E. Lindeman and G. A. Somorjai, Enhanced CO oxidation rates at the interface of mesoporous oxides and Pt nanoparticles, J. Am. Chem. Soc., 2013, 135, 16689-16696.

237 R. Abe, Recent progress on photocatalytic and photoelectrochemical water splitting under visible light irradiation, J. Photochem. Photobiol., C, 2010, 11, 179-209.
238 W. Zhou, W. Li, J.-Q. Wang, Y. Qu, Y. Yang, Y. Xie, K. Zhang, L. Wang, H. Fu and D. Zhao, Ordered mesoporous black $\mathrm{TiO}_{2}$ as highly efficient hydrogen evolution photocatalyst, J. Am. Chem. Soc., 2014, 136, 9280-9283.

239 J. Cai, J. Shen, X. Zhang, Y. H. Ng, J. Huang, W. Guo, C. Lin and Y. Lai, Light-driven sustainable hydrogen production utilizing $\mathrm{TiO}_{2}$ nanostructures: A review, Small Methods, 2019, 3, 1800184.

240 B. Fang, A. Bonakdarpour, K. Reilly, Y. Xing, F. Taghipour and D. P. Wilkinson, Large-scale synthesis of $\mathrm{TiO}_{2}$ microspheres with hierarchical nanostructure for highly efficient photodriven reduction of $\mathrm{CO}_{2}$ to $\mathrm{CH}_{4}$, ACS Appl. Mater. Interfaces, 2014, 6, 15488-15498.

241 J. N. Kondo and K. Domen, Crystallization of mesoporous metal oxides, Chem. Mater., 2008, 20, 835-847.

242 S. Waitz, C. Suchomski, T. Brezesinski and R. Marschall, Ordered mesoporous $\mathrm{LiFe}_{5} \mathrm{O}_{8}$ thin-film photoanodes for water splitting, ChemPhotoChem, 2018, 2, 1022-1026.

243 K. Kirchberg, S. Wang, L. Wang and R. Marschall, Mesoporous $\mathrm{ZnFe}_{2} \mathrm{O}_{4}$ photoanodes with template-tailored mesopores and temperature-dependent photocurrents, ChemPhysChem, 2018, 19, 2313-2320.

244 A. G. Hufnagel, K. Peters, A. Müller, C. Scheu, D. FattakhovaRohlfing and T. Bein, Zinc ferrite photoanode nanomorphologies with favorable kinetics for water-splitting, Adv. Funct. Mater., 2016, 26, 4435-4443.

245 A. A. Tahir and K. G. U. Wijayantha, Photoelectrochemical water splitting at nanostructured $\mathrm{ZnFe}_{2} \mathrm{O}_{4}$ electrodes, J. Photochem. Photobiol., A, 2010, 216, 119-125.

246 L. A. Dubraja, D. Boll, C. Reitz, D. Wang, D. Belić, A. Mazilkin, B. Breitung, H. Hahn, M. T. Elm and T. Brezesinski, Thin films of thermally stable ordered mesoporous $\mathrm{Rh} 2 \mathrm{O} 3(\mathrm{I})$ for visiblelight photocatalysis and humidity sensing, ACS Appl. Nano Mater., 2019, 2, 7126-7133.

247 A. S. Cherevan, L. Deilmann, T. Weller, D. Eder and R. Marschall, Mesoporous semiconductors: A new model to assess accessible surface area and increased photocatalytic activity?, ACS Appl. Energy Mater., 2018, 1, 5787-5799.

248 T. Grewe and H. Tüysüz, Alkali metals incorporated ordered mesoporous tantalum oxide with enhanced photocatalytic activity for water splitting, J. Mater. Chem. A, 2016, 4, 3007-3017.

249 H.-Y. Lin, H.-C. Yang and W.-L. Wang, Synthesis of mesoporous $\mathrm{Nb}_{2} \mathrm{O}_{5}$ photocatalysts with $\mathrm{Pt}, \mathrm{Au}, \mathrm{Cu}$ and $\mathrm{NiO}$ cocatalyst for water splitting, Catal. Today, 2011, 174, 106-113.

250 C.-H. Kuo, I. M. Mosa, A. S. Poyraz, S. Biswas, A. M. El-Sawy, W. Song, Z. Luo, S.-Y. Chen, J. F. Rusling, J. He and S. L. Suib, Robust mesoporous manganese oxide catalysts for water oxidation, ACS Catal., 2015, 5, 1693-1699.

251 C. Reitz, K. Brezesinski, J. Haetge, J. Perlich and T. Brezesinski, Nanocrystalline $\mathrm{NaTaO}_{3}$ thin film materials with ordered 3D mesoporous and nanopillar-like structures through PIB- $b$-PEO polymer templating: Towards high-performance UV-light photocatalysts, RSC Adv., 2012, 2, 5130-5133.

252 H. Tüysüz and C. K. Chan, Preparation of amorphous and nanocrystalline sodium tantalum oxide photocatalysts with 
porous matrix structure for overall water splitting, Nano Energy, 2013, 2, 116-123.

253 M. K. Hossain, U. S. Akhtar, A. R. Koirala, I. C. Hwang and K. B. Yoon, Steam-assisted synthesis of uniformly mesoporous anatase and its remarkably superior photocatalytic activities, Catal. Today, 2015, 243, 228-234.

254 M. Zhou, H. Bin Wu, J. Bao, L. Liang, X. W. (David) Lou and Y. Xie, Ordered macroporous $\mathrm{BiVO}_{4}$ architectures with controllable dual porosity for efficient solar water splitting, Angew. Chem., Int. Ed., 2013, 52, 8579-8583.

255 T. Weller, J. Sann and R. Marschall, Pore structure controlling the activity of mesoporous crystalline $\mathrm{CsTaWO}_{6}$ for photocatalytic hydrogen generation, Adv. Energy Mater., 2016, 6, 1600208

256 T. Weller, L. Deilmann, J. Timm, T. S. Dörr, P. A. Beaucage, A. S. Cherevan, U. B. Wiesner, D. Eder and R. Marschall, A crystalline and 3D periodically ordered mesoporous quaternary semiconductor for photocatalytic hydrogen generation, Nanoscale, 2018, 10, 3225-3234.

257 X. Zhou, X. Cheng, Y. Zhu, A. A. Elzatahry, A. Alghamdi, Y. Deng and D. Zhao, Ordered porous metal oxide semiconductors for gas sensing, Chin. Chem. Lett., 2018, 29, 405-416.

258 G. Heiland, Homogeneous semiconducting gas sensors, Sens. Actuators, 1981, 2, 343-361.

259 N. Yamazoe, G. Sakai and K. Shimanoe, Oxide semiconductor gas sensors, Catal. Surv. Asia, 2003, 7, 63-75.

260 Y. Shimizu, T. Maekawa, Y. Nakamura and M. Egashira, Effects of gas diffusivity and reactivity on sensing properties of thick film $\mathrm{SnO}_{2}$-based sensors, Sens. Actuators, B, 1998, 46, 163-168.

261 A. Rothschild and Y. Komem, The effect of grain size on the sensitivity of nanocrystalline metal-oxide gas sensors, J. Appl. Phys., 2004, 95, 6374-6380.

262 C. Xu, J. Tamaki, N. Miura and N. Yamazoe, Correlation between gas sensitivity and crystallite size in porous $\mathrm{SnO}_{2}-$ based sensors, Chem. Lett., 1990, 441-444.

263 C. Xu, J. Tamaki, N. Miura and N. Yamazoe, Grain size effects on gas sensitivity of porous $\mathrm{SnO}_{2}$-based elements, Sens. Actuators, B, 1991, 3, 147-155.

264 T. Aqeel, V. Galstyan and E. Comini, Mesoporous polycrystalline $\mathrm{SnO}_{2}$ framework synthesized by direct soft templating method for highly selective detection of $\mathrm{NO}_{2}$, Nanotechnology, 2019, 31, 105502.

265 T. Waitz, T. Wagner, T. Sauerwald, C.-D. Kohl and M. Tiemann, Ordered mesoporous $\operatorname{In}_{2} \mathrm{O}_{3}$ : Synthesis by structure replication and application as a methane gas sensor, Adv. Funct. Mater., 2009, 19, 653-661.

266 S. A. Ghom, C. Zamani, S. Nazarpour, T. Andreu and J. R. Morante, Oxygen sensing with mesoporous ceria-zirconia solid solutions, Sens. Actuators, B, 2009, 140, 216-221.

267 J.-H. Lee, Gas sensors using hierarchical and hollow oxide nanostructures: Overview, Sens. Actuators, B, 2009, 140, 319-336.

268 H. Li, F. Meng, J. Liu, Y. Sun, Z. Jin, L. Kong, Y. Hu and $\mathrm{J}$. Liu, Synthesis and gas sensing properties of hierarchical meso-macroporous $\mathrm{SnO}_{2}$ for detection of indoor air pollutants, Sens. Actuators, B, 2012, 166-167, 519-525.

269 Y. Li, W. Luo, N. Qin, J. Dong, J. Wei, W. Li, S. Feng, J. Chen, J. Xu, A. A. Elzatahry, M. H. Es-Saheb, Y. Deng and D. Zhao, Highly ordered mesoporous tungsten oxides with a large pore size and crystalline framework for $\mathrm{H}_{2} \mathrm{~S}$ sensing, Angew. Chem., Int. Ed., 2014, 53, 9035-9040.

270 Y. Shimizu, Y. Nakamura and M. Egashira, Effects of diffusivity of hydrogen and oxygen through pores of thick film $\mathrm{SnO}_{2}$-based sensors on their sensing properties, Sens. Actuators, B, 1993, 13, 128-131.

271 A. Kolmakov, D. O. Klenov, Y. Lilach, S. Stemmer and M. Moskovits, Enhanced gas sensing by individual $\mathrm{SnO}_{2}$ nanowires and nanobelts functionalized with Pd catalyst particles, Nano Lett., 2005, 5, 667-673.

272 J. Ma, Y. Ren, X. Zhou, L. Liu, Y. Zhu, X. Cheng, P. Xu, X. Li, Y. Deng and D. Zhao, Pt nanoparticles sensitized ordered mesoporous $\mathrm{WO}_{3}$ semiconductor: Gas sensing performance and mechanism study, Adv. Funct. Mater., 2018, 28, 1705268.

273 J. Zhang, D. Leng, L. Zhang, G. Li, F. Ma, J. Gao, H. Lu and B. Zhu, Porosity and oxygen vacancy engineering of mesoporous $\mathrm{WO}_{3}$ nanofibers for fast and sensitive low-temperature $\mathrm{NO}_{2}$ sensing, J. Alloys Compd., 2021, 853, 157339.

274 L. Zhang, Q. Fang, Y. Huang, K. Xu, P. K. Chu and F. Ma, Oxygen vacancy enhanced gas-sensing performance of $\mathrm{CeO}_{2}$ /graphene heterostructure at room temperature, Anal. Chem., 2018, 90, 9821-9829.

275 S. M. George, Atomic layer deposition: An overview, Chem. Rev., 2010, 110, 111-131.

276 S. R. Bishop, K. L. Duncan and E. D. Wachsman, Defect equilibria and chemical expansion in non-stoichiometric undoped and gadolinium-doped cerium oxide, Electrochim. Acta, 2009, 54, 1436-1443.

277 A. S. Asundi, J. A. Raiford and S. F. Bent, Opportunities for atomic layer deposition in emerging energy technologies, ACS Energy Lett., 2019, 4, 908-925.

278 J. Lu, J. W. Elam and P. C. Stair, Atomic layer depositionsequential self-limiting surface reactions for advanced catalyst "bottom-up" synthesis, Surf. Sci. Rep., 2016, 71, 410-472.

279 J. W. Elam, N. P. Dasgupta and F. B. Prinz, ALD for clean energy conversion, utilization, and storage, MRS Bull., 2011, 36, 899-906.

280 S. Neudeck, A. Mazilkin, C. Reitz, P. Hartmann, J. Janek and T. Brezesinski, Effect of low-temperature $\mathrm{Al}_{2} \mathrm{O}_{3}$ ALD coating on Ni-rich layered oxide composite cathode on the long-term cycling performance of lithium-ion batteries, Sci. Rep., 2019, 9, 5328.

281 A. C. Kozen, C.-F. Lin, A. J. Pearse, M. A. Schroeder, X. Han, L. Hu, S.-B. Lee, G. W. Rubloff and M. Noked, Nextgeneration lithium metal anode engineering via atomic layer deposition, ACS Nano, 2015, 9, 5884-5892.

282 X. Meng, X.-Q. Yang and X. Sun, Emerging applications of atomic layer deposition for lithium-ion battery studies, Adv. Mater., 2012, 24, 3589-3615.

283 X. Wang and G. Yushin, Chemical vapor deposition and atomic layer deposition for advanced lithium ion batteries 
and supercapacitors, Energy Environ. Sci., 2015, 8, 1889-1904.

284 B. Yan, X. Li, Z. Bai, X. Song, D. Xiong, M. Zhao, D. Li and S. Lu, A review of atomic layer deposition providing high performance lithium sulfur batteries, J. Power Sources, 2017, 338, 34-48.

285 I. E. Rauda, V. Augustyn, L. C. Saldarriaga-Lopez, X. Chen, L. T. Schelhas, G. W. Rubloff, B. Dunn and S. H. Tolbert, Nanostructured pseudocapacitors based on atomic layer deposition of $\mathrm{V}_{2} \mathrm{O}_{5}$ onto conductive nanocrystal-based mesoporous ITO scaffolds, Adv. Funct. Mater., 2014, 24, 6717-6728.

286 C. Reitz, B. Breitung, A. Schneider, D. Wang, M. von der Lehr, T. Leichtweiss, J. Janek, H. Hahn and T. Brezesinski, Hierarchical carbon with high nitrogen doping level: A versatile anode and cathode host material for long-life lithium-ion and lithium-sulfur batteries, ACS Appl. Mater. Interfaces, 2016, 8, 10274-10282.

287 A. Pandiyan, V. Di Palma, V. Kyriakou, W. M. M. Kessels, M. Creatore, M. C. M. van de Sanden and M. N. Tsampas, Enhancing the electrocatalytic activity of redox stable perovskite fuel electrodes in solid oxide cells by atomic layer-deposited Pt nanoparticles, ACS Sustainable Chem. Eng., 2020, 8, 12646-12654.

288 J. Dendooven, R. K. Ramachandran, E. Solano, M. Kurttepeli, L. Geerts, G. Heremans, J. Rongé, M. M. Minjauw, T. Dobbelaere, K. Devloo-Casier, J. A. Martens, A. Vantomme, S. Bals, G. Portale, A. Coati and C. Detavernier, Independent tuning of size and coverage of supported Pt nanoparticles using atomic layer deposition, Nat. Commun., 2017, 8, 1074.

289 J. Cai, J. Zhang, K. Cao, M. Gong, Y. Lang, X. Liu, S. Chu, B. Shan and R. Chen, Selective passivation of Pt nanoparticles with enhanced sintering resistance and activity toward CO oxidation via atomic layer deposition, ACS Appl. Nano Mater., 2018, 1, 522-530.

$290 \mathrm{~J}$. Lu, A perspective on new opportunities in atom-by-atom synthesis of heterogeneous catalysts using atomic layer deposition, Catal. Lett., 2020, DOI: 10.1007/s10562-02003412-8.

291 B. J. O’Neill, D. H. K. Jackson, J. Lee, C. Canlas, P. C. Stair, C. L. Marshall, J. W. Elam, T. F. Kuech, J. A. Dumesic and G. W. Huber, Catalyst design with atomic layer deposition, ACS Catal., 2015, 5, 1804-1825.

292 B. Zhang and Y. Qin, Interface tailoring of heterogeneous catalysts by atomic layer deposition, ACS Catal., 2018, 8, 10064-10081.

293 Z. Weng and F. Zaera, Atomic layer deposition (ALD) as a way to prepare new mixed-oxide catalyst supports: The case of alumina addition to silica-supported platinum for the selective hydrogenation of cinnamaldehyde, Top. Catal., 2019, 62, 838-848.

294 A. J. M. Mackus, M. A. Verheijen, N. Leick, A. A. Bol and W. M. M. Kessels, Influence of oxygen exposure on the nucleation of platinum atomic layer deposition: Consequences for film growth, nanopatterning, and nanoparticle synthesis, Chem. Mater., 2013, 25, 1905-1911.
295 N. Cheng, S. Stambula, D. Wang, M. N. Banis, J. Liu, A. Riese, B. Xiao, R. Li, T.-K. Sham, L.-M. Liu, G. A. Botton and X. Sun, Platinum single-atom and cluster catalysis of the hydrogen evolution reaction, Nat. Commun., 2016, 7, 13638.

296 F. Grillo, H. Van Bui, D. La Zara, A. A. I. Aarnink, A. Y. Kovalgin, P. Kooyman, M. T. Kreutzer and J. R. van Ommen, From single atoms to nanoparticles: Autocatalysis and metal aggregation in atomic layer deposition of Pt on $\mathrm{TiO}_{2}$ nanopowder, Small, 2018, 14, 1800765.

297 R. L. Puurunen, Surface chemistry of atomic layer deposition: A case study for the trimethylaluminum/water process, J. Appl. Phys., 2005, 97, 121301.

298 G. N. Parsons and R. D. Clark, Area-selective deposition: Fundamentals, applications, and future outlook, Chem. Mater., 2020, 32, 4920-4953.

299 A. J. M. Mackus, M. J. M. Merkx and W. M. M. Kessels, From the bottom-up: Toward area-selective atomic layer deposition with high selectivity, Chem. Mater., 2019, 31, 2-12.

300 P. Klement, D. Anders, L. Gümbel, M. Bastianello, F. Michel, J. Schörmann, M. T. Elm, C. Heiliger and S. Chatterjee, Surface diffusion control enables tailored aspect ratio nanostructures in area-selective atomic layer deposition, 2020, arXiv:2012.04465.

301 K. Kraffert, M. Karg, R. Schmack, G. Clavel, C. Boissiere, T. Wirth, N. Pinna and R. Kraehnert, Stabilization of mesoporous iron oxide films against sintering and phase transformations via atomic layer deposition of alumina and silica, Adv. Mater. Interfaces, 2018, 5, 1800360.

302 Y. J. Pagán-Torres, J. M. R. Gallo, D. Wang, H. N. Pham, J. A. Libera, C. L. Marshall, J. W. Elam, A. K. Datye and J. A. Dumesic, Synthesis of highly ordered hydrothermally stable mesoporous niobia catalysts by atomic layer deposition, ACS Catal., 2011, 1, 1234-1245.

303 H. N. Pham, Y. J. Pagan-Torres, J. C. Serrano-Ruiz, D. Wang, J. A. Dumesic and A. K. Datye, Improved hydrothermal stability of niobia-supported Pd catalysts, Appl. Catal., A, 2011, 397, 153-162.

304 C. Detavernier, J. Dendooven, S. P. Sree, K. F. Ludwig and J. A. Martens, Tailoring nanoporous materials by atomic layer deposition, Chem. Soc. Rev., 2011, 40, 5242-5253.

305 J. Dendooven, B. Goris, K. Devloo-Casier, E. Levrau, E. Biermans, M. R. Baklanov, K. F. Ludwig, P. Van Der Voort, S. Bals and C. Detavernier, Tuning the pore size of ink-bottle mesopores by atomic layer deposition, Chem. Mater., 2012, 24, 1992-1994.

306 P. Cop, M. Göttlicher, J. Schörmann, C. Boissiere, A. Beyer, C. Becker, K. Volz, H. Over and B. M. Smarsly, Atomic layer deposition of titania in ordered mesoporous cerium zirconium oxide thin films: A case study, J. Phys. Chem. C, 2019, 123, 12851-12861.

307 J. Dendooven, K. Devloo-Casier, E. Levrau, R. Van Hove, S. Pulinthanathu Sree, M. R. Baklanov, J. A. Martens and C. Detavernier, In situ monitoring of atomic layer deposition in nanoporous thin films using ellipsometric porosimetry, Langmuir, 2012, 28, 3852-3859.

308 J. Dendooven, K. Devloo-Casier, M. Ide, K. Grandfield, M. Kurttepeli, K. F. Ludwig, S. Bals, P. Van Der Voort and 
C. Detavernier, Atomic layer deposition-based tuning of the pore size in mesoporous thin films studied by in situ grazing incidence small angle X-ray scattering, Nanoscale, 2014, 6, 14991-14998.

309 Z. Weng, Z. Chen, X. Qin and F. Zaera, Sub-monolayer control of the growth of oxide films on mesoporous materials, J. Mater. Chem. A, 2018, 6, 17548-17558.

310 S. Pulinthanathu Sree, J. Dendooven, J. Jammaer, K. Masschaele, D. Deduytsche, J. D'Haen, C. E. A. Kirschhock, J. A. Martens and C. Detavernier, Anisotropic atomic layer deposition profiles of $\mathrm{TiO}_{2}$ in hierarchical silica material with multiple porosity, Chem. Mater., 2012, 24, 2775-2780.

311 Y.-B. Jiang, N. Liu, H. Gerung, J. L. Cecchi and C. J. Brinker, Nanometer-thick conformal pore sealing of self-assembled mesoporous silica by plasma-assisted atomic layer deposition, J. Am. Chem. Soc., 2006, 128, 11018-11019.

312 M. F. Zscherp, J. Glaser, C. Becker, A. Beyer, P. Cop, J. Schörmann, K. Volz and M. T. Elm, Epitaxial growth and structural characterization of ceria deposited by atomic layer deposition on high-surface porous yttria-stabilized zirconia thin films, Cryst. Growth Des., 2020, 20, 2194-2201.
313 S. Mahurin, L. Bao, W. Yan, C. Liang and S. Dai, Atomic layer deposition of $\mathrm{TiO}_{2}$ on mesoporous silica, J. Non-Cryst. Solids, 2006, 352, 3280-3284.

314 J. A. Libera, J. W. Elam and M. J. Pellin, Conformal ZnO coatings on high surface area silica gel using atomic layer deposition, Thin Solid Films, 2008, 516, 6158-6166.

315 J. W. Elam, G. Xiong, C. Y. Han, H. H. Wang, J. P. Birrell, J. N. Hryn, M. J. Pellin, J. F. Poco and J. H. Satcher, Atomic layer deposition for the conformal coating of nanoporous materials, MRS Proc., 2005, 876, R12.

316 V. Cremers, R. L. Puurunen and J. Dendooven, Conformality in atomic layer deposition: Current status overview of analysis and modelling, Appl. Phys. Rev., 2019, 6, 21302.

317 D. R. G. Mitchell, D. J. Attard and G. Triani, Transmission electron microscopy studies of atomic layer deposition $\mathrm{TiO}_{2}$ films grown on silicon, Thin Solid Films, 2003, 441, 85-95.

318 P. Cop, E. Celik, K. Hess, Y. Moryson, P. Klement, M. T. Elm and B. M. Smarsly, Atomic layer deposition of nanometer-sized $\mathrm{CeO}_{2}$ layers in ordered mesoporous $\mathrm{ZrO}_{2}$ films and their impact on the ionic/electronic conductivity, ACS Appl. Nano Mater., 2020, 3, 10757-10766. 